\title{
Identifying and modeling Whimbrel Numenius phaeopus breeding habitat in the outer Mackenzie Delta, Northwest Territories
}

\author{
By \\ Lisa D. Pirie \\ B.Sc., University of Victoria, 2003
}

A thesis submitted to the Faculty of Graduate Studies and Research in partial fulfillment of the requirements for the degree of Master of Science

\author{
Department of Biology \\ Carleton University \\ Ottawa, Canada
}

May 2008

C Lisa D. Pirie 2008 


$\begin{array}{ll}\begin{array}{l}\text { Library and } \\ \text { Archives Canada }\end{array} & \begin{array}{l}\text { Bibliothèque et } \\ \text { Archives Canada }\end{array} \\ \begin{array}{l}\text { Published Heritage } \\ \text { Branch }\end{array} & \begin{array}{l}\text { Direction du } \\ \text { Patrimoine de l'édition }\end{array} \\ \begin{array}{l}\text { 395 Wellington Street } \\ \text { Ottawa ON K1A 0N4 } \\ \text { Canada }\end{array} & \begin{array}{l}\text { 395, rue Wellington } \\ \text { Ottawa ON K1A 0N4 } \\ \text { Canada }\end{array}\end{array}$

Your file Votre référence ISBN: 978-0-494-40662-5 Our file Notre référence ISBN: 978-0-494-40662-5

NOTICE:

The author has granted a nonexclusive license allowing Library and Archives Canada to reproduce, publish, archive, preserve, conserve, communicate to the public by telecommunication or on the Internet, loan, distribute and sell theses worldwide, for commercial or noncommercial purposes, in microform, paper, electronic and/or any other formats.

The author retains copyright ownership and moral rights in this thesis. Neither the thesis nor substantial extracts from it may be printed or otherwise reproduced without the author's permission.
AVIS:

L'auteur a accordé une licence non exclusive permettant à la Bibliothèque et Archives Canada de reproduire, publier, archiver, sauvegarder, conserver, transmettre au public par télécommunication ou par l'Internet, prêter, distribuer et vendre des thèses partout dans le monde, à des fins commerciales ou autres, sur support microforme, papier, électronique et/ou autres formats.

L'auteur conserve la propriété du droit d'auteur et des droits moraux qui protège cette thèse. $\mathrm{Ni}$ la thèse ni des extraits substantiels de celle-ci ne doivent être imprimés ou autrement reproduits sans son autorisation.
In compliance with the Canadian Privacy Act some supporting forms may have been removed from this thesis.

While these forms may be included in the document page count, their removal does not represent any loss of content from the thesis.
Conformément à la loi canadienne sur la protection de la vie privée, quelques formulaires secondaires ont été enlevés de cette thèse.

Bien que ces formulaires aient inclus dans la pagination, il n'y aura aucun contenu manquant.

\section{Canada}




\section{Abstract}

The outer Mackenzie Delta is the site of the proposed Mackenzie Gas Project (MGP). Approval of the MGP may impact Whimbrel Numenius phaeopus populations breeding in the area through habitat loss and human disturbance. This study identified Whimbrel breeding habitat, examined the use of IKONOS imagery to identify key Whimbrel breeding habitats within the Kendall Island Bird Sanctuary in the outer Mackenzie Delta and analysed the potential impact of the MGP on Whimbrel populations. Wet-sedge low-centred polygon habitat supported the majority of breeding Whimbrel in the study site (87\%). Whimbrel were also observed breeding in dry upland tundra habitats (13\%). Supervised classification of the IKONOS imagery provided a broad classification of land cover types but was incapable of identifying polygon habitat used by breeding Whimbrel. Construction and operations of the MGP will reduce the amount of available Whimbrel breeding habitat. 


\section{Acknowledgements}

My supervisor Dr. Charles Francis is due a mountain of thanks for his supervision, support and amazing editing skills! Thank you for the contributions of my committee: Dr. Mark Forbes and Dr. Jeremy Kerr. Thanks to Dr. Grant Gilchrist for all his great editing and content suggestions. Special thanks to Vicky Johnston of the Canadian Wildlife Service for providing me with the unique opportunity to study Whimbrel in the Mackenzie Delta and Jennie Rausch for all her help and support. Thank you to everyone in the PRISM field camps for their assistance in the field and the great camp memories. Thanks especially to my field assistants Kayla Hansen-Craik and Krista Sittler for all their help and enthusiasm. I could have never gotten through those hard days trudging through the slog without them!! Thanks to Rick Lanctot and Cheri Gratto-Trevor for supplying me with field equipment and advice. I would also like to thank the members of the $4^{\text {th }}$ floor NWRC graduate lab for all of their support and friendship. Particular thanks to Margaret Campbell who was always there for me through the tough times and brought me lots of yummy treats! Thanks to Paul Smith for his statistical advice and Jeannine Paquette, Jason Duffe, Dr. Doug King and Peter Morse for their GIS help! Thanks to David Carpenter, David Ladd and all the other great people at Carleton University who kept me entertained and forced me to be social once in awhile!! Finally, thanks to my family for all their support, financially and emotionally, while I endeavoured to go out on "my own" and study my master's thesis so many thousands of kilometres away!! 


\section{Table of Contents}

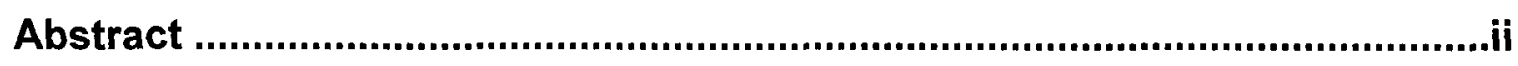

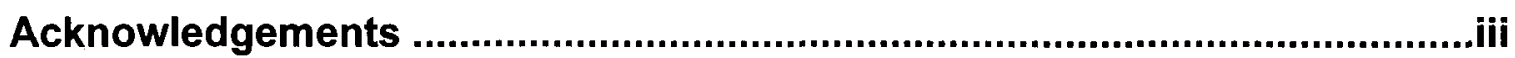

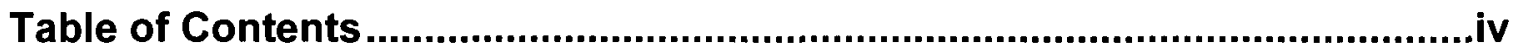

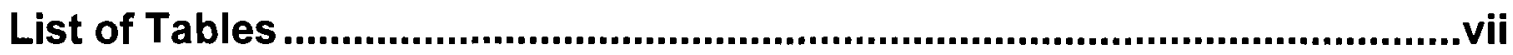

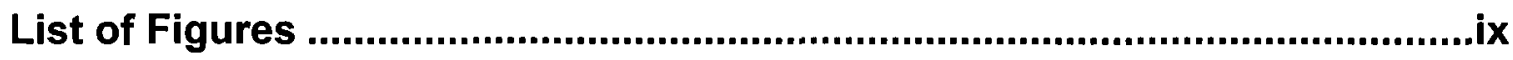

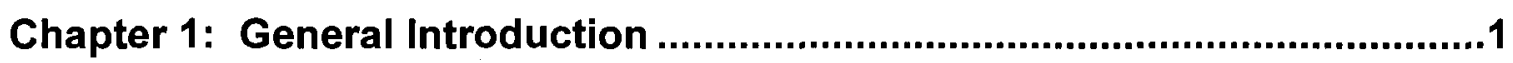

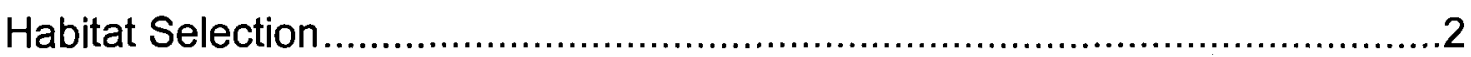

Shorebird Nest-site Selection ................................................................

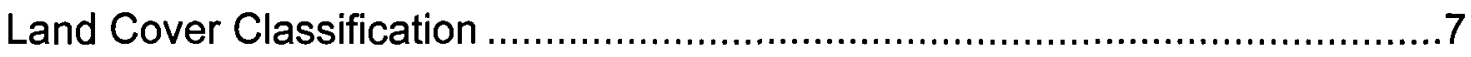

Satellite Remote Sensing in Polar Regions ...............................................10

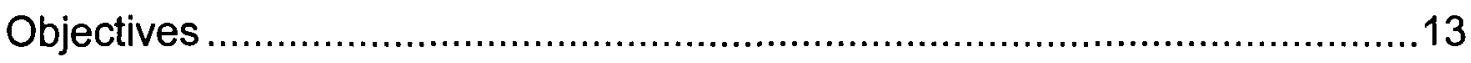

Chapter 2: Evaluating the potential impact of a gas pipeline on Whimbrel breeding habitat in the outer Mackenzie Delta, Northwest Territories .........15

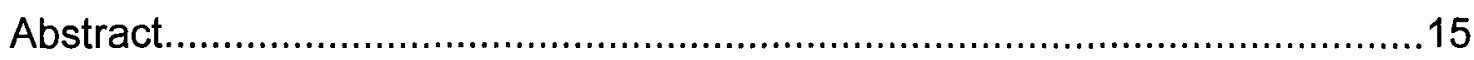

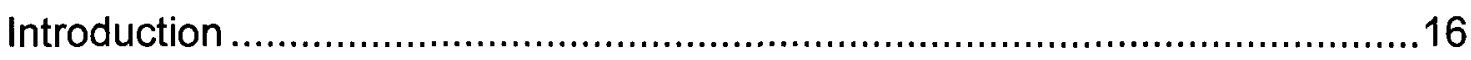

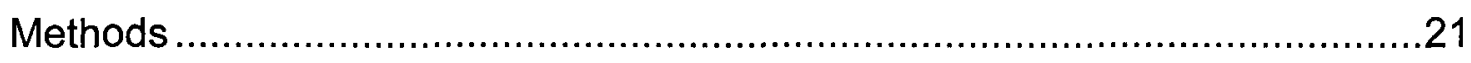

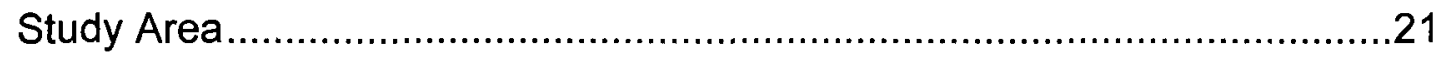

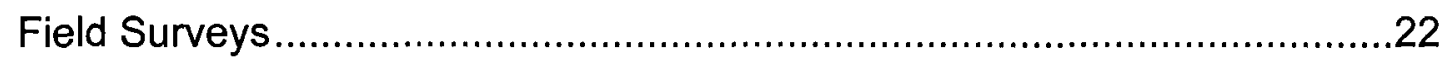

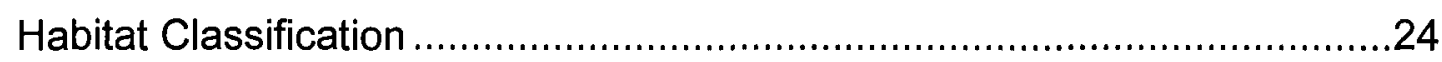

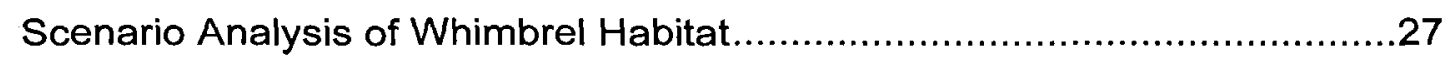

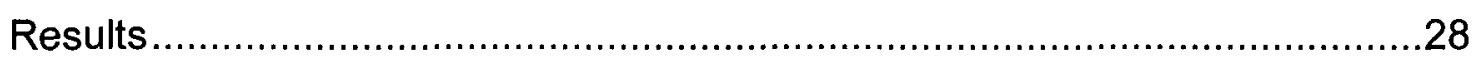

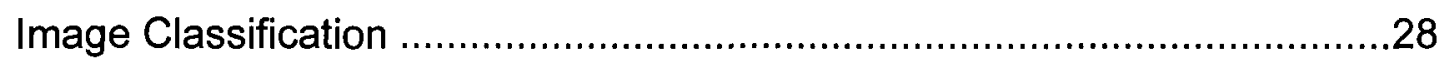




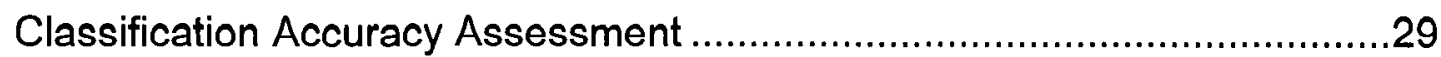

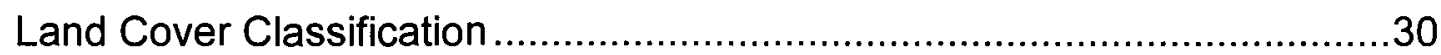

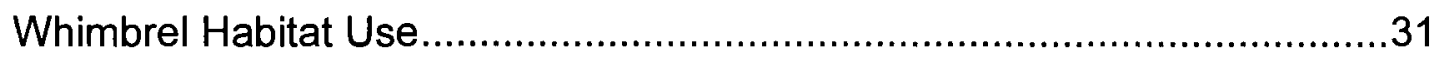

Potential Impact of the Mackenzie Gas Project ........................................32

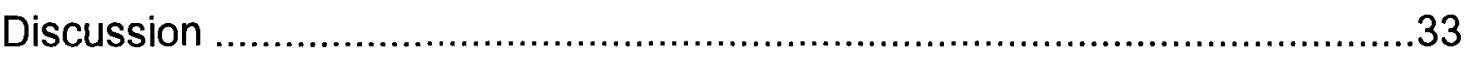

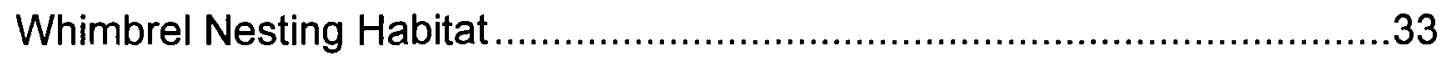

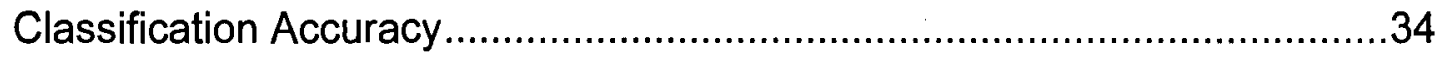

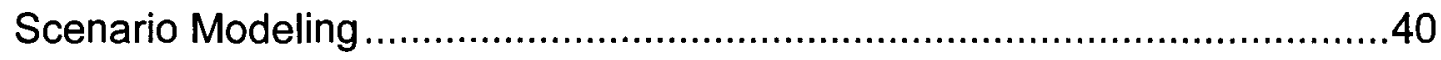

Chapter 3: Whimbrel territory and nest-site selection in the outer Mackenzie Delta, Northwest Territories. ......................................................55

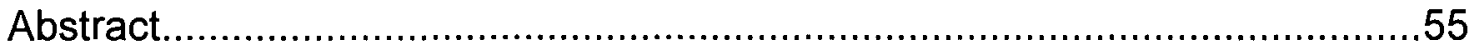

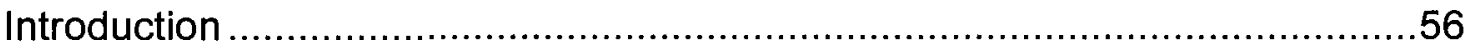

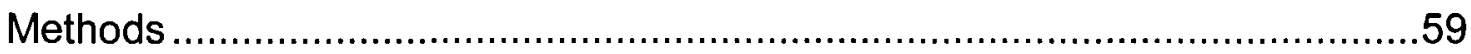

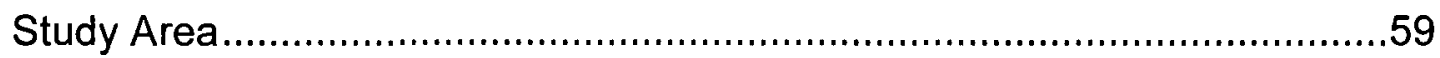

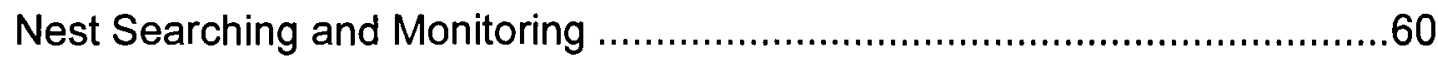

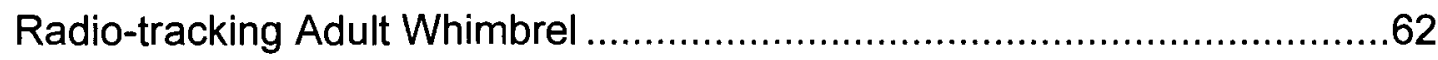

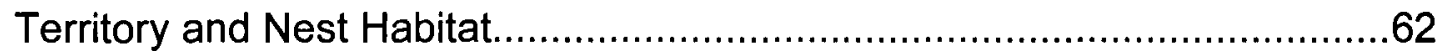

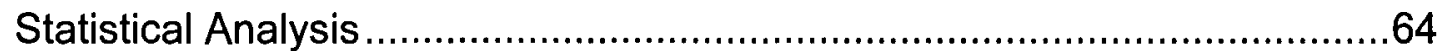

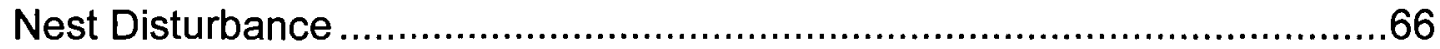

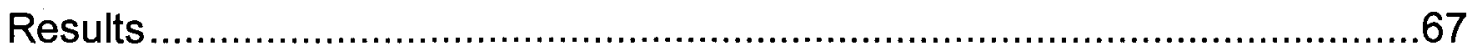

Territory Selection at the Landscape Level ...........................................67

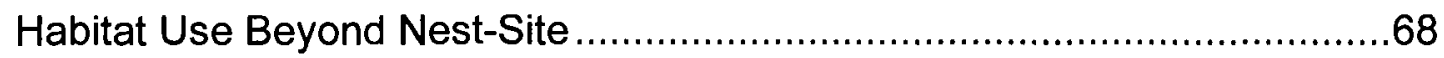

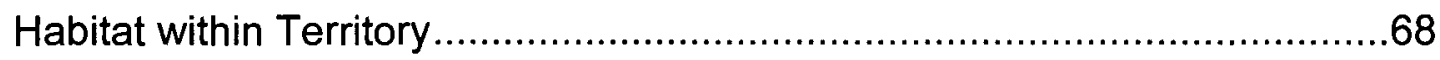

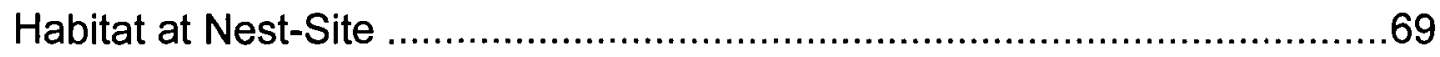




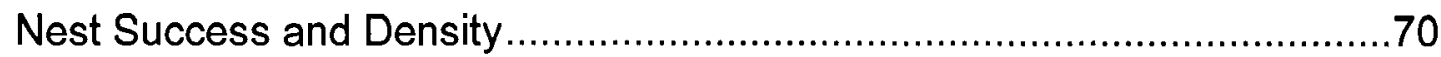

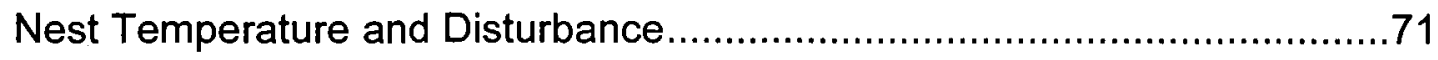

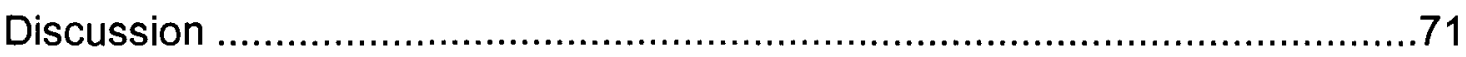

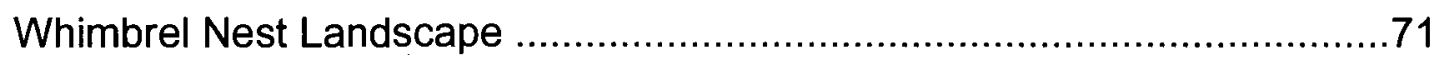

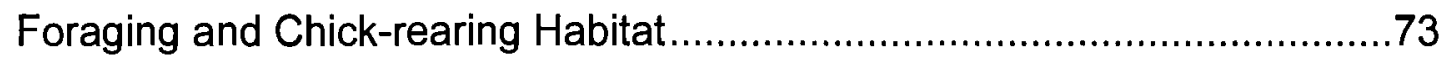

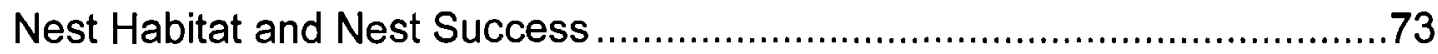

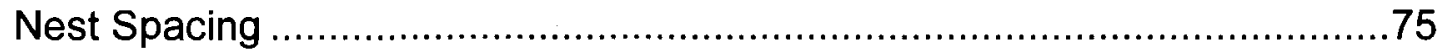

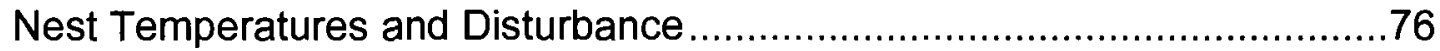

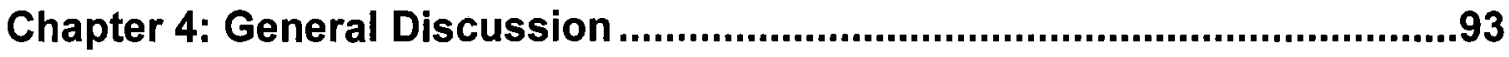

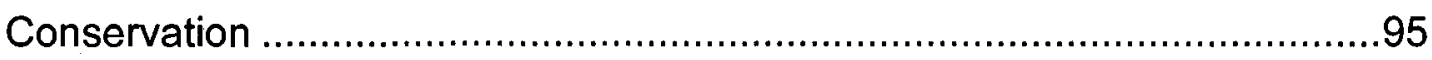

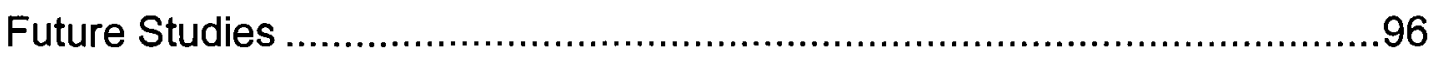

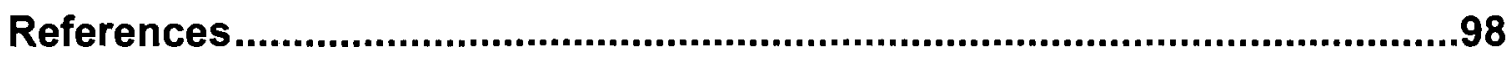

Appendix 


\section{List of Tables}

Table 2.1. Spectral ranges and resolutions of IKONOS bands used in the supervised classification.

Table 2.2. Signature separability between land cover classes used in the supervised classification

Table 2.3. Summary of error matrix results for the supervised classification of the three scenes of IKONOS imagery for the Kendall Island Bird Sanctuary and Fish Island in the outer Mackenzie Delta, Northwest Territories

Table 2.4. Error matrix resulting from accuracy assessment of the supervised classification for the three scenes representing the Kendall Island Bird Sanctuary and Fish Island in the outer Mackenzie Delta, Northwest Territories

Table 2.5. The percent of terrestrial habitat encompassed by each land cover class and area estimates of land cover classes from the supervised classification of the Kendall Island Bird Sanctuary and Fish Island in the Mackenzie Delta, Northwest Territories

Table 2.6. Results for three scenarios potentially resulting from the construction of a natural gas processing facility and pipeline, in breeding Whimbrel habitat on Taglu and Fish Island in the outer Mackenzie Delta, Northwest Territories.

Table 3.1. Comparison of microhabitat characteristics of Whimbrel nests and non-nest sites using two-tailed t-test and Mann-Whitney $U$ tests.

Table 3.2. A comparison of the number of Whimbrel nests and non-nests located on hummocks and ridges using a two-tailed t-test.

Table 3.3. Comparison of microhabitat characteristics of hummocks and ridges for Whimbrel nests and non-nest sites.

Table 3.4. Discriminant function analysis of microhabitat variables of Whimbrel nest-sites on failed vs. successful and hummocks vs. ridges

Table 3.5. Comparison of macro-habitat measurements between Whimbrel nests on hummocks and ridges and successful and failed nests.

Table 3.6. Comparison of microhabitat characteristic of failed and successful Whimbrel nests. 
Table 3.7: Mayfield estimates of nest survival for Whimbrel nesting on hummocks and ridges.

Table 3.8. Nesting densities of Whimbrel and distance to nearest neighbour in wet-sedge low-centred polygon habitat on Fish Island, Mackenzie Delta, Northwest Territories.

Table 3.9. Mean nest temperatures during periods when Whimbrel is on and off nest, number of departures and length of time away from nest during departure as observed during a 4-hour period, and the time taken by Whimbrel to return to the nest after video cameras were set up. 


\section{List of Figures}

Figure 2.1. Map showing the location of the Mackenzie Delta in the Northwest Territories.

Figure 2.2. Taglu and Fish Islands and the Kendall Island Bird Sanctuary in the outer Mackenzie Delta, Northwest Territories..

Figure 2.3. The proposed Taglu Island gas processing facility (pink outline), proposed pipeline (gray line) for the Mackenzie Gas Project, wet-sedge lowcentred polygon habitat (purple cross hatch) and the Kendall Island Bird Sanctuary boundary between Taglu and Fish Islands in the outer Mackenzie Delta, Northwest Territories.

Figure 2.4. Spatial modeling framework created using Model Builder in ArcMap to develop three potential scenarios that could result from construction of a natural gas processing facility and pipeline on Taglu and Fish Islands in the outer Mackenzie Delta, Northwest Territories.

Figure 2.5. The results of the supervised classification of the Kendall Island Bird Sanctuary and Fish Island in the outer Mackenzie Delta, Northwest

Territories.

Figure 3.1. Map showing the locations of Whimbrel nests found in 2006 (blue stars) and 2007 (red crosses) on Taglu and Fish Islands, in the outer Mackenzie Delta, Northwest Territories

Figure 3.2. An example of wet-sedge LCP habitat on Fish Island in the outer Mackenzie Delta, Northwest Territories

Figure 3.3. Location of radio-tracking points for adult Whimbrel breeding on Fish Island in the outer Mackenzie Delta, Northwest Territories.

Figure 3.5. Example of a Whimbrel nest on a hummock (a) and on a ridge (b) in wet-sedge low-centred polygon habitat in the outer Mackenzie Delta, Northwest Territories

Figure 3.6. The distribution of discriminant function scores comparing failed and successful Whimbrel nests (above) and nests on hummocks and nests on ridges. 


\section{Chapter 1: General Introduction}

The North American Whimbrel Numenius phaeopus has undergone a significant population decline in the United States and Canada and is a species of high concern (Donaldson et al., 2000, Brown et al., 2001, US Shorebird Conservation Plan, 2004). Whimbrel are a migratory species, spending their winters as far south as Central and South America and flying north to the Canadian Arctic to breed. As with many shorebird species, their migratory nature can make them vulnerable to changes in habitat, habitat loss, toxic chemicals and pollution, increased predator populations as well as climate change (Morrison, 2001).

Whimbrel breeding habitat in the outer Mackenzie Delta, Northwest Territories, may be impacted by the pending Mackenzie Gas Project (MGP) which is currently undergoing environmental assessment prior to formal approval. The MGP proposes to extract natural gas resources that lie beneath the Delta and transport them to existing pipeline systems in the south. To minimize the impact of any changes in habitat used by breeding migratory species, it is important to first understand the extent to which particular habitats are used and to assess the availability of these habitats. Knowledge of habitat selection processes with particular reference to shorebird breeding can allow us to understand observed breeding habitat selection preferences. 
The process of identifying and selecting important habitats to conduct intensive habitat analysis in remote Arctic regions can potentially be improved using various remote sensing materials. Further, remote sensing can provide a means of determining the availability of suitable habitat across a larger scale than would otherwise be possible when ground studies are logistically difficult.

In this thesis, I examine Whimbrel breeding habitat use and distribution in the outer Mackenzie Delta using both ground and satellite approaches and attempt to predict the impact of pipeline development on their habitat. In this chapter I provide some background related to habitat selection in birds, and identification of habitat using remote sensing data, then provide an outline of the remaining two chapters.

\section{Habitat Selection}

Habitat selection refers to the choice of a particular habitat over other available habitats (Partridge, 1978). This selection may result from geographical cues leading to the selection or avoidance of habitat types, innate responses passed down by ancestors that may have made successful evolutionary choices, previous experience of an individual or the exploration of habitat possibilities (Hutto, 1985). Optimal habitat choice models assume that individuals actively select the highest-quality habitat available that maximizes their fitness and reproduction (Fretwell and Lucas, 1970, Burger, 1985). Suitability of a habitat may be determined by a number of factors, including food productivity (Cody, 
1981, 1985), competition (Cody, 1981, 1985; Rosenzweig, 1985), risk of predation (Martin, 1995) and others. Several of these factors are density dependent suggesting that habitat suitability will decrease if density is increased (Fretwell and Lucas, 1970).

Two theories proposed by Fretwell and Lucas (1970) address the theory of density dependence: ideal-free distribution and ideal-despotic distribution. Ideal-free distribution suggests that as density increases, individuals spread out throughout habitats to equalize their return, resulting in high-quality habitat supporting more individuals than poor-quality habitats. Ideal-despotic distribution suggests that healthy, dominant individuals may establish themselves in highquality habitats excluding subordinate individuals to poorer habitat types.

The presence of individuals in poorer habitat types (sinks) may be an important factor in stabilizing high-quality habitat populations (source). Constraints on the availability of high-quality habitat can lead to the dispersal of individuals to the poor-quality habitats, creating a source-sink dynamic resulting in population equilibrium (Pulliam, 1988). The source-sink model assumes that an individual can accurately determine habitat quality and will move from the sink to the source when space becomes available (Kristan, 2003).

Migratory birds pass through a wide range of habitats before settling at a specific one for breeding, foraging or wintering (Cody, 1985). Selection of a particular habitat involves a series of hierarchical decisions: general habitat 
selection (landscape), territory selection and nest-site selection (Gochfeld, 1977; Johnson, 1980; Burger, 1985; Hutto, 1985). The selection of a general habitat and the ecological processes affecting it restricts the processes acting on the territory and consequently the nest-site (Barg et al., 2006). Assuming that individuals are capable of perceiving and evaluating habitat quality (Fretwell and Lucas, 1970) they ultimately select a nest-site through a series or hierarchical decisions (Jones, 2001) that contribute to their reproductive success (Martin, 2001).

\section{Shorebird Nest-site Selection}

Shorebird nest-site selection might be influenced by food availability, because nearby food resources may allow incubating shorebirds to forage within view of the nest (Beveridge, 2007). Limitations on food availability can negatively affect the fecundity and reproductive success of breeding birds (Martin, 1987). Shallow water ponds on Niglintgak in the Mackenzie Delta, Northwest Territories provide feeding areas for Red-necked Phalaropes Phalaropus lobatus (Beveridge, 2007). Incubating males were often observed feeding at ponds adjacent to their nests. Smith et al. (2007) did not find any evidence supporting the influence of food limitation on nest-site selection of shorebirds at East Bay, Southampton Island, Nunavut. Female White-rumped Sandpipers Calidris fuscicollis, and male Red Phalaropes Phalaropus fulicarius, were often observed foraging within $100 \mathrm{~m}$ from their nest, while Black-bellied Plovers Pluvialis squatarola, Semipalmated Plovers Charadrius semipalmatus and Ruddy 
Turnstones Arenaria interpres fed within their nesting territories as well as in communal feeding areas and separate feeding territories.

The placement of Whimbrel nests on the lee side of hummocks in Churchill, Manitoba apparently affords the incubating bird protection from prevailing $\mathrm{N}$ to $\mathrm{E}$ winds originating from the Hudson Bay (Skeel, 1976, 1983). In hummock-bog habitat, the presence of a nearby shrub may also provide additional wind protection. Nest-sites that are sheltered from the wind may experience less convective heat loss for incubating adults or unattended eggs (Reid et al., 2002).

Selection of habitats that are highly heterogeneous can provide a disruptive effect that prevents predators from developing search images thereby reducing predation on open nesting birds (Storaas and Wegge, 1987; Martin, 1988; Skeel, 1983). Skeel (1983) suggests that Whimbrel breeding in Churchill are least conspicuous in the hummock-bog habitat because the abundance of prominent hummocks, bare patches of ground, scattered trees and high shrub densities create a disruptive pattern, whereas the homogenous sedge-meadow and heath tundra habitats may make nests more conspicuous to avian predators.

Vegetation structure at the nest-site may provide a favourable microclimate (Walsberg, 1985) as well as offer concealment from predators (Götmark et al., 1995). Prairie breeding shorebirds such as the Upland Sandpiper Bartramia longicauda, Wilson's Phalarope Phalaropus tricolor, and 
Marbled Godwit Limosa fedoa nest in upland habitats that are characterized by tall, dense grasses (Colwell and Oring, 1990). At East Bay, White-rumped Sandpipers, and Red Phalaropes, which flush at close distances to the nest, chose nests with high nest concealment (Smith et al., 2007). Other species nesting in the same area, Black-bellied Plovers, Semipalmated Plovers and Ruddy Turnstones flush at distances $>20 \mathrm{~m}$ and nest in less concealed sites. High nest concealment has been correlated with decreasing nest predation (Götmark et al, 1995). However, some birds select a nest site that provides visibility allowing them to detect predators at an early stage and react appropriately (Götmark et al., 1995).

Another factor influencing nest-site selection may be the choice of neighbours. More timid species may choose nest-sites that are close to more aggressive species, seeking shelter under their 'protective umbrella' (Dyrcz et al., 1981). For example: Bar-tailed Godwit Limosa lapponica nests in Northern Norway are distributed closer to Whimbrel nests than expected by chance. The Bar-tailed Godwit does not attack avian predators during incubation and relies on cryptic strategies to avoid ground predation. On the other hand, Whimbrel react aggressively in nest defence and will react to avian predators within a $500 \mathrm{~m}$ radius of the nest. By nesting near its Whimbrel neighbour, the Bar-tailed Godwit may benefit from the aggressive response when predators are nearby (Larsen and Moldsvor, 1992). 
The spacing of nesting individuals may also play an important role in nest success. Closely spaced nests would be at a disadvantage if a predator focused further efforts in areas where it had previously been successful (Tinbergen et al., 1967). The frequency of flights to and from foraging sites in areas of closely spaced nests may also increase the chance of a nest being revealed to predators (Skeel, 1983). Skeel suggests that the spacing of Whimbrel nests is a trade off between reduced detection (through dispersion) and the enhancement of joint defence (nesting near to conspecifics).

\section{Land Cover Classification}

Predictive habitat modeling using land cover information obtained from satellite remote sensing data increases the potential to effectively identify and manage the causes of habitat loss. This may contribute to the design of successful conservation plans to protect wildlife (Jennings, 2000; Goetz et al., 2003; Kerr and Ostrovsky, 2003). Remote sensing provides a means of estimating the availability of a particular habitat type, predicting species distributions and assemblages, and monitoring environmental changes particularly resulting from industrial developments. Such data are desirable in remote and vast areas such as the Canadian Arctic where studying large regions on the ground in detail is impossible due to logistical constraints (Gratto-Trevor, 1994, 1996; Morrison, 1997). The availability of land cover maps would allow researchers to avoid unnecessary studies of unsuitable habitat and focus their logistical efforts on studying areas likely to be relevant to their study. 
Land cover maps can be created using digital image classification to analyse spectral patterns from satellite imagery. Classification procedures use the spectral information represented by the digital numbers in one or more spectral bands in a remote sensing image to categorize all the pixels into land cover classes or 'themes' resulting in a thematic map of the original image. There are two common classification procedures: 'unsupervised' and 'supervised'. The unsupervised classification method does not require prior knowledge of the habitat and relies on algorithms that examine the unknown pixels in the imagery and use natural grouping or clusters in the image values to aggregate them into land cover classes. The supervised classification method requires a priori knowledge of the habitat to develop training areas to represent the desired land cover types and utilizes the spectral attributes of each type to categorize each pixel in the imagery (Lillesand and Kiefer, 2004).

There are many varieties of satellite remote sensing imagery with a broad range of spatial resolutions. Satellite imagery is generally classified as either coarse or high resolution imagery. Coarse resolution imagery such as SPOT Vegetation (VGT) which was used to produce a land cover map for North America has a resolution of $1 \mathrm{~km}$. Landsat, SPOT, IKONOS and Quickbird imagery are all classified as high resolution imagery but have a broad range in spatial resolution. The latest Landsat satellite (Landsat 7) has seven multispectral bands ranging from $30-60 \mathrm{~m}$ spatial resolution. It also has a panchromatic band providing a spatial resolution of $15 \mathrm{~m}$. Spot 4 satellite 
imagery provides four multispectral bands with a $20 \mathrm{~m}$ spatial resolution and a panchromatic band with a $10 \mathrm{~m}$ spatial resolution. The more recent Spot 5 imagery increases the spatial resolution of the multispectral bands to $10 \mathrm{~m}$ (with the exception of the middle infrared band which remains at $20 \mathrm{~m}$ ) and the panchromatic band to $5 \mathrm{~m}$. The IKONOS 2 and Quickbird satellite imagery both have four multispectral bands (red, green, blue and near infrared) as well as a panchromatic band. IKONOS has a spatial resolution of $4 \mathrm{~m}$ for its multispectral bands and a $1 \mathrm{~m}$ resolution for its panchromatic band. The resolution of Quickbird is $2.44-2.88 \mathrm{~m}$ for multispectral imagery and $0.61-0.72 \mathrm{~m}$ for the panchromatic imagery. RADARSAT is another type of imagery that ranges in resolution from $3-100 \mathrm{~m}$ and has advanced abilities to obtain information about the earth's surface regardless of most weather conditions and light levels.

A wide range of habitat mapping studies using satellite remote sensing, have been conducted using these various types of satellite imagery. For example: Kerr et al. (2001) developed an advanced land cover classification using SPOT 4/NGT imagery to estimate habitat heterogeneity and were able to predict butterfly species-richness patterns in Canada. Supervised classification of IKONOS imagery was used to map shallow water marine habitats in the Turks and Caicos; this study showed a $20 \%$ improvement of IKONOS over Landsat classifications (Mumby and Edwards, 2002). However, they were unable to successfully discriminate between 13 categories of coral, algal and seagrass habitats. SPOT 5 imagery was used to map seagrass beds in the Mediterranean 
Sea (Pasqualini et al., 2005). Supervised classifications were conducted on SPOT 5 imagery with a $10 \mathrm{~m}$ spatial resolution and a fused image with a $2.5 \mathrm{~m}$ resolution. Both images were found useful for this application producing $96 \%$ and $73 \%$ accuracies respectively. Taft and Haig (2004) mapped winter wetland habitats for shorebirds in the Willamette Valley, Oregon using RADARSAT (Taft and Haig, 2004). They classified three images using both supervised and unsupervised techniques to create land cover maps with four habitat classes and attained overall accuracies for the images ranging from $45-60 \%$. Overall, RADARSAT proved a useful alternative for mapping winter shorebird habitat in agricultural areas when cloud cover often prevented the use of other satellite imagery (Taft and Haig, 2004).

\section{Satellite Remote Sensing in Polar Regions}

A number of satellite remote sensing studies have studied the potential of using such imagery to map wildlife habitat in the North American tundra for: muskox, waterfowl, bison, reindeer, caribou, snow geese , shorebirds and migratory bird sanctuaries (Ferguson, 1991; Pearce, 1991; Markson and Derkson, 1994; Matthews, 1991; George et al., 1977; Wickware et al., 1980; Dickson et al., 1989; Gratto-Trevor, 1994, 1996; Morrison, 1997; Didiuk and Ferguson, 2005). Largely the focus has been on using Landsat Multispectral Thematic Mapper (TM) satellite imagery as it is more readily available for northern landscapes and is more cost effective than high-resolution imagery such as IKONOS. 
Landsat TM has produced limited results in mapping habitat in the north, particularly when using unsupervised classification methods. Unsupervised classifications were unable to produce thematically detailed land cover data $(\sim 16$ classes) for some northern environments with acceptable accuracy. Classification of muskox habitat on Banks Island resulted in over 48 classes with poor visual interpretability (Ferguson, 1991). A classification of bison habitat in the Northwest Territories resulted in more than $5 \%$ of the habitat not being classified as a particular land cover type, including important bison habitat (Matthews, 1991). Both studies also used supervised classification methods to assess habitat extent. Ferguson (1991) found that discrimination between dwarf shrub tundra and hummocky tundra was difficult due to the variability in reflectance cause by varying slopes, substrate and the extent of vegetation cover. Using the supervised method, Matthews (1991) reduced the abundance of unclassified pixels to less than $1 \%$ of the total area but observed significant overlap between many classes in the supervised classification for bison habitat. Combining like classes (i.e. important forage habitats or less important land cover types) into one category increased the accuracy and produced acceptable classifications (Ferguson, 1991; Matthews, 1991).

Studies in the Canadian Arctic have explored the use of Landsat TM as a viable option for mapping shorebird habitat. A combination of unsupervised and supervised methods was used to develop a classification of 17 habitat types for Princes Charles Island, Foxe Basin, NWT (Morrison, 1997). Overall, the 
classification produced an accuracy of over $90 \%$ and was relatively consistent over large areas. The use of Landsat TM and unsupervised approaches for classification of staging and nesting shorebird habitat in the outer Mackenzie Delta resulted in the identification of 21 habitat types of major importance (Jaques, 1987a, b; Dickson et al, 1989; Dickson and Smith, 1991). Visual interpretation of enhanced Landsat TM imagery was necessary to refine the identification of preferred habitats. Gratto-Trevor $(1994,1996)$ tested whether the results of these studies could be extrapolated to a larger area and found that in areas that were extensively ground-truthed, priority shorebird habitat was correctly identified; however, difficulties arose when extrapolating these data to surrounding areas that exhibited rapid habitat changes such as coastal regions and areas prone to flooding.

To date, few studies have looked at the use of higher resolution satellite imagery in the Arctic, due in part to lack of availability and cost. SPOT satellite imagery which records spectral data at a resolution of $20 \mathrm{~m} \times 20 \mathrm{~m}$ (an improvement on the $30 \mathrm{~m} \times 30 \mathrm{~m}$ resolution of Landsat TM) has been used to map muskox habitat on Devon Island in the Queen Elizabeth Islands with satisfactory results (Pearce, 1991). The $20 \mathrm{~m}$ spatial resolution of SPOT was able to identify important waterfowl habitats such as smaller wetlands and the unique moss/peat shoreline in the Alaskan Arctic Coastal Plain that were not detectable using Landsat data (Markon and Derksen, 1994). 


\section{Objectives}

In the following chapters, I examine Whimbrel breeding habitat in the outer Mackenzie Delta. In chapter 2, I identify areas of Whimbrel breeding habitat through direct ground studies. Using my knowledge of Whimbrel breeding habitat and various Geographic Information Systems (GIS), I subsequently assess the potential of using high-resolution IKONOS satellite imagery to develop a suitable predictive habitat model. I then explore the potential of using a habitat map created using various techniques from the satellite image to estimate the potential impact of the MGP on Whimbrel breeding habitat assessing three scenarios that vary in their degree of industrial development.

In chapter 3, I identify and define areas of Whimbrel breeding habitat on three scales: landscape, territory and nest-site. I compare nest-site habitat to areas of available habitat within Whimbrel nesting territories to determine if Whimbrel are exhibiting habitat selection preferences. I examine nest success between nests on two types of habitat structures in which I found nests: hummocks and raised polygon ridges. I identify and analyse habitat differences that may have contributed observed variation in nest success rates. Finally I examine the spatial distribution of nests and assess Whimbrel response to human disturbance and the ability of i-button temperature data loggers to monitor changes in nest temperature during parental departures. In the final chapter, I re-visit the results of chapters 2 and 3 and propose direction for further studies in 
predictive habitat modeling of shorebird breeding habitat in Arctic landscapes, scenario analyses and Whimbrel habitat selection in particular. 


\section{Chapter 2: Evaluating the potential impact of a gas pipeline on Whimbrel breeding habitat in the outer Mackenzie Delta, Northwest Territories}

Abstract

The proposed Mackenzie Gas Project (MGP) may reduce amounts of available breeding habitat for Whimbrel Numenius phaeopus, in the outer Mackenzie Delta, Northwest Territories. A combination of ground surveys and high resolution IKONOS imagery was used to map breeding habitat for Whimbrel in the Delta. During ground surveys, I found Whimbrel nests $(n=28)$ in extensive areas of wet-sedge low-centred polygon (LCP) habitat on two islands in the Delta (Taglu and Fish Islands) in both years of the study. Supervised classification using spectral analysis of IKONOS imagery identified additional areas of lowland, wet-sedge habitat in the region, but visual examination of the images was necessary to determine whether they exhibited LCP structure. Areas with dense shrubs, no standing water and/or lacking polygon structure, did not support breeding Whimbrel, as determined by ground surveys. Scenario analyses, using habitat maps developed from a combination of methods, were used to estimate the potential effects of the MGP on Whimbrel habitat. Assuming effective complete habitat loss within $20 \mathrm{~m}, 50 \mathrm{~m}$, or $250 \mathrm{~m}$ of any infrastructure or pipeline, the currently proposed pipeline development would result in loss of $8 \%$, 
$12 \%$ or $30 \%$ of existing Whimbrel habitat. Additional habitat may be lost if water levels rise and/or if water quality is affected.

\section{Introduction}

The Canadian Arctic provides breeding grounds for most species of North American shorebirds (Godfrey, 1986; Gratto-Trevor, 1994; Gratto-Trevor, 1996; Morrison, 2001). Migratory shorebirds depend on numerous habitat and landscape types throughout their annual cycle (Donaldson et al., 2000) and habitat loss resulting from industrial development may contribute to widespread declines of shorebird populations (Morrison, 2001, Brown et al., 2001).

As the availability of natural resources is declining elsewhere, interest is turning to Arctic Canada. The Canadian North contains a wealth of untapped natural resources. Industrial development to extract these resources may alter sensitive Arctic ecosystems, on which many wildlife are dependent. Studies are legally required to assess the potential environmental impact of these developments.

The Mackenzie Delta, in the Northwest Territories (Figure 2.1) is recognized as a key terrestrial habitat for migratory birds (Alexander et al., 1991). It also has been identified by previous studies as an important location for breeding shorebirds (Tarves, 1987; Jaques, 1987a, b; Dickson et al, 1989; Dickson and Smith, 1991; Gratto-Trevor, 1994, 1996). 
Oil and gas exploration has been ongoing in the Mackenzie Delta since 1965. In 1974, the Berger Inquiry was commissioned to evaluate the social, economic and environmental impacts of a proposal to extract oil and gas reserves and transport them via pipeline down the Mackenzie Valley. The report resulting from the inquiry made a recommendation of a 10 -year moratorium to deal with important issues before exploration attempts could be made. This time has passed and renewed interest in oil and gas extraction has resurfaced as the Mackenzie Gas Project (MGP), which is currently undergoing environmental assessment. Approval of the MGP would result in the construction of at least a $1220 \mathrm{~km}$ long natural gas pipeline connecting three new onshore gas processing facilities in the Mackenzie Delta itself to existing pipeline systems in Northern Alberta.

A significant portion of the proposed MGP will occur in the Kendall Island Bird Sanctuary (KIBS, Figure 2.2), located in the outer Mackenzie Delta. Although a migratory bird sanctuary only the surface rights are protected and managed by Environment Canada, while the rights to the subsurface (in Northern regions) is held by the Department of Indian and Northern Affairs and may be leased out for exploitation. Environment Canada has the right to deny permits allowing activity on the land, but in the past have permitted exploration activities in KIBS. Taglu Island, in KIBS, is the site of one of the three planned onshore gas processing facilities for the proposed MGP (Figure 2.3). Construction could affect nesting shorebirds through direct loss of breeding habitat, loss resulting 
from conversion of habitat to other habitat types including changes in water flow, disturbance, and contamination or spills.

One of the species likely to be affected by these developments is the Whimbrel Numenius phaeopus. It is listed as a species of concern in the Northwest Territories by the Committee on the Status of Endangered Wildlife in Canada (2006) and has been identified by both the U.S and Canadian Shorebird Conservation Plans as a species of high conservation concern (Donaldson et al., 2000, Brown et al., 2001, US Shorebird Conservation Plan, 2004). Whimbrel breed in low densities across the heterogeneous landscape of the Canadian Arctic (Skeel and Mallory, 1996). Suitable habitats may be limited and spread over large areas making identification of these key breeding habitats difficult.

Assessing the impacts of the MGP on Whimbrel in this region requires identification of the habitats they are using for breeding and chick-rearing. Taglu and Fish Islands have been identified in previous studies as areas of Whimbrel breeding habitat (Tarves, 1987; Jaques, 1987a, b; Dickson et al, 1989; Dickson and Smith, 1991; Gratto-Trevor, 1994, 1996). Remote sensing data, such as satellite imagery, could be useful for identifying additional suitable habitats in this region. Identification of these regions could then contribute to models that evaluate the impact of MGP under various disturbance scenarios.

Remote sensing techniques potentially offer a cost-effective way of determining both the availability of habitat, and mapping wildlife habitats over 
large areas by extrapolating data from smaller ground-surveys. Identification of these habitats using remote sensing can decrease the need for costly reconnaissance studies and extensive ground surveys, allowing efforts to be focused on understanding habitat requirements within those areas. With the increased interest in the Canadian Arctic, the availability of satellite remote sensing imagery has also increased. A number of studies have successfully used satellite imagery to map and classify muskox, bison and waterfowl habitat (Ferguson, 1991; Pearce, 1991; Matthews, 1991; Markon and Derksen, 1994). However, habitat classifications developed using imagery from one region may not be suitable in other regions because differing vegetation patterns, moisture regimes, landforms and geological substrates in Arctic landscapes produce different spectral responses in satellite imagery (Morrison, 1997). Previous habitat classification studies using Landsat Thematic Mapper (TM) imagery to evaluate shorebird habitats in the Arctic had limited success. The $30 \mathrm{~m}$ spatial resolution of Landsat TM imagery (Gratto-Trevor, 1994, 1996; Morrison, 1997) cannot adequately resolve some habitat features such as low-centred polygon (LCP) ridges and hummocks which are often important habitat characteristics for several shorebird species (Dickson et al., 1989). These features may be an integral component to shorebird breeding habitat, suggesting higher spatial resolution afforded by IKONOS or Quickbird satellite imagery may improve the accuracy of mapping. 
Once a habitat map has been developed, scenario analysis through model building and simulation experiments, supported by understanding of ecosystem structure and function provide a systematic way of making predictions regarding the impacts proposed developments (Mohren, 2003). A model proposing the changes in ratings for habitat quality for Whimbrel if the MGP is approved suggests that disturbance effects will be greatest within $250 \mathrm{~m}$ of the facility and up to $1000 \mathrm{~m}$ of active airstrips (AMEC, 2005). Breeding Whimbrel actively respond to human intruders $100-200 \mathrm{~m}$ distant from their nests with aggressive distraction flights (Skeel, 1983; Larsen and Moldsvor, 1992; Skeel and Mallory, 1996). Human disturbance may increase the risk of direct loss of eggs due to predation of the nests or indirect loss of eggs due to inclement weather conditions while adults are exhibiting anti-predator behaviour (AMEC, 2005). Developing scenario analyses to predict the impact of MGP construction and facility operations on Whimbrel breeding habitat could be used to evaluate potential modifications to the MGP to minimize its impact on Whimbrel populations in the outer Mackenzie Delta.

The objectives of my study were: 1) to identify Whimbrel breeding habitat in selected study areas in the outer Mackenzie Delta through ground studies; 2) to evaluate whether I could use remote sensing data to identify additional Whimbrel breeding habitat in the outer Mackenzie Delta; and 3) to use a habitat map developed through a combination of mapping techniques, to predict the 
potential impact of MGP development on Whimbrel breeding habitat through various scenarios.

\section{Methods}

\section{Study Area}

The study area encompassed the 62,300 hectare Kendall Island Bird Sanctuary (KIBS) and the adjacent Fish Island, within the outer Mackenzie River Delta $(765,000 \mathrm{ha})$, east of the Mackenzie Bay bordering the Beaufort Sea Coast (Figures 2.1 and 2.2). The Canadian Wildlife Service (CWS) established KIBS in 1961, to provide long-term protection for migratory birds and their key habitats (CWS, 1992). The Mackenzie Delta is a subdivision of the Arctic Coastal Plain Region and is characterized by a mosaic of low lying, alluvial islands dominated by wetlands with relatively saturated soils (Kemper, 2006).

Arctic wetland areas with poor drainage commonly exhibit patterned ground (low- or high-centred polygon structures) (Ritchie, 1984) dominated by hydrophilic graminoids (Carex sp.), Equisetum and Salix. Some wetland areas have similar vegetation compositions but do not exhibit patterned ground. Annual spring flooding deposits nutrient-rich sediments in the wetlands and the warm river water melts the remaining snow thawing the ground and creating a deeper active layer than many of the surrounding areas (Burn, 2002). This, in combination with the irrigation caused by flooding, allows the vegetation to 
flourish (Burn, 2002), creating attractive breeding and feeding habitat for shorebirds (CWS, 1995).

Dry upland habitats occur throughout the study area. Upland habitats are typically patterned with small tussocks vegetated with Carex, Salix, Ericaceae and other herbaceous plants and patches of shrubs up to $3 \mathrm{~m}$ in height. Also associated with upland habitats are valleys with small wetland patches featuring a combination of high- and low-centred polygons.

\section{Field Surveys}

In 2006, my field studies began on 7 June, after water levels subsided from seasonal flooding of the outer Delta, and continued until 18 July, when all Whimbrel nests hatched. In 2007, surveys began on 7 June and continued until 21 July. I established my camps in coordination with on-going shorebird research by the Program for Regional and International Shorebird Monitoring (PRISM) and CWS. Camp locations were selected based on the identification of the sites as good shorebird breeding habitat in previous surveys by Gratto-Trevor $(1994,1996)$ and a preliminary visit in July 2005 to confirm the continued presence of breeding Whimbrel. In 2006 camp was established on Taglu Island $\left(69^{\circ} 22^{\prime} 4^{\prime \prime} \mathrm{N}, 134^{\circ} 57^{\prime} 17^{\prime \prime} \mathrm{W}\right)$ and in 2007 on Fish Island $\left(69^{\circ} 22^{\prime} 21^{\prime \prime} \mathrm{N}\right.$, $\left.134^{\circ} 53^{\prime} 38^{\prime \prime} \mathrm{W}\right)$

I intensively surveyed Taglu and Fish Islands for Whimbrel nests in both years of the study. In addition, the PRISM crew established five 12 ha plots in 
lowland areas of Taglu Island in 2006 and five on Fish Island in 2007 for detailed shorebird surveys. In 2007, four of five Taglu Island plots from 2006 were resurveyed. Preliminary surveys of these areas were conducted to determine shorebird presence prior to selection. These plots were surveyed daily and nests and nesting activities of all birds, including Whimbrel were recorded. Whimbrel are aggressive and act defensively when a human intruder is within several hundred metres of a nest. Therefore I used behavioural observations as a key component to nest searching. Aggressive displays, scolding trill calls and flushing are indicative of Whimbrel nesting behaviour (Skeel and Mallory, 1996). When a pair was observed exhibiting defensive behaviour, I searched all raised areas (hummocks and ridges) in which the pair continued their aggressive displays until the nest was located. I used a Global Positioning System (GPS) to record nest location and described the habitat at each nest. The aggregation of nesting Whimbrel on Taglu and Fish Islands sometimes resulted in overlapping territories and caused some difficulty in determining which area a pair was defending. When it appeared that two pairs of Whimbrel were acting aggressively towards surveyors, surveyors would split up and draw the pairs apart to identify the individual territories. Once a surveyor was in their immediate territory, the pair would focus only on that surveyor, making it easier locate the nest.

I used a small zodiac to travel between Taglu and Fish Islands and throughout KIBS. I surveyed 55 patches of habitat ranging in size from $20-100$ 
ha in various locations for evidence of breeding Whimbrel. Each habitat patch was selected by visual interpretation of satellite imagery and aerial photos for the area and represented a variety of habitat types: dry graminoid meadows, areas with dense shrubs, upland tundra and saturated lowland habitats. At each location I described the habitat based on its primary vegetation type, micro-relief (low-centred polygons, high-centred polygons, tussock meadows, graminoid meadows), soil moisture and land aspect. Visual estimates were made of the percent ground cover (graminoids, low shrubs, tall shrubs, mosses and lichens, bare ground, water). I recorded the coordinates for the location with a GPS and took digital photographs of each site. This ground-truthing information was used as 'training data' and/or for assessing the accuracy of the remote sensing classification.

\section{Habitat Classification}

Geo-referenced IKONOS 2 multispectral and panchromatic imagery (Table 2.1) of KIBS and Fish Island was acquired by the Canadian Wildlife Service in 2003 from Space Imaging LCC. The imagery consisted of three scenes, each with an $11.3 \mathrm{~km}$ swath width (GeoEye, 2006). The first scene was collected June 22, 2002, the second and third scenes were collected on August 8, 2002. I classified each scene individually because of spectral differences in the images. A small amount of cloud contamination was present in the imagery which I masked and excluded from my analysis along with gravel pads and other unnatural habitat. 
Using Focus for PCl Geomatica 10.0, I conducted supervised classifications using the red, green, blue and near infrared spectral bands for each of the three IKONOS scenes to produce a thematic map of the study area (Lillesand and Kiefer, 2004). Supervised classification requires a priori knowledge of the identity and location of land cover types which can be derived from a combination of field work, personal experience, and analysis of georeferenced aerial photography and maps (Jensen, 1986). I utilized groundtruthing data that was collected in 2006 and 2007 to create representative areas of land cover to train the supervised classification. The supervised classification analysed the spectral characteristics of these areas and identified pixels of like spectral qualities, creating a thematic map representing various land cover types.

I initially defined six terrestrial land cover classes in the imagery. Two of these classes had poor signature separability from other classes. To attain greater signature separability between the classes I reduced the final classification to four land cover classes by combining areas with dense shrubs and tall stands of trees into one category and all other lowland habitats into another. I used the maximum likelihood classifier algorithm (MLC) to determine spectrally similar areas within the imagery (NRCAN, 2007). Pixels that did not likely belong to one of my habitat classes were assigned to the null class (other habitat). To remove unwanted fine-scale noise from the classified images, I used a $5 \times 5$ pixel FMO - Mode Filter. My final classification resulted in three thematic 
maps (one for each scene) containing a mosaic of pixels, each belonging to one of the four land cover classes or 'other habitats'.

I subsequently performed an accuracy assessment of the final supervised classifications by sampling 100 random pixels distributed throughout each of the three scenes. I compared each random pixel from the classified imagery to my knowledge of habitat based on a combination of ground-truthing data and visual interpretation of the original false colour image, to determine the percentage of the image that was correctly classified. I stratified the samples to land cover class percentages to provide a proportional representation of the image occupied by each land cover class (PCl, 2005).

After the accuracy assessment I conducted an additional supervised classification of the IKONOS imagery using the red, green and near-infrared multispectral bands to identify bodies of water. Several categories were created due to the vast differences in spectral reflectance of the various water bodies. Thematic maps representing water were created for each of the three scenes, and integrated into the original classifications.

I converted the classified images into raster thematic maps using ArcMap. I vectorized the raster maps to produce shapefiles identifying each habitat class (PCl, 2005) and calculated the total area classified for each habitat using Hawth's Tools (Beyer, 2008). The different water body types were combined into one category to represent overall water. 
Following ground-truthing of wet-sedge habitats I found that certain differences in habitat structure such as hummocks and polygon ridges within polygons were not spectrally recognizable using the multispectral bands of the IKONOS imagery. The higher resolution panchromatic band provided me with improved visual interpretation of low- and high-centred polygon habitat based on pattern. I used ArcMap to combine the multispectral bands and the panchromatic band to create a pan-sharpened multispectral image (Lillesand and Kiefer, 2000). The resulting pan-sharpened multispectral image was used to identify areas of non-shrubby lowland habitat from the classified images that exhibited wet-sedge low-centre polygon (LCP) patterns. I then digitized them in ArcMap to create polygon shapefiles and calculated the total area using Hawth's Tools.

\section{Scenario Analysis of Whimbrel Habitat}

I used ArcMap 9.2 and my habitat classification maps to build a scenario analysis to estimate the potential impact of the MGP on Whimbrel breeding habitat. Using ArcMap Model Builder, I developed a visual modelling framework of multiple geo-processing tasks to develop three scenario analyses: $20 \mathrm{~m}, 50 \mathrm{~m}$ and $250 \mathrm{~m}$ buffers on all sides of the proposed pipeline trench and Taglu facility (Figure 2.4). The $20 \mathrm{~m}$ buffer was selected based on the $40 \mathrm{~m}$ right-of-way for the construction of the proposed pipeline trench which represents the minimum amount of habitat loss or alteration. I chose the $50 \mathrm{~m}$ and $250 \mathrm{~m}$ buffers to illustrate two degrees of disturbance based on the AMEC model proposal that 
disturbance effects will be greatest $0-250 \mathrm{~m}$ away from pipeline and facility construction and operations (2005).

I made observations of territorial Whimbrel behaviour in the 2006 and 2007 field seasons to estimate an approximate territory size, using Whimbrel response to approaching observers and radio-tracking results (see Chapter 3 ). I used the average territory size to estimate the maximum number of breeding Whimbrel pairs each area of good habitat could support and the maximum number of breeding pairs that could potentially exist in the habitat remaining for each scenario. The maximum number of pairs was also determined based on my assumption that in 2006 and 2007 the lowland habitat was saturated.

\section{Results}

\section{Image Classification}

I defined six terrestrial land cover types within the study area: wet sedge lowland habitats (with and without LCP structure), saturated habitats, dry upland tundra habitats, tall willow stands, dense shrub lowland habitats, and dry graminoid lowland habitats. My final classification (Figure 2.5) had four land cover classes:

1. Non-shrubby Lowland Habitats (non-shrubby lowlands) - Areas of lowland meadows with vegetative covers of low-centred polygon habitat, flat 
graminoid meadows, or areas void of vegetation. Levels of moisture range from dry to moderately wet.

2. Saturated Habitats - areas of habitat saturated with deep $(>15 \mathrm{~cm})$ standing water that often exhibited LCP or high-centred polygon (HCP) structures. In areas of LCP habitat vegetation predominantly consists of hydrophilic sedges with little or no herbaceous or shrubby vegetation. HCP habitats are typically covered with sedges and herbs.

3. Dense Shrub Lowland Habitats (shrubby habitat) - areas where the predominant vegetation cover was composed of dense shrubs or tall willow stands with no open areas present.

4. Dry Upland Tundra Habitats (upland habitat) - areas dominated by tussocks with widespread herbaceous plants and patches of low shrubs $(<1 \mathrm{~m})$ are interspersed throughout.

All classes could be reliably separated except dry upland tundra habitats and dense shrub lowland habitats (Table 2.2). In the third scene, there were also limited spectral differences between non-shrubby lowland habitats and dense shrub lowland habitat.

\section{Classification Accuracy Assessment}

My overall accuracies for the three scenes were 77,74 and $85 \%$ respectively (Table 2.3). Non-shrubby lowland classification resulted in the lowest errors of omission and commission overall (Table 2.3). Pixels of nonshrubby lowlands were correctly classified $80-96 \%$ of the time (Table 2.4 ). 
Scene 1 had the highest errors of omission for this land cover type. The inclusion of incorrect habitat types to the lowland habitat class was infrequent with minimal inclusion of shrubby habitat. Classification of saturated and shrubby habitats produced high errors of omission. Errors of commission were low for saturated habitats but were increased for shrubby habitat due to the frequent incorrect assignment of upland habitat. The upland habitat class in Scene 1 and 2 had low error levels but scene 3 had a $48 \%$ error of commission resulting from incorrect assignment of pixels from shrubby habitat and 'Other Habitats' (Table 2.3).

\section{Land Cover Classification}

My classification identified $25 \%(11,752 \mathrm{ha})$ of terrestrial habitat in the study area as non-shrubby lowlands (Table 2.5). Shrubby habitat encompassed $26 \%$ of the area, $17 \%$ was upland habitat and only $0.7 \%$ was identified as saturated habitat. Approximately 38,377 ha of water bodies including ocean, river channels, lakes and ponds were classified from the imagery. Some small inland lakes and ponds in the imagery were unclassified due to the wide spectral variation in water throughout the imagery. The classification of the imagery was unable to identify $31 \%$ of the terrestrial landscape. Visual examination of the images suggest that unclassified areas were largely edges and transition habitats, particularly between water and terrestrial areas and within some upland habitat. Some of the unidentified habitat was also attributed to the inability of the classification to identify all saturated habitat. 
Based on visual examination of the false colour images, I identified 1168 hectares within the study area as wet-sedge LCP, accounting for $10 \%$ of the nonshrubby lowland land cover type. Lowland habitats in scene 1 and 2 that appeared to be ideal Whimbrel breeding grounds in the imagery were found to be too dry. Many of the LCP's identified in scene 3 were found to have dense shrubs on the polygon ridges.

Whimbrel Habitat Use

In 2006 and 2007 I found 28 nests located on low ridges or hummocks in wet sedge LCP habitat on Taglu and Fish Islands (Chapter 3, Figure 3.1). Whimbrel were observed breeding in $40 \%$ of the available wet-sedge LCP habitat identified using the satellite imagery. Radio-tracking studies indicate that this habitat was also important for foraging and chick rearing (Chapter 3 ). Nest sites were vegetated with a combination of dwarf and low shrubs, graminoids, mosses and herbs. Surveys of other lowland habitat patches ( $n=43$, Figure 2.6) identified from visual interpretation of the IKONOS imagery did not find breeding Whimbrel activities. My subsequent ground surveys of these habitats in the months of June and July, suggested that the sites differed from Whimbrel nesting habitat by being too dry, having poor structural complexity (i.e. no patterned ground) or having high shrub densities. I surveyed approximately 6000 ha $(-75 \%$ of all upland habitat in the study area) of upland tundra habitat in the outer delta. I found one Whimbrel nest in a dry upland habitat with adjacent wetland valleys consisting of a network of both LCP and high-centred polygon (HCP) structures. 
Three of twelve additional upland habitat patches I visited in July, late in the breeding season were observed to have two to three pairs of Whimbrel present that exhibited parental behaviour. Thus an estimated $50 \%(\sim 3000 \mathrm{ha})$ of the upland habitat I surveyed had evidence of Whimbrel breeding activities, but at relatively low densities. Based on these observations I estimate that upland breeding Whimbrel account for approximately $13 \%$ of the breeding population in the study area.

\section{Potential Impact of the Mackenzie Gas Project}

Dickson et al. (1989) estimated Whimbrel breeding territory size in the Mackenzie Delta to be up to 24 ha. Based on my observations of Whimbrel activity, I estimated an approximate territory size of 20 ha for breeding Whimbrel on the Taglu and Fish Islands. I estimated the total area of wet-sedge LCP Whimbrel breeding habitat on Taglu and Fish Islands to be 470 ha, thus potentially supporting 19-23 pairs. I observed 14 breeding pairs on Taglu and Fish Islands in each year of the study. If this was the maximum capacity for breeding Whimbrel in the area, it would suggest a territory size of 33 ha. My first MGP scenario, assuming a $20 \mathrm{~m}$ buffer of habitat loss around industrial infrastructure, suggested this would result in a $7.6 \%$ ( 35.5 ha) loss of the Whimbrel breeding habitat on Taglu and Fish Islands (Table 2.6). The number of potential Whimbrel pairs would be expected to decline from 24 to 21 assuming a 20 ha territory size and from 14 to 13 for a 33 ha territory size. The $50 \mathrm{~m}$ buffer scenario suggested a habitat loss of $11.6 \%$ ( $54.3 \mathrm{ha}$ ) supporting a maximum of 
20 or 12 Whimbrel pairs depending on territory size. In the final scenario (250 m buffer), $28.9 \%$ (94.7 ha) of the available habitat would be lost and the area would be able to support $30 \%$ less Whimbrel pairs.

\section{Discussion}

Whimbrel Nesting Habitat

Whimbrel have previously been observed breeding in wet-sedge lowcentred polygon habitat and upland tundra habitats in the Mackenzie Delta (Dickson et al., 1989; Gratto-Trevor, 1994, 1996; Ashenhurst, 2004). Dickson et al. (1989) showed that shorebirds in the outer Mackenzie Delta have a strong preference for well-developed LCP habitat because they provide dry areas for nesting and nearby adjacent shallow water for foraging. This study confirmed the previous findings of small breeding communities of Whimbrel in wet-sedge LCP habitat on Taglu and Fish Islands in association with other breeding shorebirds (Hudsonian Godwits Limosa haemastica, Red-necked Phalaropes Phalaropus lobatus, Stilt Sandpipers Calidris himantopus, and Pectoral Sandpipers Calidris melanotos).

A few observations of breeding Whimbrel were made in upland habitat with adjacent wetland valleys, but they account for less than $15 \%$ of breeding Whimbrel in KIBS and Fish Island. Breeding behaviour in these areas was not well studied, because many upland areas were $>10 \mathrm{~km}$ from the main study site and were not visited until late in the breeding season. Low numbers of Whimbrel 
exhibiting parental behaviour were observed in some of these locations but it could not be confirmed if the Whimbrel had nested there or walked to the areas with their broods. Studies in Churchill found small numbers of Whimbrel breeding in heath-tundra habitats (Skeel, 1983). Previous studies of upland habitat in the Mackenzie Delta were of low sampling intensity. My findings, in which I found low nesting densities in upland habitat matches previous studies. Dickson et al., (1989) found Whimbrel nesting in uplands but in low densities (1 pair/km² or less), while Gratto-Trevor $(1994,1996)$ did not encounter any Whimbrel in upland habitats. Another study looking at the effects of seismic lines on the abundance and distribution of breeding migratory birds found Whimbrel to be slightly more abundant in upland habitats with wet low-lying areas than in LCP habitat (Ashenhurst, 2004). Further focus on upland habitat is required to assess the full extent to which Whimbrel use this habitat type for breeding. Although uplands were much less important than lowland habitats within my study area, upland habitats may be more extensive elsewhere in the Mackenzie Delta, and hence even at low densities could support significant numbers of Whimbrel

\section{Classification Accuracy}

The supervised classification methods using high resolution IKONOS imagery were moderately successful at differentiating land cover into four broad categories of habitat the outer Mackenzie Delta. The initial use of six land cover types allowed for greater discrimination between habitat types in the classification, but resulted in low classification accuracies. Classification 
accuracies generally improve with a decrease in the number of land cover classes (Rees, 1990). The combination of tall willow stands and dense shrub lowland habitats did not affect my results because Whimbrel have only been observed nesting in more open habitats (Dickson et al., 1989; Gratto-Trevor, 1994, 1996). Having dry lowland habitats in a separate class from wet lowland habitats would have been beneficial to the land cover map however, spectrally they were almost indistinguishable.

Overall the signatures of the final four classes were nearly completely separate with the exception of upland habitat and shrubby habitat. The signature separability for these two habitat types was good in scene 1, but poor in scenes 2 and 3. This may be because the collection of imagery for scene 1 was early in the summer when willows were bare, while the other two scenes were collected in August after vegetation had flourished. This would likely cause similar reflectance values between upland habitat which has high levels of herbaceous vegetation and shrubby habitat which is dominated by willows. Although there was poor separation between these two classes, it was desirable to try to separate these habitats, because the upland habitat is potentially suitable for breeding Whimbrel. Areas known to be upland habitat based on ground data, appeared visibly distinct through colour patterns in the false colour composites of the IKONOS imagery, and thus could be readily identified using visual interpretation. The signature separability of non-shrubby lowlands and shrubby 
habitat was poor in scene 3 , but nevertheless, the majority of non-shrubby lowland habitat was still accurately identified.

Edges and transition habitats, as well as a large portion of the dry upland tundra were poorly classified. This may be due in part to the varying slopes throughout the habitat particularly around the periphery and in areas that slope into small wetland valleys. Slopes can result in shadows that change the spectral characteristics of the habitat (Gratto-Trevor, 1996). While this affected the accuracy of the estimated area of this land cover class, it was fairly clear from visual examination of the false colour image, which unclassified areas were part of upland habitat, and these areas were included when selecting areas for ground-truthing for Whimbrel.

The classification procedure had the highest accuracy at identifying nonshrubby lowlands. Identification of the other habitat types had more errors, particularly comparing saturated and shrubby habitats. Difficulties in accurately identifying saturated habitats are likely due to the often discontinuous nature of this habitat type. The wettest centres of a saturated habitat were generally identified but surrounding areas were often unclassified. The presence of areas of raised ground interspersed with standing water results in differing spectral reflectance values. Including these raised areas in the training data would result in a combination of spectral reflectance which would decrease the spectral separability between non-shrubby lowlands and saturated habitat. Training 
areas were selected to contain only the wet portions of this habitat type therefore the area of saturated habitat is probably underestimated.

Another factor affecting the classification accuracy could be the use of imagery collected in a different year or different time of year than the study was conducted (Gratto-Trevor, 1996). High resolution satellite imagery is costly and it is often difficult to obtain imagery collected at the time of the field study. In this case, the information collected during the field season (June and July) may not reflect conditions at the time of the imagery acquisition (July and August; Markson and Derkson, 1994). For example water levels in the Delta may change from year to year as a result of different flooding regimes, storm surges and annual changes in ice break-up, making areas that are suitable for shorebird nesting in one year unsuitable in other years (Gratto-Trevor, 1996). Further, imagery collected in early spring prior to nesting may show a greater percentage of saturated habitats that will have subsided before birds initiate nesting.

Scene 3 had the highest classification accuracy. The decrease in the accuracies of the other scenes are comparable to results observed in previous studies by Dickson et al. (1989) and Gratto-Trevor $(1994,1996)$ who found that as the distance from the original ground truth sites increases, the classification accuracy decreases. The 2006 and 2007 field camp locations on Taglu and Fish Islands were both encompassed within scene 3 . This, as well as the fact, that all observed breeding Whimbrel were located within this scene probably contributed to the increased classification accuracy of the scene, as more ground-truthing 
was conducted in nearby areas than in areas throughout the rest of the imagery. The decrease in accuracy for scene 1 may also be attributed to the different time of season that the imagery was collected. Although the imagery for scene 2 was collected at the same time as for scene 3, the lower accuracy may have occurred due to a greater proportion of upland habitat it supported, which was often difficult to distinguish from shrubby habitats late in the season.

The supervised classification was useful for identifying areas of lowland habitat that did not have dense shrubs and that were not saturated with water. However, it was unable to identify areas within the non-shrubby lowlands that exhibited LCP patterned habitat and in which Whimbrel nested. The supervised classification was limited to analysing spectral differences that identify different habitat types but was incapable of analysing textural differences that would indicate patterned ground. It was therefore necessary to combine the supervised classification with visual interpretation (digitizing) to provide a suitable predictive model of these habitat types.

The fusion of the higher resolution panchromatic imagery with the multispectral imagery improved the visual identification of LCP's. My fieldwork, as well as previous studies, show lowland breeding Whimbrel select habitat with dry areas for nesting and shallow pools for foraging (Dickson et al., 1989) typical of wet-sedge LCP's. Wet-sedge LCP habitat (470 ha) on Taglu and Fish Islands in KIBS supported most of nesting Whimbrel in the study area. Structural complexity, availability of raised ground, low shrub densities and moderate levels 
of moisture all appear to be important components of preferred Whimbrel breeding habitat. The absence of breeding Whimbrel in other areas identified from remote sensing imagery as wet-sedge LCP habitat may be attributed to higher densities of shrubs on polygon ridges and hummocks which I detected during subsequent ground truthing in 2006 and 2007. Areas with dense shrubs may be avoided by breeding Whimbrel due to restricted vision of approaching predators to nesting birds. Götmark et al. (1995) suggested that it may be beneficial for adults to have good visibility at the nest to reduce the risk of predation during incubation.

The use of remote sensing to determine breeding habitat for arctic nesting shorebirds provides only a limited solution to the otherwise logistically difficult task of field surveys. A combination of techniques was required to identify the structurally complex habitat that Whimbrel use in the study area. Supervised classification methods alone were only able to identify broad scale habitat types. Visual interpretation of the imagery within these types was necessary to identify Whimbrel breeding habitat in KIBS.

Another challenge with habitat mapping in this area is the highly dynamic nature of the habitat, which may change among years and within each year due to changes in water level. As a result, the distribution of suitable Whimbrel breeding habitat may change from year to year. This further limits the potential for using remote sensing data for habitat mapping if one needs to rely on images collected in previous years. 
Scenario Modeling

Only a small portion of habitat in KIBS and Fish Island (1168 ha) appears to be suitable for Whimbrel breeding. Loss of any of this habitat could negatively affect Whimbrel breeding populations in the area. A key part of determining the environmental impacts of industrial development activities is to model the impacts of different development scenarios on populations dependent on the affected area. My simulations suggest that up to $30 \%$ of suitable habitat could be lost by the proposed development, assuming Whimbrel avoid areas within $250 \mathrm{~m}$ of any infrastructure.

The impact of this habitat loss on Whimbrel depends on a number of additional factors. If the habitat was not saturated with birds, then loss of $30 \%$ of habitat may result in relatively little loss of Whimbrel. Conversely, increased predation may increase the loss.

Additional factors need to be explored to accurately determine the true effects of habitat disturbance to conduct a scenario analysis for the effects MGP will have on Whimbrel breeding habitat in the Mackenzie Delta. Construction of elevated structures could increase the number of predators by creating additional platforms for feeding, perch hunting or nesting (Truett et al., 1994). A number of man-made structures already present in the study area (Northwest Tel Cellular Communications tower, tall pilings) serve as artificial perches for Rough-legged Hawks Buteo lagopus and Raven Corvus corax. 
An additional challenge to modeling impacts is consideration of yearly climate fluctuations, the possibility of water contamination, vegetation changes, subsidence and disturbance from facility operations. Water contamination could result from construction, pipe ruptures or facility operations. Water contamination can have widespread effects because of the contiguous nature of the wetland habitat used by Whimbrel and other nesting shorebirds. The potential for subsidence or decrease in land elevation, occurring as a result of the extraction of natural gas from the underground reservoir (Environment Canada submission to the MGP environmental assessment, 2006) could result in low-lying areas using by breeding Whimbrel becoming inundated with water and therefore less suitable habitats. Environment Canada estimates a minimum of 185 ha of habitat would be inundated. Subsidence may also occur as a result of the melting permafrost because of the effects of winter construction and maintenance activities (Lawson, 1986, Felix and Raynolds, 1989, Emers et al., 1995). In this study, I found that lowland breeding Whimbrel are dependent on the complex mosaic of dry raised ridges of polygons that often are only $10-15 \mathrm{~cm}$ above water; even subtle subsidence leading to increased water levels could destroy the availability of suitable breeding habitat. Lastly, the response of Whimbrel to the presence of humans and air traffic during the year-round operations of the proposed Taglu facility could in itself reduce Whimbrel breeding habitat on Taglu Island. Whimbrel respond aggressively to the presence of field 
workers (within $200 \mathrm{~m}$ or less) and take flight when air traffic takes off or lands (Pirie, Pers.Obs.).

Intensive scenario analyses, practical knowledge of habitat types, Whimbrel ecology and GIS techniques must be combined to determine the effects of the proposed MGP. These analyses should consider all factors that may influence Whimbrel breeding habitat including: habitat saturation, food productivity, increased predator activity, water contamination, subsidence and related flooding, as well as Whimbrel reactions to human disturbances such as air traffic and machinery. 
Table 2.1. Spectral ranges and resolutions of IKONOS bands used in the supervised classification.

\begin{tabular}{lccc} 
Band & $\begin{array}{l}\text { Spectral Range } \\
(\mathrm{nm})\end{array}$ & Spectral Area & Ground Resolution (m) \\
\hline 1 & $445-516$ & Blue & 4 \\
2 & $506-595$ & Green & 4 \\
3 & $632-698$ & Red & 4 \\
4 & $757-853$ & Near-infrared & 4 \\
Pan & $526-929$ & Panchromatic & 1 \\
\hline
\end{tabular}




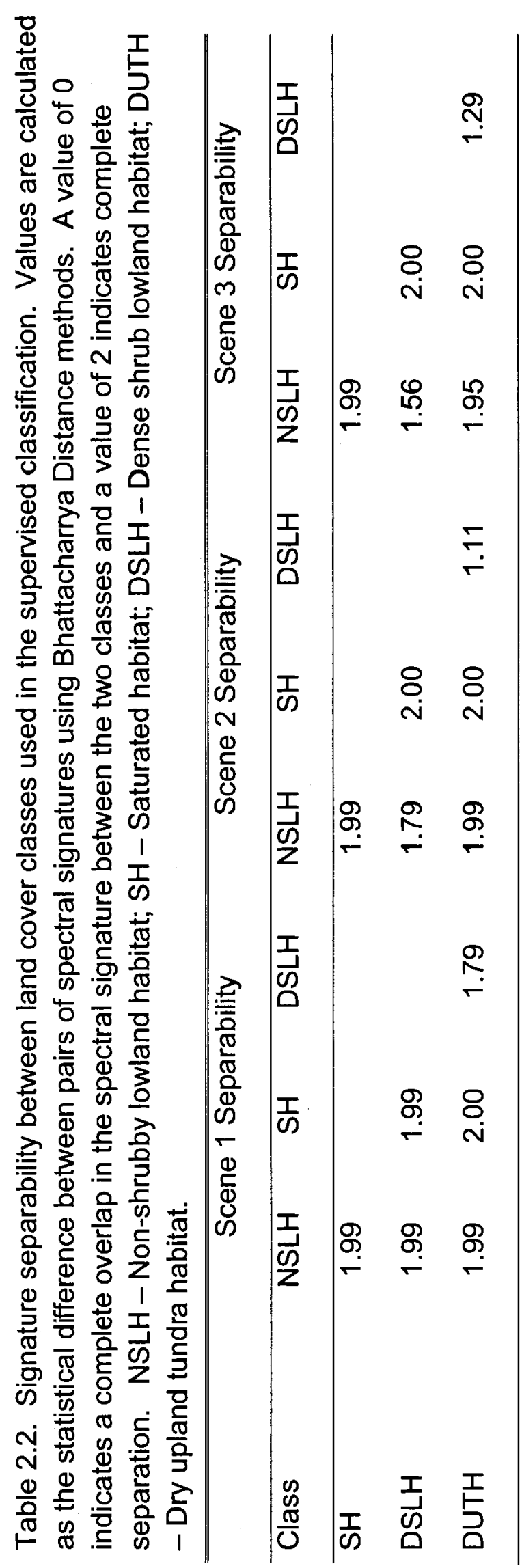




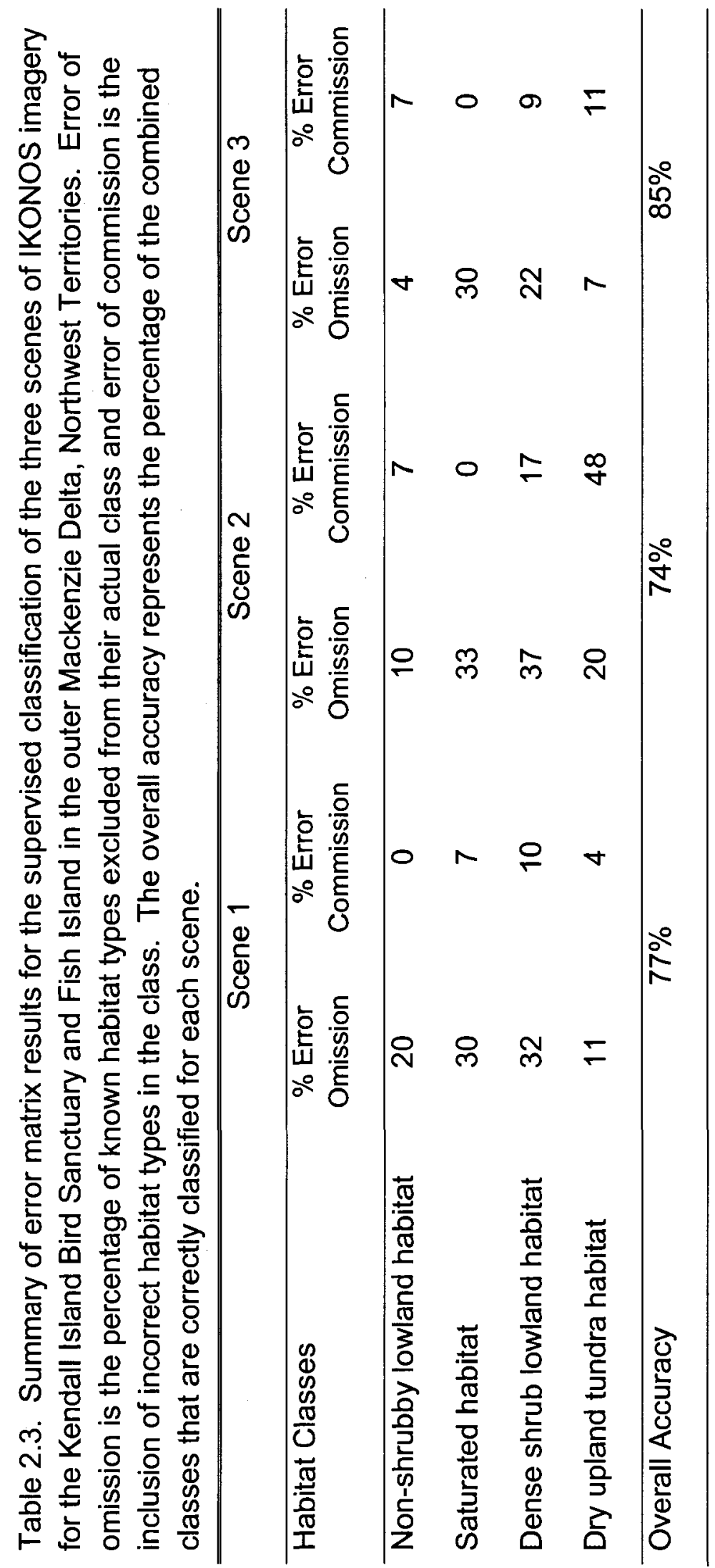




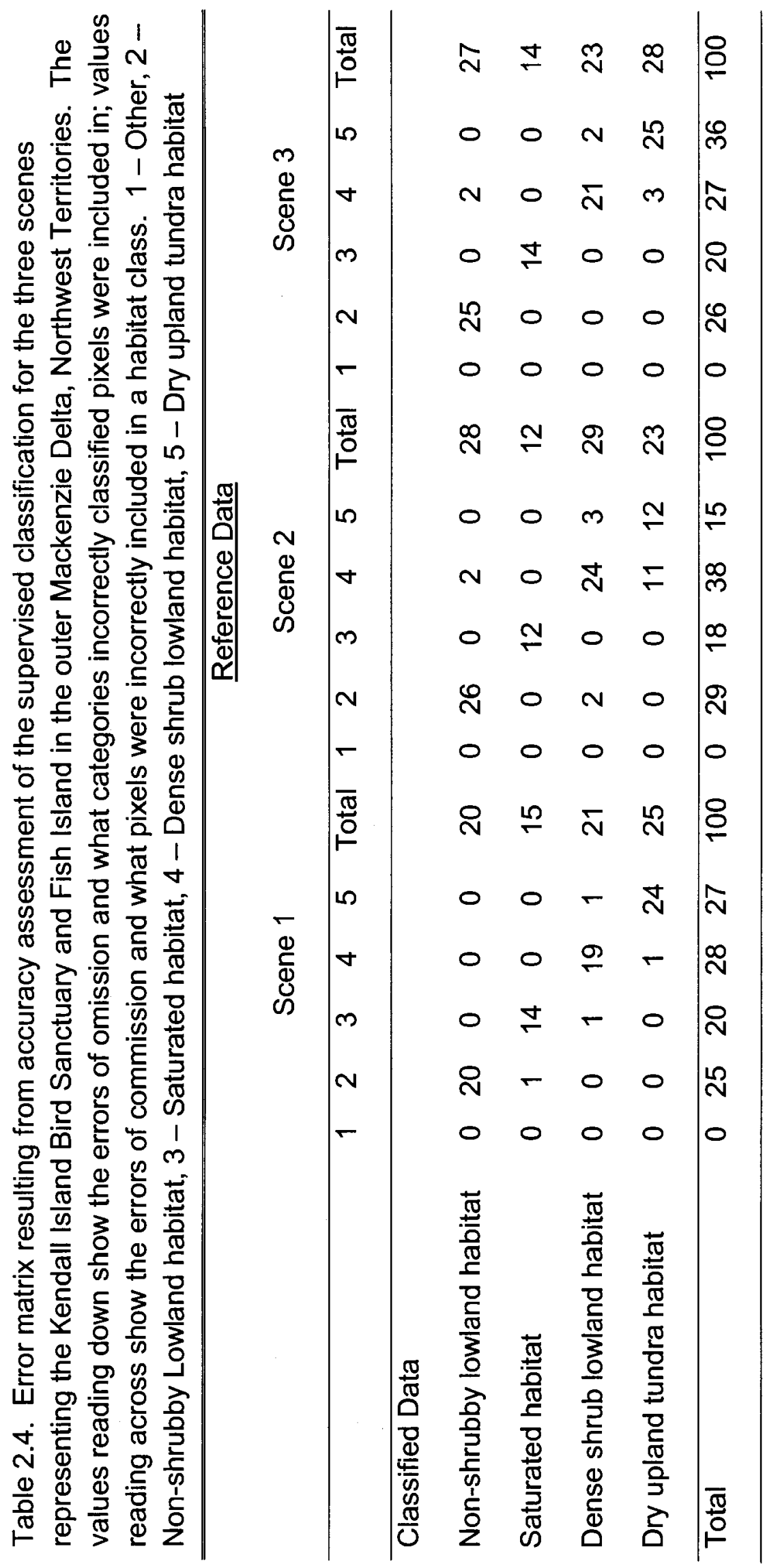


Table 2.5. The percent of terrestrial habitat encompassed by each land cover class and area estimates of land cover classes from the supervised classification of the Kendall Island Bird Sanctuary and Fish Island in the Mackenzie Delta, Northwest Territories.

Class \% terrestrial habitat Total area in ha

\begin{tabular}{lcc}
\hline Non-shrubby lowland habitat & 25 & 11752 \\
Saturated habitat & 0.7 & 308 \\
Dense shrub lowland habitat & 26 & 12401 \\
Dry upland tundra habitat & 17 & 8140 \\
Other Habitats (Null Class) & 31 & 14565 \\
Water bodies & NA & 38337 \\
\hline
\end{tabular}


Table 2.6. Results for three scenarios potentially resulting from the construction of a natural gas processing facility and pipeline, in breeding Whimbrel habitat on Taglu and Fish Island in the outer Mackenzie Delta, Northwest Territories.

\begin{tabular}{|c|c|c|c|}
\hline & $20 \mathrm{~m}$ buffer & $50 \mathrm{~m}$ buffer & $250 \mathrm{~m}$ buffer \\
\hline Habitat lost (ha) & 35.5 & 54.3 & 94.7 \\
\hline Habitat remaining (ha) & 434.5 & 415.7 & 334.0 \\
\hline Percent habitat lost & 8 & 12 & 29 \\
\hline Max. Whimbrel Pairs (20 ha. $)^{1}$ & 21 & 20 & 16 \\
\hline Max. Whimbrel Pairs (33 ha.) $)^{2}$ & 13 & 12 & 10 \\
\hline
\end{tabular}

\footnotetext{
${ }^{1}$ Maximum number of possible breeding Whimbrel pairs the area of habitat remaining could support based on an average territory size of 20 ha.

${ }^{2}$ Maximum number of possible breeding Whimbrel pairs the area of habitat remaining could support if the observed density in the field represents a saturated habitat.
} 


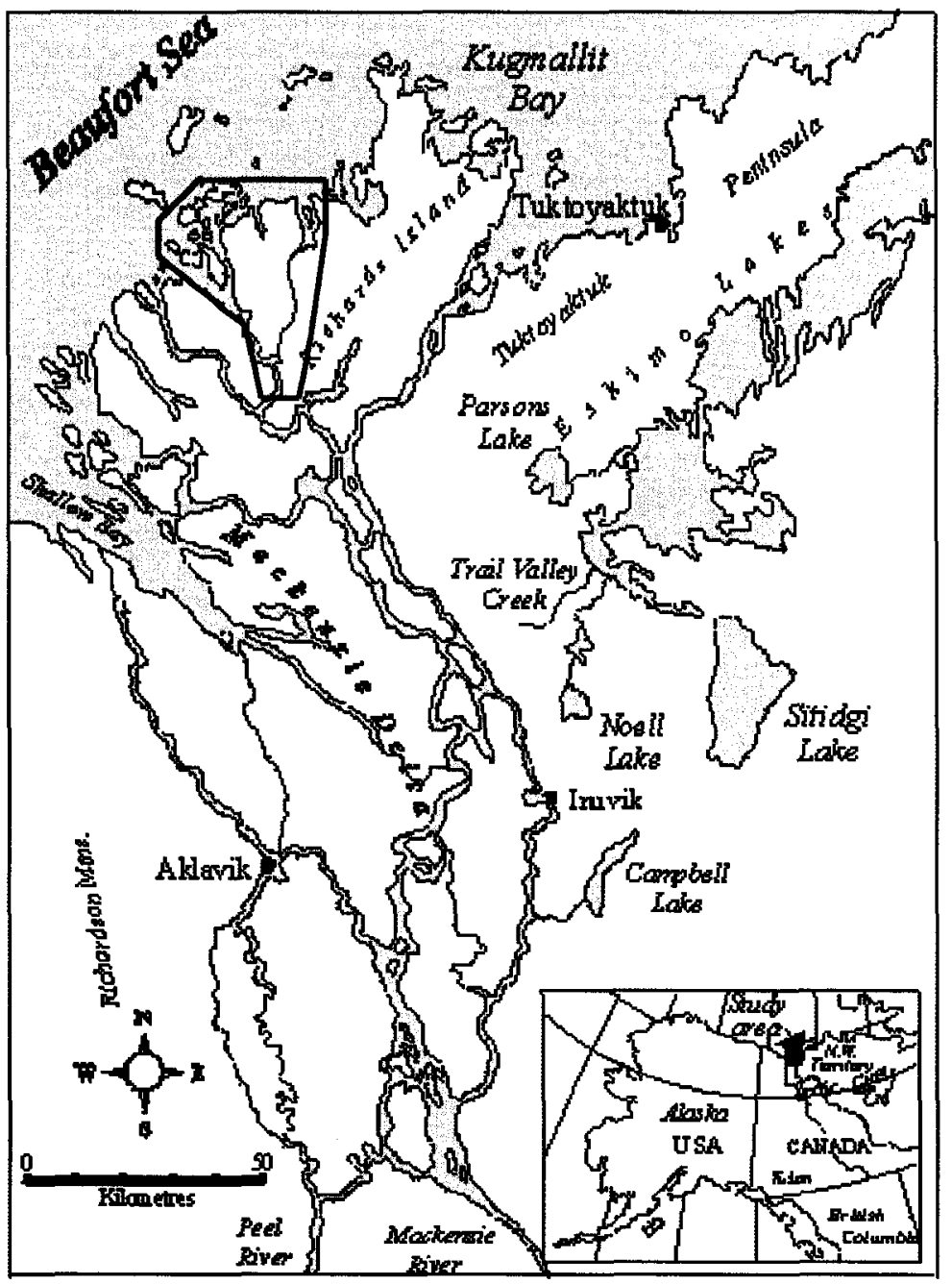

Figure 2.1. Map showing the location of the Mackenzie Delta in the Northwest Territories. The red outline represents the approximate boundaries of the Kendall Island Bird Sanctuary which is shown in more detail in Figure 2.2. 


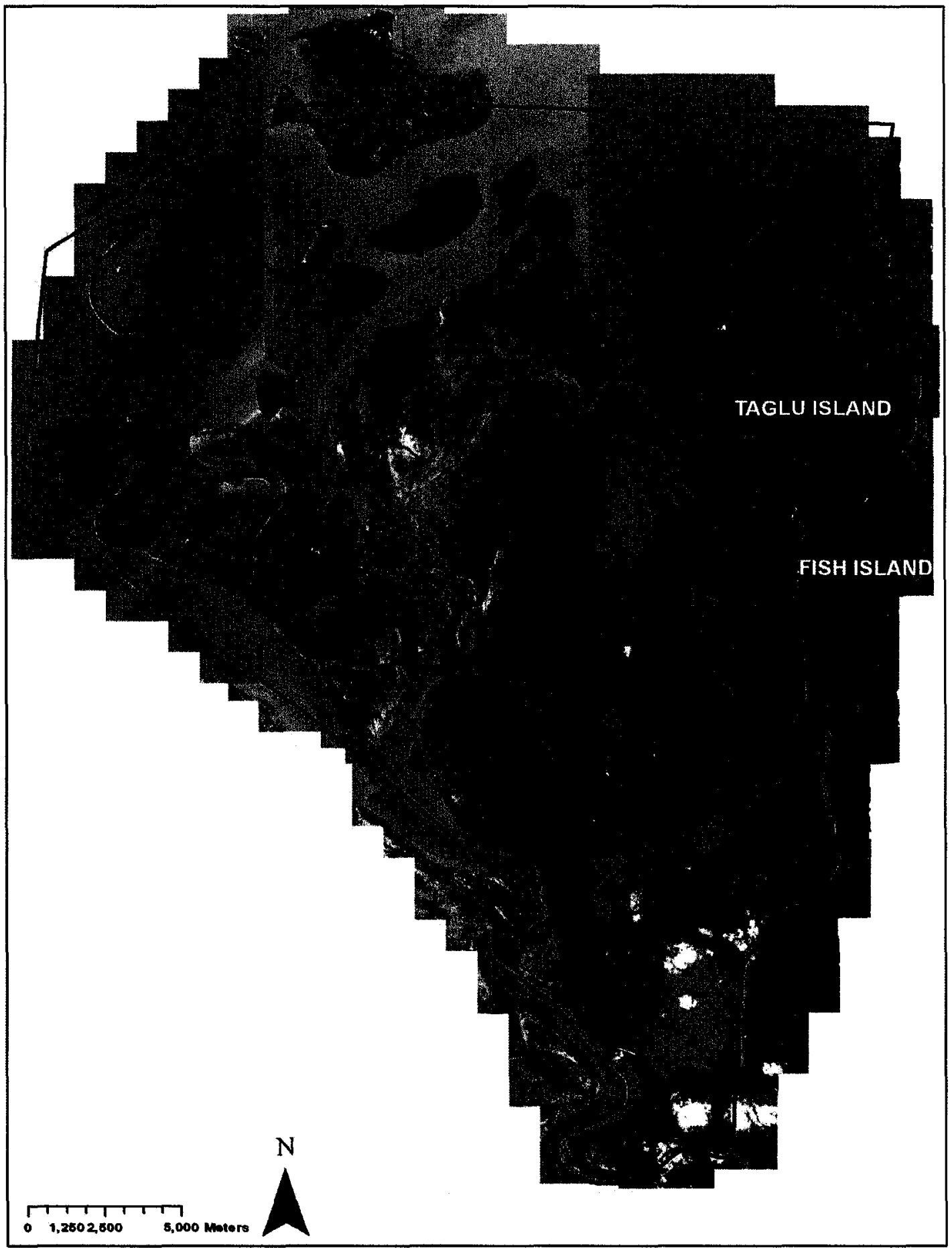

Figure 2.2. A false colour satellite image of Taglu and Fish Islands in the Kendall Island Bird Sanctuary, outer Mackenzie Delta, Northwest Territories. The red outline indicates the boundaries of the sanctuary. 


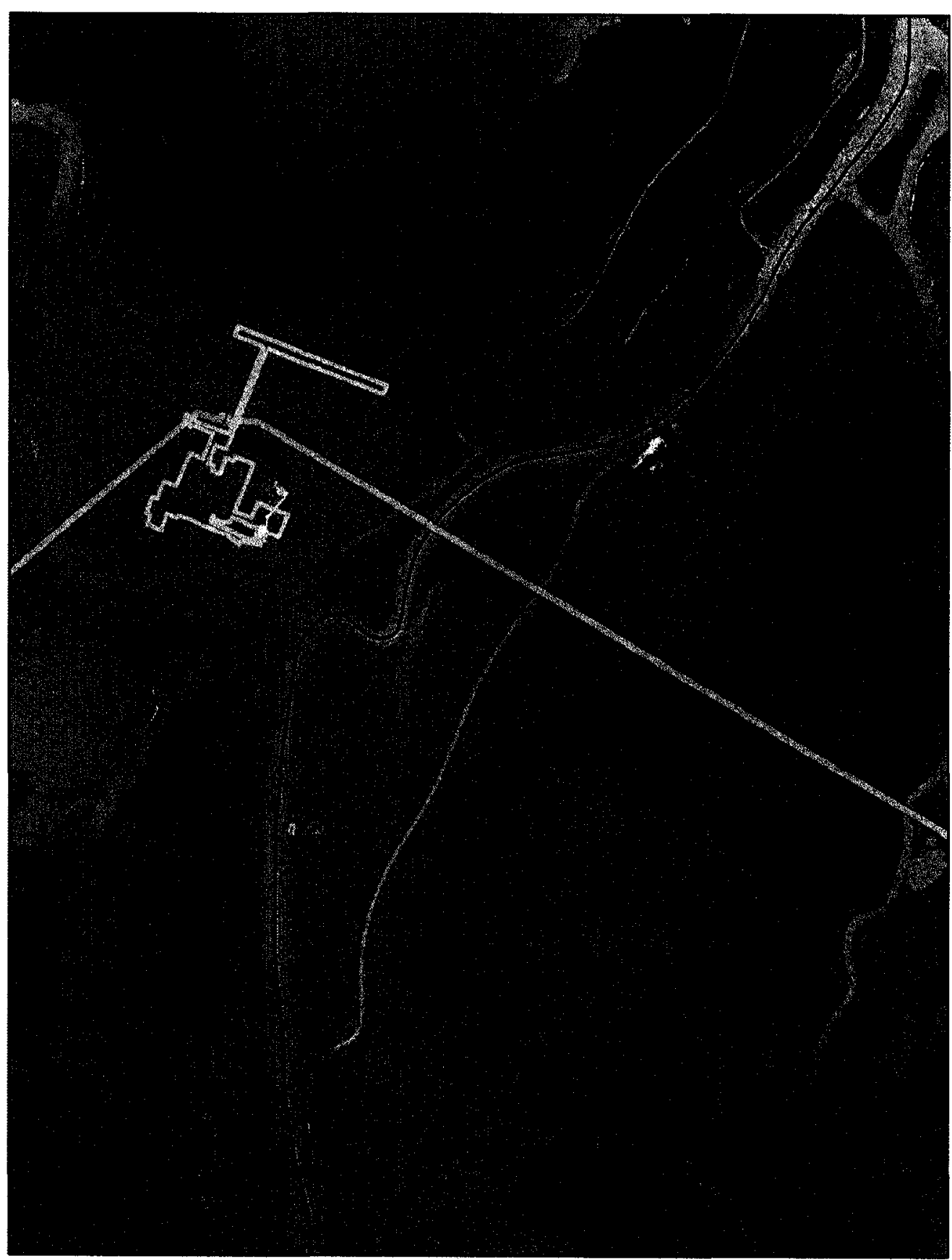

Figure 2.3. The proposed Taglu Island gas processing facility (pink outline) and proposed pipeline (gray line) for the Mackenzie Gas Project, wet-sedge lowcentred polygon habitat (purple cross hatch) and the Kendall Island Bird Sanctuary boundary between Taglu and Fish Islands in the outer Mackenzie Delta, Northwest Territories. 


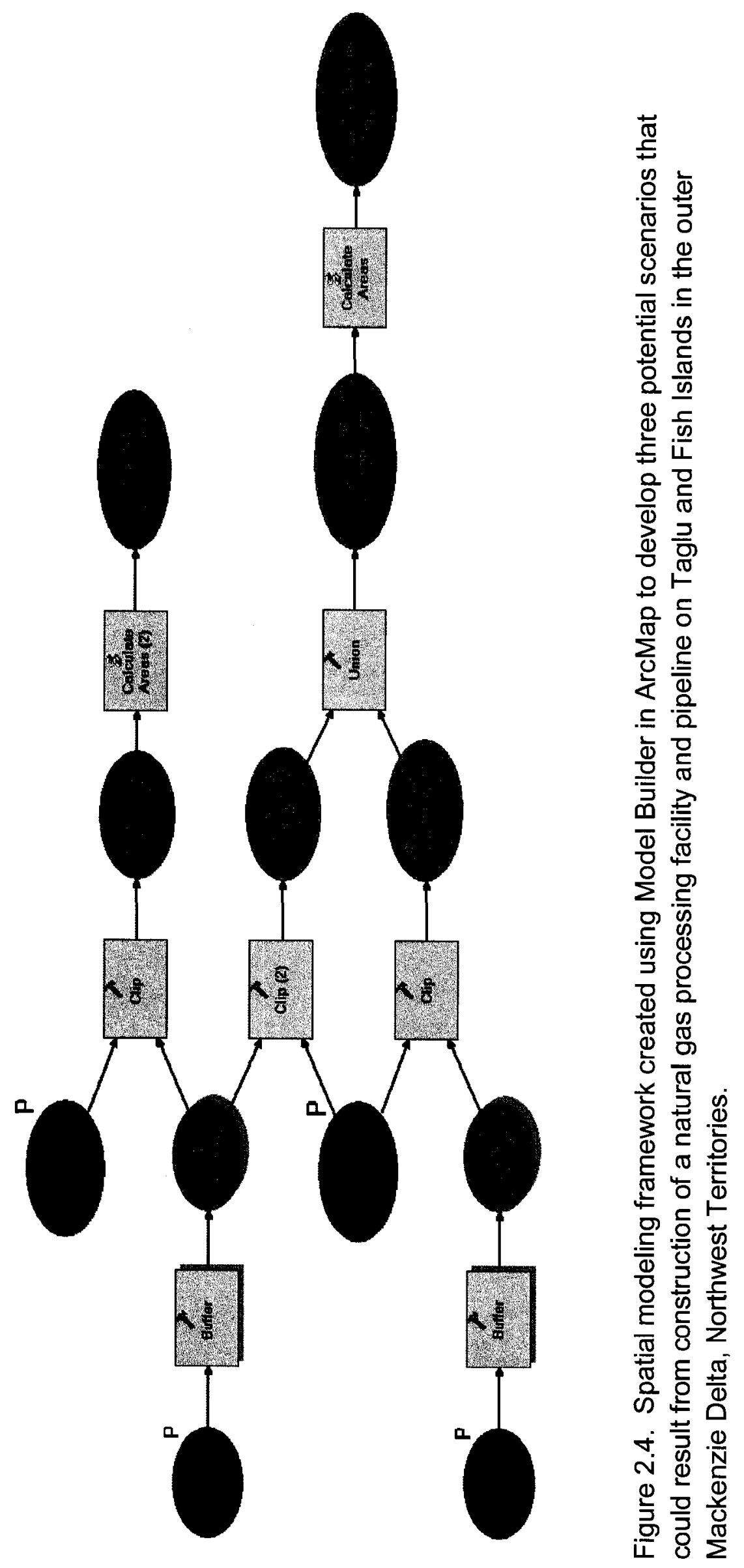




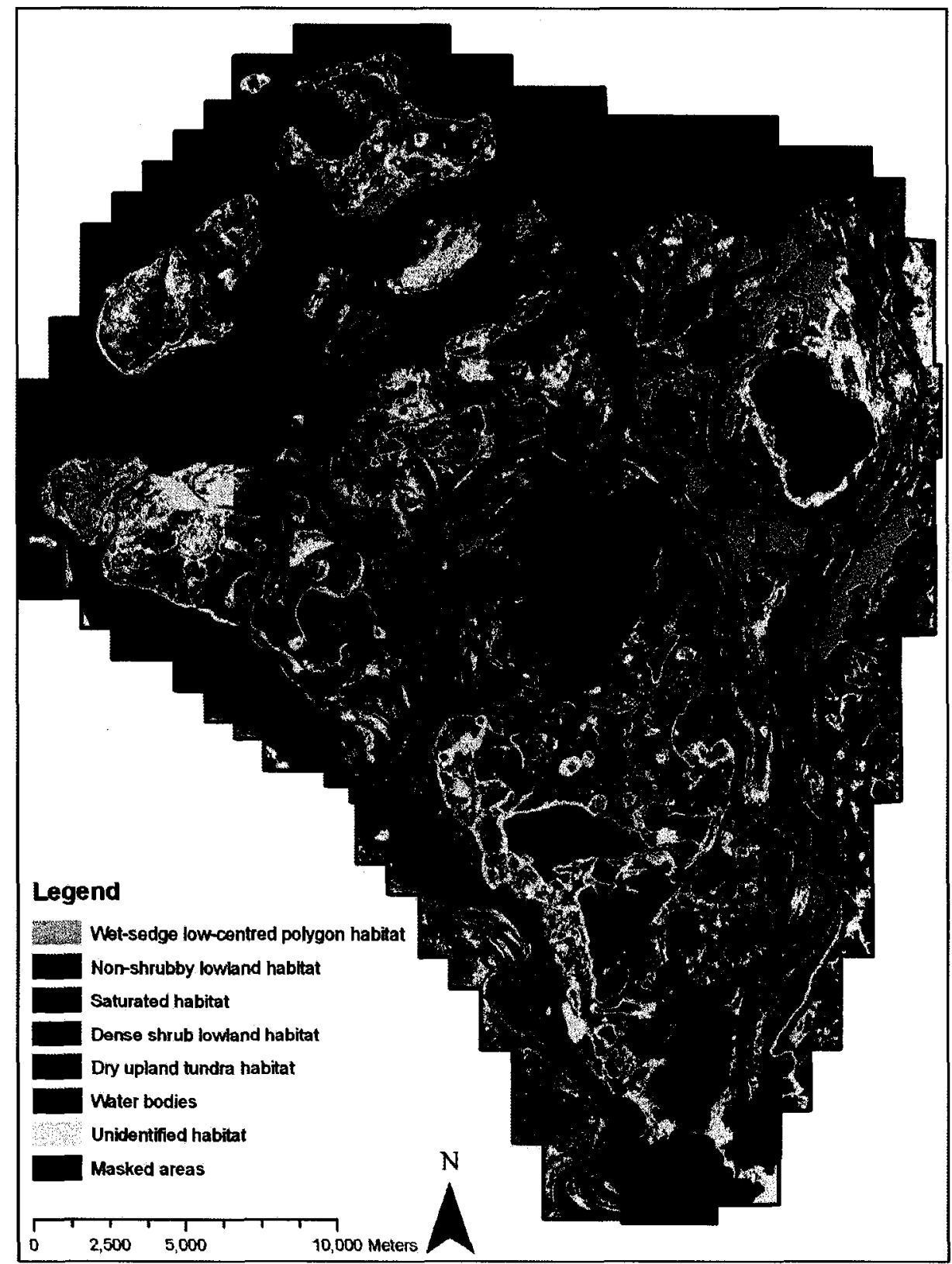

Figure 2.5. The results of the supervised classification of the Kendall Island Bird Sanctuary and Fish Island in the outer Mackenzie Delta, Northwest Territories indicating areas of wet-sedge low-centred polygon habitat (which were visually identified from within the non-shrubby lowland habitat), four land cover classes, areas that were unidentified in the classification, water bodies, and areas that were masked out of the imagery prior to classification. 


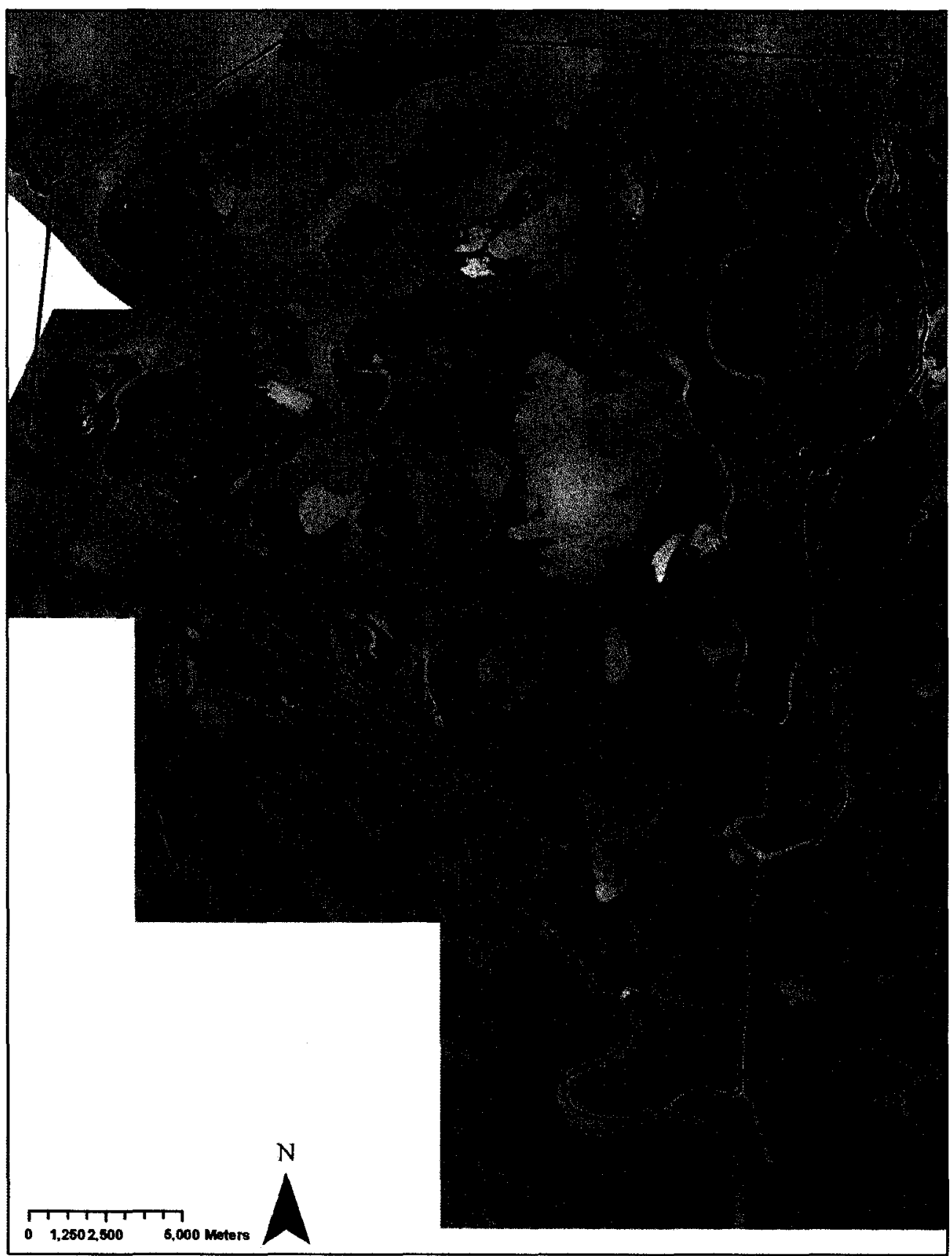

Figure 2.6. Locations of ground-truth plots and areas where breeding Whimbrel were observed in KIBS and on Fish Island in the outer Mackenzie Delta, Northwest Territories. Lowland sites (blue stars); upland sites (orange circles); dense shrub lowland sites (green diamonds); areas of breeding Whimbrel activities (pink crosses). Survey sites may have extended up to several hundred metres from the marked locations. 


\title{
Chapter 3: Whimbrel territory and nest-site selection in the outer Mackenzie Delta, Northwest Territories.
}

\author{
Abstract \\ I located, monitored and described the habitat for 28 lowland Whimbrel \\ nests in 2006 and 2007 on Taglu and Fish Islands located within the outer \\ Mackenzie Delta, Northwest Territories, the site of the proposed Mackenzie Gas \\ Project (MGP). Whimbrel breeding in wet-sedge low-centred polygon (LCP), \\ account for $87 \%$ of all Whimbrel nesting in the Kendall Island Bird Sanctuary and \\ the adjacent Fish Island, thus identifying this habitat type as important for \\ maintaining breeding populations in the outer Mackenzie Delta. \\ Lowland breeding Whimbrel remained in LCP habitat to forage during \\ incubation and chick-rearing. Nest-sites had fewer shrubs, were more elevated \\ and had a greater vegetation density than randomly selected non-nests. Nest \\ success was significantly higher for nests placed on hummocks $(69 \%)$ than those \\ placed on ridges (19\%) within the LCP. Successful nests had a higher \\ vegetation density and percent cover graminoids and were placed further away \\ from the nearest low shrub than those of failed nests.
}




\section{Introduction}

The outer Mackenzie River Delta has been identified as an important location for breeding shorebirds (Tarves, 1987; Dickson et al., 1989; GrattoTrevor, 1994; Gratto-Trevor, 1996). The proposed Mackenzie Gas Project (MGP), which plans to exploit reserves of natural gas that lie beneath the outer Delta, is currently undergoing environmental assessment. The MGP proposes the construction of three onshore gas processing facilities and a $1220 \mathrm{~km}$ long pipeline connecting the facilities to established pipeline systems in northern Alberta. Construction of the pipeline and facilities may impact shorebird breeding populations.

The Whimbrel Numenius phaeopus, is a large migratory shorebird that breeds in the outer Mackenzie Delta in areas that will be affected by pipeline construction and operations. Gratto-Trevor (1994) estimated that 2600 Whimbrel nest in the outer Mackenzie Delta (765 000 area) approximately $5 \%$ of the North American population (Morrison et al., 2006). The Whimbrel has been identified as a Valued Component for the MGP Environmental Impact Statement because of its status as a species of concern in the Northwest Territories (CESCC, 2006) and its potential usefulness as an umbrella species for other nesting shorebirds (AMEC Americas Ltd., 2005; Nature Canada, 2006). Understanding Whimbrel habitat selection in the Mackenzie Delta is integral to determining the potential impact development of the MGP might have on Whimbrel breeding habitat. 
In Churchill, Manitoba, Whimbrel breed in three different habitats: hummock-bog, sedge-meadows and heath-tundra habitats. Whimbrel were found breeding in greater abundances in hummock-bog habitats and showed a greater nest success (Skeel, 1983). Previous studies in the Mackenzie Delta found Whimbrel breeding in wet-sedge low-centred polygon habitat (LCP) on Taglu and Fish Islands and in wet tussock upland tundra habitats in the Mackenzie Delta ((Tarves, 1987; Jaques, 1987a, b; Dickson et al, 1989; Dickson and Smith, 1991; Gratto-Trevor, 1994, 1996; Ashenhurst, 2004). Whimbrel nested to a lesser extent in dry upland habitats and lowland habitats that lacked structural complexity or were susceptible to frequent flooding (Dickson et al., 1989). The density of breeding Whimbrels in wet-sedge LCP habitat (3.3-6 pairs $\left./ \mathrm{km}^{2}\right)$ exceeded densities in other habitats $\left(<1\right.$ pair $\left./ \mathrm{km}^{2}\right)$ in the outer Mackenzie Delta (Dickson et al., 1989). Increased densities of breeding Whimbrel and other shorebirds may provide greater nesting success resulting from joint detection and chasing of predators (Skeel, 1983; Skeel and Mallory, 1996).

Studies in Churchill, Manitoba found that nesting success differed between three habitat types. Hypothesized causes included differences in crypticity resulting from varying habitat complexity, and increased predator protection in areas with higher nesting densities (Skeel, 1976, 1983). The selection of a concealed nest-site may decrease the chance of predation; however some species of birds may select a nest site that provides a clear view 
of their surroundings to increase early detection of predators (Götmark et al., 1995). Gratto-Trevor (1994) found that aquatic invertebrates were most numerous in wet-sedge willow habitats. Previous studies have shown that, Whimbrel forage close to the nest site during incubation (Dickson et al., 1989), and remain in the nesting territory to forage with newly hatched chicks (Skeel and Mallory, 1996).

MGP facility operations may have a negative effect on nesting Whimbrel through increased disturbance or habitat conversion. Studies have shown that Whimbrel will tolerate a certain level of disturbance and have been observed nesting within $230 \mathrm{~m}$ of drilling rigs (Barry and Spencer, 1976). However, Whimbrel respond with aggressive distraction flights when human intruders come within $100-200$ m of their nest (Larsen and Moldsvor, 1992; Skeel and Mallory, 1996; Pirie, Pers. Obs.). Human disturbances may expose the nest to increased predation if the bird departs the nest to deter the intruder. Furthermore, eggs may be lost due to exposure when nests are disturbed during inclement weather conditions (AMEC, 2005). Changes to habitat during MGP construction could also result in lower nesting success if key breeding habitats are impacted. Increased knowledge of breeding Whimbrel habitat use in the outer Mackenzie Delta could provide the necessary information to propose modifications that could minimize the impacts of the MGP if it is approved.

The objectives of this study were: 1) to identify and define areas of Whimbrel breeding habitat in the outer Mackenzie Delta; 2) to compare nest 
habitat to the available habitat to determine if Whimbrel exhibit nest selection preferences; 3) to assess nest success in relation to microhabitat characteristics; 4) to determine whether nest placement was random, clustered or spread out to maximize spacing; 5) to assess whether change in nest temperatures during parental departures can be used to assess the response of breeding Whimbrel to human disturbances.

\section{Methods}

\section{Study Area}

I conducted field studies in the Kendall Island Bird Sanctuary (KIBS) and on the adjacent Fish Island in the outer Mackenzie Delta of the Northwest Territories (Chapter 2, Figure 2.1). Field camps were established in coordination with the Program for Regional and International Shorebird Monitoring (PRISM) and the Canadian Wildlife Service (CWS) who were continuing on-going shorebird research in the area. In 2006 I established camp on Taglu Island $\left(69^{\circ} 22^{\prime} 4^{\prime \prime} \mathrm{N}, 134^{\circ} 57^{\prime} 17^{\prime \prime} \mathrm{W}\right)$ and in 2007 on Fish Island $\left(69^{\circ} 22^{\prime} 21^{\prime \prime} \mathrm{N}\right.$, $\left.134^{\circ} 53^{\prime} 38^{\prime \prime} \mathrm{W}\right)$.

The field site lies east of the Mackenzie Bay bordering the Beaufort Sea coast and is a subdivision of the Arctic Coastal Plain Region. Taglu and Fish Islands are low lying alluvial islands dominated by Arctic sedge wetland habitat. Taglu Island is within KIBS, which was established by the CWS in 1961 to provide long-term protection for migratory birds and their key habitats (CWS, 1992); Fish Island lies adjacent to the sanctuary. In areas with poor drainage, 
low-centre polygons (LCP) vegetated with hydrophilic graminoids (Carex sp.) Equisetum and Salix are common with willows and forbs growing on the raised polygon ridges (ridges) and hummocks. Polygons varied considerably in size, but were typically $10-20 \mathrm{~m}$ with bordering ridges $1-2 \mathrm{~m}$ wide and about $0.1-0.3$ $\mathrm{m}$ above water level. In late May or early June the ice in the channel breaks up. This often causes temporary flooding of Taglu and Fish Islands, and deposits nutrient-rich sediments in the wetlands (Burn, 2002). Other areas in KIBS are dry Pleistocene upland habitats with patches of wetland areas exhibiting highcentred polygon (HCP) or LCP structures. Uplands are vegetated with sedge tussocks (Carex sp.), Salix (less than $0.5 \mathrm{~m}$ in height), Ericaceae and other herbaceous plants. Patches of shrubs reaching heights of up to $3 \mathrm{~m}$ are scattered throughout.

There were a variety of avian and terrestrial predators in the study area. Terrestrial predators were predominantly Arctic Fox Alopex lagopus. Avian predators include Rough-legged Hawk Buteo lagopus, Raven Corvus corax, and Short-eared Owl Asio flammeus.

\section{Nest Searching and Monitoring}

Nest observations were made from 7 June to 18 July in 2006 and 7 June to 21 July in 2007. I intensively surveyed all of Taglu and Fish Islands to find Whimbrel nests in both years of my study. Additionally, the PRISM team intensively surveyed five 12 ha plots on Taglu Island in 2006 and an additional five 12 ha plots on Fish Island in 2007. Four of the plots surveyed on Taglu 
Island in 2006 were resurveyed in 2007 . Selection of plots was based on preliminary observations of breeding shorebirds. These plots were surveyed daily by two observers for periods of four hours at a time. Shorebirds were identified and behaviour was monitored to determine locations of nests and territories. Whimbrel are aggressive and act defensively when a human is within their nesting territory with aggressive displays, scolding trill calls and flushing (Skeel and Mallory, 1996). When I observed this behaviour, I searched all hummocks and ridges within several hundred metres for nests. In some cases, the territories of more than one Whimbrel pair overlapped. To identify the territories of the individual pairs, surveyors would split up and each would follow one pair until the nest was found.

In addition, I systematically surveyed patches of a variety of habitat elsewhere throughout KIBS, ranging in size from $20-100$ ha including upland habitats with neighbouring wetland valleys $(n=12)$, dense willow patches $(n=6)$, and other lowland habitats exhibiting various degrees of structural complexity and moisture $(n=37)$ for evidence of breeding Whimbrel. Potential locations to search were identified using visual interpretation of IKONOS satellite imagery (Chapter 2). I selected areas distributed throughout the study site that covered as many different habitats as possible. A 10 foot zodiac with a $9.9 \mathrm{hp}$ outboard motor was used to travel throughout the study site.

I recorded nest locations using a Global Positioning System (GPS) unit and marked nests with a wooden tongue depressor $1 \mathrm{~m}$ North of the nest to 
assist with relocation of the nests on subsequent visits. I was unable to place nest markers further from the nests because nest sites were typically surrounded by water up to $25 \mathrm{~cm}$ deep. Tongue depressors were relatively camouflaged in the habitat and were not believed to increase predation. Nests were revisited every three days to determine nest fate. The use of temperature data loggers (see Nest Disturbance) required observers to approach the nest at a close distance. Observers limited compression of vegetation around the nest by staying off the hummocks and ridges. Minimal time was spent during each revisit to avoid cueing potential predators.

\section{Radio-tracking Adult Whimbrel}

In 2007 I attached radio-transmitters (Model BD-2, Holohill Systems Ltd.) to seven adult Whimbrel captured at the nest using walk-in nest traps (protocols reviewed by NWRC, Environment Canada, Animal Care Committee). I used the R-1000 telemetry receiver (Communications Specialists Inc.) and a 3-element Yagi directional antenna (Wildlife Materials Inc.) to locate Whimbrel with transmitters. Locations were recorded and plotted on maps to determine whether Whimbrel remained near the nest or if they moved to different habitat types for foraging during incubation and subsequent chick rearing.

\section{Territory and Nest Habitat}

I examined habitat at two different scales around each Whimbrel nest; at the nest itself and at the scale of the territory. At the scale of the territory, I 
described the general habitat for approximately $250 \mathrm{~m}$ radius around each nest (approximately 20 ha). Territories were not mapped, but Whimbrel actively defended their nests against human intruders within a $200-250 \mathrm{~m}$ radius around the nest (Pirie, pers. obs.). I estimated the approximate vegetation cover for graminoids, low shrubs, tall shrubs and moss within the $250 \mathrm{~m}$ radius. Visual estimates were made of the proportion of standing water, including ponds and standing water within LCP centres. Surface roughness related to density of landscape structures such as hummocks, ridges and tussocks was assigned as low, medium or high (Rodrigues, 1994). I assessed soil moisture by the amount of water that seeped out into my footprints when walking across the ground and defined it as dry, moist, wet or saturated.

At the scale of the nest, I took microhabitat measurements within a few metres around each nest and at five random non-nest sites within the territory of each nesting Whimbrel pair. Non-nest sites were selected within the territory boundaries to provide a more accurate analysis of nest-site selection (Jones, 2001; e.g. Ramsay et al., 1999). Selection of available habitat without considering territory boundaries may include habitat that is not available to the study species (Jones, 2001). Non-nest sites were selected by choosing random coordinates, but if the chosen location was an area of standing water I selected the nearest hummock or ridge to represent areas where Whimbrel could potentially nest. Percent vegetation composition was estimated within a $1 \mathrm{~m}$ radius of the nest (graminoid, dwarf shrub $(<0.1 \mathrm{~m})$, low shrub $(<0.5 \mathrm{~m})$, herbs, 
mosses and equisetum). The percent of standing water in the LCP centres within a $1 \mathrm{~m}$ radius of the nest was measured. Vegetation height at nest, $1 \mathrm{~m}$ from nest and $3 \mathrm{~m}$ from nest were measured in each cardinal direction. I used a grid $(22 \mathrm{~cm} \times 28 \mathrm{~cm})$ to determine the vegetation density at the nest at ground level and at $1 \mathrm{~m}$ in each cardinal direction. Density was estimated as the percentage of the grid that was obscured when observing the grid from the nest. Distance from the nest to the nearest shrub, height of nearest shrub, distance to nearest standing water, water depth and elevation of the nest were recorded.

I used the Hawth's Tools extension for ArcMap 9.2 (Beyer, 2008) to calculate distances between conspecific nests. The distance from each nest and random non-nest site to the lake was calculated using the ruler tool in ArcMap.

$\underline{\text { Statistical Analysis }}$

Statistical analysis of micro- and macro-habitat was performed using SPSS (15.0). I combined dwarf shrubs and low shrubs into one shrub category to account for inconsistencies in classifying shrubs into size categories. Since values of percent herbs and percent equisetum were low, I combined them into the category "forbs". Percent water was excluded from analysis because its mean was $<5 \%$ and preliminary analyses showed no effect. For vegetation height and vegetation density, measurements for the four cardinal directions were averaged.

I conducted a two-tailed Pearson correlation to assess collinearity between the habitat variables. Percent moss and percent forbs were negatively 
correlated with percent graminoids $(p<0.01)$ therefore only percent graminoids was used for further analysis. A two-way ANOVA was used to determine if there was a year effect between vegetation on hummock and ridge nest and non-nest sites. Minimal differences in microhabitat vegetation were observed between years so I pooled data from both years.

I compared the microhabitat of nests to non-nest sites using two-tailed ttests. I did not use DFA because setting prior probabilities proportional to the sample sizes did not work well owing to the large differences between nest and non-nest sample sizes. Non-parametric Mann-Whitney $U$ tests were used to test distance to nearest shrub and distance to nearest standing water. I also compared the microhabitat of nests on hummocks to non-nests on hummocks, and nests on ridges to non-nests on ridges using two-tailed t-tests.

I used discriminant function analysis (DFA) to test for microhabitat differences between failed and successful nests, and between nests on hummocks and nests on ridges. The stepwise Wilk's Lamda method was used to evaluate the nest habitat variables. For classification, I set the prior probabilities proportional to the initial sample size. Significance was assessed for chance corrected classifications (Titus et al. 1984). I used the non-parametric Mann-Whitney $U$ test to determine if the distance to the nearest neighbour or the distance to the nearest lake differed between failed or successful nests.

To study nest dispersion I used the Clark and Evans test to determine if Whimbrel nests were aggregated, over-dispersed or randomly placed on Fish 
Island (Clark and Evans, 1954). Nests on Taglu Island $(n=6)$ were not analysed for dispersion because of the small sample size. Z-tests were used to assess significant deviations from random patterns (Krebs, 1989).

I used the Mayfield method to estimate nest success for Whimbrel nests (Mayfield, 1961). A nest was considered successful if it hatched at least one chick. A mean of 24 days was used to represent the incubation period for Whimbrel (Skeel, 1983). If a nest was found abandoned or depredated on a visit, I arbitrarily assumed that the nest failed halfway between that visit and the previous visit (3 day intervals; Mayfield, 1961). All abandoned and depredated nests were considered failed nests. Standard error for the daily survival rate was calculated following Johnson (1979). I compared daily survival rates between nest site types (hummocks versus ridges) using CONTRAST (Hines and Sauer, 1989).

\section{Nest Disturbance}

I placed digital temperature data logger i-buttons (Maxim Integrated Products, DS1922L) in each nest beneath the eggs and slightly covered them with nesting materials to estimate attentiveness patterns based on changes in nest temperature. i-buttons were programmed to take temperature readings every two minutes and were retrieved and replaced every three days. To test whether i-button temperature data could be used to measure whether a Whimbrel was away from the nest, I also set up video cameras at a sample of seven nests to record nest activities for a period of four hours at each nest. 
Video cameras were set up on tripods at least $30 \mathrm{~m}$ from each nest and did not appear to influence incubating Whimbrel behaviour. The clock on the video camera was calibrated with i-button times to ensure that recording times corresponded with temperature times. I reviewed video footage and recorded the time the Whimbrel returned to its nest after I departed and the times of departures and returns throughout the video recording. Times were compared to i-button readings to determine if the temperature within the nest changed during the absence of a brooding Whimbrel.

\section{Results}

\section{Territory Selection at the Landscape Level}

In 2006 and 2007 I found and monitored 28 Whimbrel nests on Taglu and Fish Islands (Figure 3.1). All nests on these islands were located in wet-sedge LCP habitat on hummocks surrounded by water within polygon centres or on the raised polygon ridges (Figure 3.2). This habitat accounts for $40 \%$ (470 ha) of available wet-sedge LCP habitat in the study area. The remaining LCP habitat had greater densities of shrubs on ridges and shrubs growing throughout polygon centres, and showed no indication of breeding Whimbrel activities. Surveys of other lowland habitat types (dry grassland meadows, saturated wetlands, dense willow habitats) in the study area did not find breeding Whimbrel. In 2006 and 2007, I ground surveyed approximately 6000 ha of upland tundra habitat throughout the study area. I found and monitored one Whimbrel nest in upland habitat. Three other upland areas had two or more pairs of Whimbrel exhibiting 
breeding activities but were visited late in the season when nests were likely already hatched. An estimated 3140 ha of upland tundra habitat, approximately $40 \%$ of all upland tundra in the study area, appeared to have breeding Whimbrel activity, but likely supported no more than four pairs. The single upland nest was excluded from habitat analysis.

\section{Habitat Use Bevond Nest-Site}

Radio-transmitters were placed on seven adult Whimbrel nesting on Fish Island. Only four of these Whimbrel retained their transmitters or remained at the field site throughout the incubation period. Two transmitters fell off and one Whimbrel had its nest depredated and left the area. Whimbrel were never recorded at locations with habitat differing from the nest site between June and July during incubation and for a week following hatch. Locations recorded after nest-hatch suggested that chick-rearing was continued in the nesting territory (Figure 3.3).

\section{Habitat within Territory}

All nesting territories found were located completely within wet-sedge LCP habitat. Visual estimates of vegetation cover for Taglu and Fish Islands were approximately $55 \%$ graminoids, $20 \%$ low shrubs, $10 \%$ bare moss and $15 \%$ other. Standing water with emergent graminoids contained within the centres of LCP's covered approximately $60 \%$ of the area on both islands. This reflects the mosaic 
of dry vegetation on which nests occurred, surrounded by emergent vegetation in standing water.

\section{Habitat at Nest-Site}

Percent shrubs, elevation and vegetation density differed between nestsites and non-nests (Table 3.1). Nests were situated on hummocks $(n=13)$ or low, raised polygon ridges $(n=15$; Figure 3.4). Fewer non-nests were on hummocks $(n=27)$ than on ridges $(n=113$; Table 3.2) indicating a difference in availability of the two microhabitat types. Hummocks had a greater density of graminoids and a lower percentage of shrubs. Ridges had a greater variety of vegetation with more shrubs, herbs and Equisetum (Figure $3.5 \mathrm{a}$, b; Table 3.3). Microhabitat did not vary between years so data were pooled for 2006 and 2007 . The DFA supported univariate analyses, indicating significant differences between nests on hummocks and nests on ridges. Classification of the DFA was $96.1 \%$ correct (a $90 \%$ improvement on chance, Table 3.4, $\mathrm{P}<0.001$ ). Nests on ridges had fewer graminoids and more shrubs than nests on hummocks. The nearest shrub was significantly farther away for hummocks. Vegetation density at the nest was lower for ridge nests while density at $1 \mathrm{~m}$ was decreased for hummock nests because hummocks are surrounded by water (Figure 3.6 a). Nests on hummocks were significantly further away from nesting conspecifics than nests on ridges, while distance to nearest lake (large open water bodies, not associated with LCP's) did not differ (Table 3.5). No significant differences were 
observed when comparing the microhabitat of hummocks for nests and non-nest sites, or ridges for nests and non-nest sites.

\section{Nest Success and Density}

Successful nests had a higher percentage of graminoids and greater vegetation density (excluding shrubs) at the nest than failed nests. Classification based on the DFA was $82 \%$ with a $61 \%$ improvement on chance (Table 3.4 , $p<0.001)$. The nearest shrub was closer in failed nests and was taller than the nearest shrub to a successful nest (Figure 3.6b; Table 3.6). Distance to nearest neighbour and nearest lake did not differ between failed or successful nests.

Nest success differed between nests on hummocks and ridges. The daily survival rate was significantly higher on hummocks. The survival of a nest over the 24 day (average) incubation period was $69 \%$ on hummocks $(n=13)$ compared to $19 \%$ for ridge nests $(n=15$; Table 3.7 ). Most nest failure was due to predation with the exception of two nests in 2007, one which had two cold eggs that showed signs of pipping and one for which was found empty early in the incubation stage.

The density of Whimbrel nests in wet-sedge LCP habitat on Fish Island was 2.85 and 3.4 pairs $/ \mathrm{km}^{2}$ in 2006 and 2007 respectively. Nest placement in 2006 and 2007 did not show any significant departure from randomness (Table 3.8). The density of Whimbrel nests on Taglu Island was 3.3 pairs $/ \mathrm{km}^{2}$ in 2006 and 1.7 pairs $/ \mathrm{km}^{2}$ in 2007 . Nest dispersion could not be evaluated for Taglu Island due an insufficient sample size. 


\section{Nest Temperature and Disturbance}

The i-buttons were unable to detect significant temperature differences during the time that Whimbrel were absent from the nest $(n=4 ;$ Table 3.9). Ibutton data was only available for four nests due to i-buttons missing from nests after the three day temperature recording period, presumably removed by adult Whimbrel. Nest temperatures ranged from $20^{\circ} \mathrm{C}$ to $24^{\circ} \mathrm{C}$ whether the bird was on or off the nest. It took Whimbrel a mean time of 09:11(minutes:seconds; SE = 01:55) to return to the nest after I departed the area. Whimbrel left the nest 2-3 times during the four hour recording period and were away for a mean 06:27 (SE $=01: 16)$.

\section{Discussion}

\section{Whimbrel Nest Landscape}

When determining an appropriate nest-site Whimbrel must make a number of hierarchical decisions (Gochfeld, 1977; Johnson, 1980; Burger, 1985; Hutto, 1985), including identifying a suitable landscape, territory, and finally a nest site. A small population of Whimbrel nest in wet-sedge LCP habitat in the outer Mackenzie Delta. Despite extensive ground surveys there was no evidence that Whimbrel use other lowland habitat types for breeding. Many of these alternative habitats lack the structural complexity that is afforded by wetsedge LCP habitat, and they may have increased potential for flooding. Annual flooding occurs in the springtime (late May to early June); the presence of raised 
ground such as hummocks and ridges may allow earlier nest initiation for Whimbrel because they become exposed sooner as waters recede (Dickson et al., 1989). Furthermore, nest sites become available while adjacent flooded areas are available for foraging. Low-lying habitats without ridges may also be subject to summer flooding as a result of high winds and rain. This was observed on Niglintgak Island on the west side of KIBS in 2006, where most lowland Red-necked Phalarope (Phalaropus lobatus) nests were lost to rising water levels after an intense windstorm (Beveridge, 2007). The placement of nests on raised ground such as hummocks and polygon ridges would reduce the risk of nest loss during flooding events.

Selection of a more complex and irregular habitat structure may also enhance the crypticity of the nest and the incubating bird (Skeel, 1983). The irregularity and complexity of wet-sedge LCP habitat could make it difficult for avian predators to spot the large Whimbrel eggs in open nests (egg sizes: length $60.7 \pm 0.3(\mathrm{SE}) \mathrm{mm}$ (range $59.3-63.5$ ), breadth $41.2 \pm 0.2 \mathrm{~mm}$ (range $38.8-$ 43.2); $n=19$, Pirie, Pers. Obs.; Skeel, 1983). However, some wet-sedge LCP habitats may not be suitable if the waters surrounding raised ground are too deep (Dickson et al., 1989) causing problems for foraging for adults and their broods.

Whimbrel were also observed nesting in dry upland tundra habitats that were interspersed with patches of structurally complex wetland valleys. Several areas of upland habitats within KIBS showed evidence of breeding Whimbrel in low densities (Ashenhurst, 2004; Pirie, Pers. Obs.). Surveys of four upland 
habitat plots (66 and 168 ha) further inland in the Mackenzie Delta estimated densities of 2.4 to 7.1 Whimbrel nesting territories per square kilometre (Johnston et al., 2007). Little is known about upland breeding Whimbrel habitat preferences and further studies are necessary to compare nesting behaviour and microhabitat selection in upland habitat with those birds in this study that nested in wet-sedge LCP habitat.

\section{Foraging and Chick-rearing Habitat}

Wet-sedge LCP habitat provides both nesting and foraging habitat for breeding Whimbrel. Through radio-tracking of adults during incubation and following hatch, I determined that no other habitat type plays a role for foraging during incubation or during chick-rearing for these birds. This suggests that food availability within the nest territory plays a significant role in the selection of territories and nest-sites.

\section{Nest Habitat and Nest Success}

Comparison of nest habitat to non-nest habitat within the nesting territory showed that the percent of shrubs, elevation, vegetation density at the nest and the availability of hummocks or ridges may influence Whimbrel nest-site selection. In this study I found Whimbrel nesting on two microhabitat types within the wet-sedge LCP habitat: hummocks and polygon ridges. Only slightly more nests were found on ridges $(n=15)$ than hummocks $(n=13)$, despite the fact that 
random selection of non-nest sites indicated that ridge habitat was 5 times more abundant than hummock habitat (Table 3.2).

In both 2006 and 2007, nest success was higher for nests placed on hummocks than those placed on ridges. Microhabitat showed several significant differences between hummock and ridge nest sites. Hummocks were predominantly vegetated with graminoids and may provide a better view of the surroundings; while the presence of shrubs $(>0.1 \mathrm{~m})$ around nests on ridges may result in a limited view of the surroundings, despite the potentially greater concealment they may offer. Successful nests were further from the nearest shrub than failed nests which may support the theory that a nearby shrub hinders the ability of a sitting Whimbrel to detect approaching predators. An unobstructed view of the surroundings may be beneficial by allowing early detection of nest predators by territorial species (Finch, 1989; Götmark et al., 1995). Whimbrel are territorial species and often engage in aggressive and distractive displays to chase off potential aerial and ground predators (Skeel and Mallory, 1996). Increased visibility around the nest may allow Whimbrel to quickly identify potential predators thereby reducing the chance of nest predation.

Another possible reason for the difference in nest success is that terrestrial predators (e.g., Arctic Fox) may be able to access the nests more readily. Foxes may prefer to travel on dry ground, and thus would be less likely to discover or depredate a nest on a hummock. Because the differences in vegetation between successful and unsuccessful nests were closely correlated 
with differences between ridges and hummocks, it was not possible to distinguish effects due to differences in vegetation versus those due to differences in geometry of the sites.

\section{Nest Spacing}

Nest spacing is described as a behavioural trait that may increase the effectiveness of camouflage (Tinbergen et al., 1967). Whimbrel eggs are relatively large and when exposed may be easily visible to predators. In an area where nests are closely spaced there is higher potential for nest locations to be revealed to predators when adults depart from and return to the nest (Skeel, 1983). While the close proximity to other nests may increase the predation pressure on an individual's nest, the presence of nearby conspecifics contributes to joint defence against predators (Skeel, 1983). In the Mackenzie Delta, adjacent Whimbrel pairs often assist with aggressive tactics to deter aerial predators (L. Pirie, pers. obs.). Skeel (1983) suggested that the distance between nests is a compromise between reducing detection and enhancing joint defence. In Churchill, Manitoba, Whimbrel nests in hummock-bog habitat were further from their nearest neighbour than would be expected if distribution was random and had an $86 \%$ nest success (Skeel, 1983). The limited availability of suitable habitat on Fish Island may restrict nesting Whimbrel from attaining the wide spacing of nests seen in the hummock-bog habitat in Churchill. A complete comparison of nests in Churchill to nests on Fish Island would be necessary to fully evaluate the effects of dispersion. 
Nest Temperatures and Disturbance

The inability of i-buttons to detect temperature changes during departures from the nest may have been due to the placement of i-buttons underneath vegetation in the nest on the cool moist ground. It was necessary to ensure ibuttons were covered well as several that were inadequately hidden disappeared from the nest, presumably removed by Whimbrel. However, this probably meant they were not sensitive to any small changes in temperature of the nest contents. The recorded temperatures were much lower than the lower metabolic temperature for the eggs. Based on the video footage, Whimbrel returned quickly to the nest when a perceived human threat left the area (Table 3.8). However, any departure from the nest may be observed by watchful predators who may return at a later time to depredate the nest. Departures from the nest, as observed from video footage, either for foraging or to partake in predator mobbing lasted for short periods of time (Table 3.8).

\section{Conclusions}

Lowland wet-sedge LCP habitats are an important breeding habitat for breeding Whimbrel. Lowland breeding Whimbrel forage, nest and rear their chicks completely within wet-sedge LCP habitats and often within $250 \mathrm{~m}$ of the nest itself. Whimbrel appear to select nest-sites that provide increased visibility around the nest, potentially allowing them a clear view of approaching predators. Whimbrel exhibit nest-site selection preferences for hummocks over polygon ridges, and had greater nest success on hummocks. However, there is a low 
abundance of suitable hummocks in wet-sedge LCP habitat which in combination with Whimbrel territoriality may force some nesting pairs to select less suitable ridge sites. Whimbrel response to human intruders and their apparent preference of wet-sedge LCP habitat over upland habitats suggests that industrial developments in the outer Mackenzie Delta should take careful consideration and look at alternatives when planning development in known lowland Whimbrel breeding habitat. 
Table 3.1. Comparison of microhabitat characteristics of Whimbrel nests and non-nest sites using two-tailed t-test and Mann-Whitney $U$ tests.

\begin{tabular}{|c|c|c|c|}
\hline Microhabitat Variable & $\begin{array}{l}\text { Mean } \pm \text { SE } \\
\text { Nest }\end{array}$ & $\begin{array}{c}\text { Mean } \pm \text { SE } \\
\text { Non-Nest }\end{array}$ & $t$ or $U$ \\
\hline Graminoids (\%) & $51.96 \pm 3.61$ & $46.07 \pm 1.31$ & $t=1.768$ \\
\hline Shrubs (\%) & $10.54 \pm 2.79$ & $15.07 \pm 1.20$ & $t=-2.127^{*}$ \\
\hline $\begin{array}{l}\text { Vegetation height at nest } \\
\text { (m) }\end{array}$ & $0.14 \pm 0.01$ & $0.12 \pm 0.01$ & $t=1.390$ \\
\hline $\begin{array}{l}\text { Vegetation height at } 1 \mathrm{~m} \\
\text { (m) }\end{array}$ & $0.15 \pm 0.01$ & $0.15 \pm 0.01$ & $t=-0.068$ \\
\hline $\begin{array}{l}\text { Vegetation height at } 3 \mathrm{~m} \\
(\mathrm{~m})\end{array}$ & $0.11 \pm 0.01$ & $0.12 \pm 0.01$ & $t=-0.652$ \\
\hline Nearest standing water $(\mathrm{m})$ & $1.59 \pm 0.15$ & $1.85 \pm 0.19$ & $U=1869.50$ \\
\hline Nearest shrub (m) & $0.23 \pm 0.12$ & $0.35 \pm 0.09$ & $U=2275.50$ \\
\hline Height of Shrub (m) & $0.20 \pm 0.02$ & $0.19 \pm 0.01$ & $t=0.546$ \\
\hline Elevation of nest $(\mathrm{m})$ & $0.18 \pm 0.01$ & $0.14 \pm 0.01$ & $t=2.623^{*}$ \\
\hline $\begin{array}{l}\text { Vegetation density at nest } \\
(\mathrm{m})\end{array}$ & $0.12 \pm 0.02$ & $0.08 \pm 0.01$ & $t=2.853^{\star *}$ \\
\hline $\begin{array}{l}\text { Vegetation density at } 1 \mathrm{~m} \\
\text { (m) }\end{array}$ & $0.17 \pm 0.02$ & $0.17 \pm 0.01$ & $t=0.290$ \\
\hline Water depth $(m)$ & $0.07 \pm 0.01$ & $0.06 \pm 0.01$ & $t=1.965$ \\
\hline
\end{tabular}

Significance: ${ }^{* *}$, highly significant $(P<0.005) ;{ }^{*}$, significant $(P<0.05)$ 
Table 3.2. A comparison of the number of Whimbrel nests and non-nests located on hummocks and ridges using a two-tailed t-test.

\begin{tabular}{lccc}
\hline & Hummock & Ridge & $t$-value \\
No. of nests & 13 & 15 & \\
No. of non-nests & 27 & 113 & $-3.150^{\star \star}$ \\
\hline
\end{tabular}

Significance: ${ }^{\star \star}$, highly significant $(P<0.005) ;{ }^{*}$, significant $(P<0.05)$ 
Table 3.3. Comparison of microhabitat characteristics of hummocks and ridges for Whimbrel nests and non-nest sites.

\begin{tabular}{|c|c|c|c|}
\hline Microhabitat Variable & Nest or non-nest & $\begin{array}{l}\text { Mean } \pm \text { SE } \\
\text { Hummock }\end{array}$ & $\begin{array}{l}\text { Mean } \pm S E \\
\text { Ridge }\end{array}$ \\
\hline \multirow[t]{2}{*}{ Graminoids (\%) } & Nest & $62.69 \pm 5.12$ & $42.67 \pm 3.75$ \\
\hline & Non-nest & $56.67 \pm 2.92$ & $43.54 \pm 1.36$ \\
\hline \multirow[t]{2}{*}{ Shrubs (\%) } & Nest & $6.54 \pm 1.31$ & $14.00 \pm 1.56$ \\
\hline & Non-nest & $9.81 \pm 2.65$ & $16.33 \pm 1.00$ \\
\hline \multirow[t]{2}{*}{ Vegetation height at nest $(\mathrm{m})$} & Nest & $0.14 \pm 0.01$ & $0.13 \pm 0.01$ \\
\hline & Non-nest & $0.12 \pm 0.01$ & $0.12 \pm 0.01$ \\
\hline \multirow[t]{2}{*}{ Vegetation height at $1 \mathrm{~m}(\mathrm{~m})$} & Nest & $0.15 \pm 0.01$ & $0.16 \pm 0.01$ \\
\hline & Non-nest & $0.15 \pm 0.01$ & $0.15 \pm 0.01$ \\
\hline \multirow[t]{2}{*}{ Vegetation height at $3 \mathrm{~m}(\mathrm{~m})$} & Nest & $0.11 \pm 0.02$ & $0.12 \pm 0.01$ \\
\hline & Non-nest & $0.07 \pm 0.01$ & $0.13 \pm 0.01$ \\
\hline \multirow[t]{2}{*}{ Nearest standing water $(\mathrm{m})$} & Nest & $1.30 \pm 0.19$ & $1.84 \pm 0.20$ \\
\hline & Non-nest & $1.57 \pm 0.19$ & $1.92 \pm 0.23$ \\
\hline \multirow[t]{2}{*}{ Nearest shrub $(m)$} & Nest & $0.21 \pm 0.03$ & $0.13 \pm 0.04$ \\
\hline & Non-nest & $1.29 \pm 0.37$ & $0.03 \pm 0.01$ \\
\hline \multirow[t]{2}{*}{ Height of Shrub (m) } & Nest & $0.21 \pm 0.03$ & $0.18 \pm 0.02$ \\
\hline & Non-nest & $0.22 \pm 0.02$ & $0.18 \pm 0.01$ \\
\hline \multirow[t]{2}{*}{ Elevation of nest $(m)$} & Nest & $0.18 \pm 0.02$ & $0.17 \pm 0.01$ \\
\hline & Non-nest & $0.14 \pm 0.02$ & $0.14 \pm 0.01$ \\
\hline \multirow[t]{2}{*}{ Vegetation density at nest $(\mathrm{m})$} & Nest & $0.15 \pm 0.04$ & $0.10 \pm 0.02$ \\
\hline & Non-nest & $0.07 \pm 0.01$ & $0.08 \pm 0.01$ \\
\hline \multirow[t]{2}{*}{ Vegetation density at $1 \mathrm{~m}(\mathrm{~m})$} & Nest & $0.15 \pm 0.04$ & $0.20 \pm 0.02$ \\
\hline & Non-nest & $0.19 \pm 0.03$ & $0.16 \pm 0.01$ \\
\hline \multirow[t]{2}{*}{ Water depth $(m)$} & Nest & $0.08 \pm 0.01$ & $0.07 \pm 0.01$ \\
\hline & Non-nest & $0.06 \pm 0.01$ & $0.05 \pm 0.01$ \\
\hline
\end{tabular}


Table 3.4. Discriminant function analysis of microhabitat variables of Whimbrel nest-sites on failed vs. successful and hummocks vs. ridges. Values represent the level of discrimination for each variable between each set of comparisons. Only microhabitat variables contributing to the discrimination are shown.

\begin{tabular}{lcc}
\hline Variable & $\begin{array}{c}\text { Failed vs. Successful } \\
\text { Nest Sites }\end{array}$ & Hummock vs. Ridge \\
\hline Graminoids (\%) & 0.848 & 0.508 \\
Shrubs (\%) & 0.879 & -0.869 \\
Nearest shrub & -0.904 & 0.969 \\
Height of nearest shrub & 0.628 & \\
Vegetation density at nest & & 0.882 \\
Vegetation density at 1m & 82.1 & -1.024 \\
\hline \% Correct Classification & 61 & 96.4 \\
\% Improvement on Chance & & 96 \\
\hline P<0.001
\end{tabular}

$\mathrm{P}<0.001$ 
Table 3.5. Comparison of macro-habitat measurements between Whimbrel nests on hummocks and ridges and successful and failed nests.

\begin{tabular}{|c|c|c|c|c|}
\hline & \multicolumn{2}{|c|}{ Distance to nearest lake $(\mathrm{m})$} & \multicolumn{2}{|c|}{$\begin{array}{l}\text { Distance to nearest } \\
\text { neighbour }(\mathrm{m})\end{array}$} \\
\hline & Mean \pm SE & $U$ & Mean \pm SE & $U$ \\
\hline Nest on hummock & $625.15 \pm 109.91$ & $86.0^{n s}$ & $411.28 \pm 47.30$ & $31.5^{* *}$ \\
\hline Nest on ridge & $598.33 \pm 105.16$ & & $224.68 \pm 35.81$ & \\
\hline Successful nest & & $90.0^{n s}$ & & $55.5^{n s}$ \\
\hline Failed nest & $593.51 \pm 82.96$ & & $265.95 \pm 38.29$ & \\
\hline
\end{tabular}


Table 3.6. Comparison of microhabitat characteristic of failed and successful Whimbrel nests.

\begin{tabular}{lcc}
\hline \multicolumn{1}{c}{ Microhabitat Variable } & $\begin{array}{c}\text { Mean } \pm \text { SE } \\
\text { Failed }\end{array}$ & $\begin{array}{c}\text { Mean } \pm \text { SE } \\
\text { Successful }\end{array}$ \\
\hline Graminoids $(\%)$ & $46.76 \pm 4.18$ & $60.00 \pm 6.00$ \\
Shrubs $(\%)$ & $11.47 \pm 0.94$ & $9.09 \pm 2.85$ \\
Vegetation height at nest $(\mathrm{m})$ & $0.14 \pm 0.01$ & $0.14 \pm 0.01$ \\
Vegetation height at $1 \mathrm{~m}(\mathrm{~m})$ & $0.15 \pm 0.01$ & $0.16 \pm 0.01$ \\
Vegetation height at $3 \mathrm{~m}(\mathrm{~m})$ & $0.13 \pm 0.01$ & $0.10 \pm 0.02$ \\
Nearest standing water $(\mathrm{m})$ & $1.61 \pm 0.21$ & $1.56 \pm 0.20$ \\
Nearest shrub $(\mathrm{m})$ & $0.02 \pm 0.01$ & $0.56 \pm 0.28$ \\
Height of Shrub $(\mathrm{m})$ & $0.21 \pm 0.02$ & $0.17 \pm 0.02$ \\
Elevation of nest $(\mathrm{m})$ & $0.19 \pm 0.02$ & $0.16 \pm 0.02$ \\
Vegetation density at nest $(\mathrm{m})$ & $0.10 \pm 0.02$ & $0.15 \pm 0.04$ \\
Vegetation density at $1 \mathrm{~m}(\mathrm{~m})$ & $0.16 \pm 0.02$ & $0.20 \pm 0.04$ \\
Water depth $(\mathrm{m})$ & $0.07 \pm 0.01$ & $0.07 \pm 0.01$ \\
\hline
\end{tabular}


Table 3.7: Mayfield estimates of nest survival for Whimbrel nesting on hummocks and ridges.

\begin{tabular}{|c|c|c|}
\hline & \multicolumn{2}{|c|}{ Nest Site Type } \\
\hline & Hummock & Polygon Ridge \\
\hline No. of nests & $\overline{11}$ & 13 \\
\hline $\begin{array}{l}\text { No. of nest days without } \\
\text { losses }\end{array}$ & 197 & 133 \\
\hline No. of nests lost & 3 & 9 \\
\hline $\begin{array}{l}\text { Estimated daily survival rate } \\
\text { of a nest ( } \hat{\mathbf{s}})\end{array}$ & 0.985 & 0.932 \\
\hline SE of $\hat{s}$ & 0.009 & 0.022 \\
\hline$X^{2} d f=2$ & & .03 \\
\hline $\begin{array}{l}\text { Nest Success (nest survival } \\
\text { rate based on average } \\
\text { incubation time of } 24 \text { days) }\end{array}$ & 0.692 & 0.186 \\
\hline
\end{tabular}


Table 3.8. Nesting densities of Whimbrel and distance to nearest neighbour in wet-sedge low-centred polygon habitat on Fish Island, Mackenzie Delta, Northwest Territories.

\begin{tabular}{lcccccc}
\hline Year & $\begin{array}{c}\text { No. } \\
\text { of } \\
\text { pairs }\end{array}$ & $\begin{array}{c}\text { Total } \\
\text { area } \\
\left(\mathrm{km}^{2}\right)\end{array}$ & $\begin{array}{c}\text { No. of } \\
\text { pairs/km² }\end{array}$ & $\begin{array}{c}\text { Observed } \\
\text { mean distance } \\
\text { to nearest } \\
\text { neighbour } \\
(\mathrm{m} \pm \mathrm{SE})\end{array}$ & $\begin{array}{c}\text { Expected } \\
\text { mean } \\
\text { distance if } \\
\text { randomly } \\
\text { distributed } \\
(\mathrm{m} \pm \mathrm{SE})\end{array}$ & $R^{\mathrm{a}}$ \\
\hline 2006 & 10 & 3.5 & 2.86 & $312.71 \pm 20.4$ & $295.80 \pm 48.9$ & $1.06^{n s}$ \\
2007 & 12 & 3.5 & 3.42 & $248.36 \pm 69.2$ & $270.03 \pm 40.7$ & $0.92^{n s}$ \\
Overall & 22 & 7.0 & 3.14 & $277.61 \pm 38.7$ & & \\
\hline
\end{tabular}

${ }^{a} R$ is a measure of departure from random distribution. Values range from 0 (maximum aggregation) to 2.1491 (maximum spacing). A value of 1 indicates random distribution. 
Table 3.9. Mean nest temperatures during periods when Whimbrel is on and off nest, number of departures and length of time away from nest during departure as observed during a 4-hour period, and the time taken by Whimbrel to return to the nest after video cameras were set up.

\begin{tabular}{lccccc}
\hline Nest & $\begin{array}{c}\text { Mean Temp on } \\
\text { nest }\left({ }^{\circ} \mathrm{C}\right)\end{array}$ & $\begin{array}{c}\text { Mean Temp off } \\
\text { nest }\left({ }^{\circ} \mathrm{C}\right)\end{array}$ & $\begin{array}{c}\text { No. } \\
\text { departures }\end{array}$ & $\begin{array}{c}\text { Mean time } \\
\text { away (min) }\end{array}$ & $\begin{array}{c}\text { Initial return } \\
\text { time (min) }\end{array}$ \\
\hline 20 & 21.90 & 21.67 & 3 & 4.86 & 6.82 \\
$20 b^{*}$ & - & - & 1 & - & 6.32 \\
$21^{\star \star}$ & - & - & 1 & 1.12 & 12.13 \\
$22^{\star \star}$ & - & - & 2 & 4.80 & 4.55 \\
25 & 20.26 & 20 & 2 & 5.78 & 7.78 \\
26 & 23.35 & 23 & 2 & 9.03 & 16.48 \\
27 & 22.17 & 22.25 & 2 & 7.67 & 8.2 \\
\hline
\end{tabular}

${ }^{\text {*}}$ A second attempt was made to video tape nest $W 20$. The bird departed the nest only once near the end of the four hour taping period and did not return before the taping was finished and has no i-button data available.

${ }^{* *}$ Retrieval of the i-buttons for W21 and W22 was unsuccessful therefore no mean temperatures are available. 


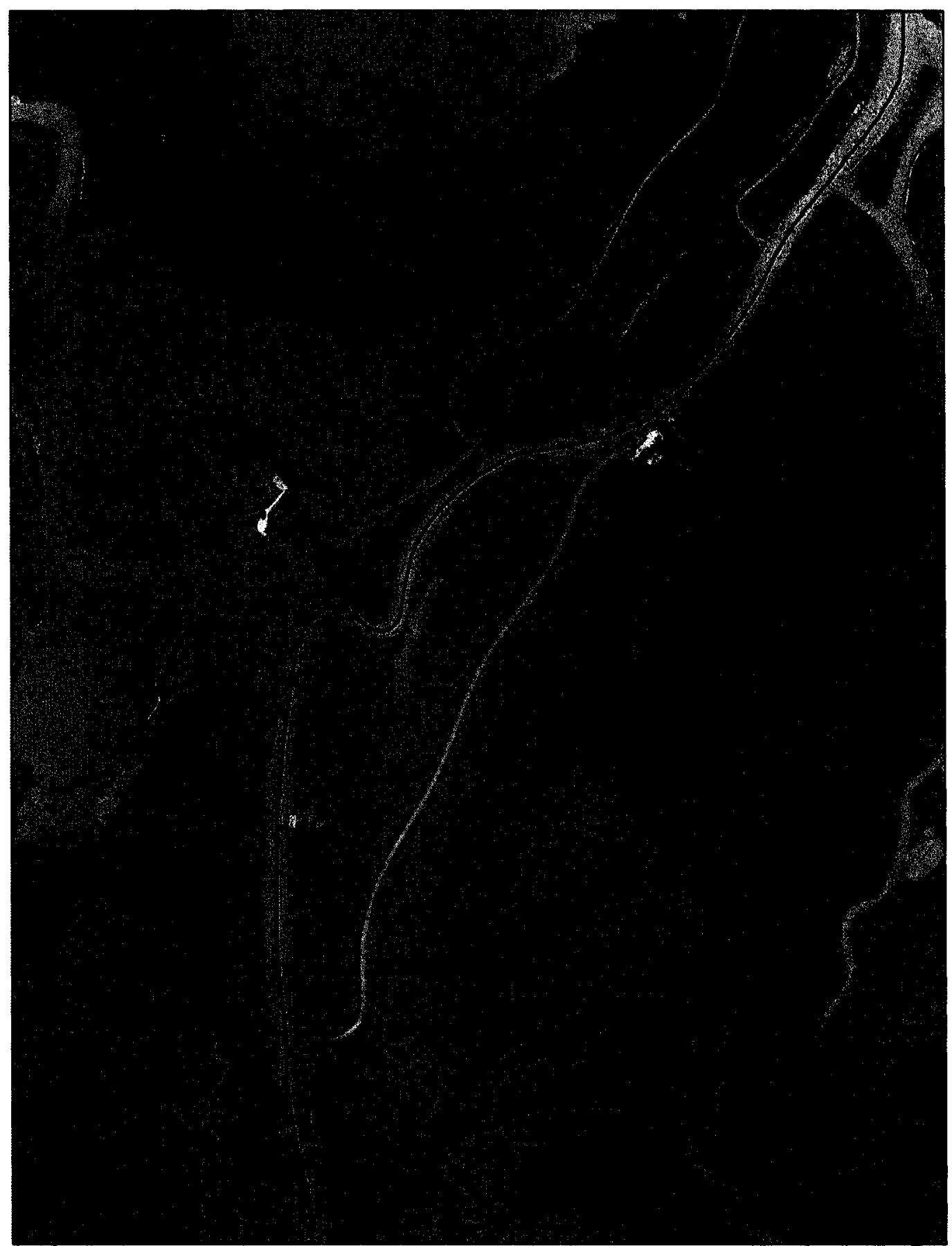

Figure 3.1. Map showing the locations of Whimbrel nests found in 2006 (blue stars) and 2007 (red crosses) on Taglu and Fish Islands, in the outer Mackenzie Delta, Northwest Territories. The red line indicates the eastern boundary of the Kendall Island Bird Sanctuary between Taglu and Fish Island. 


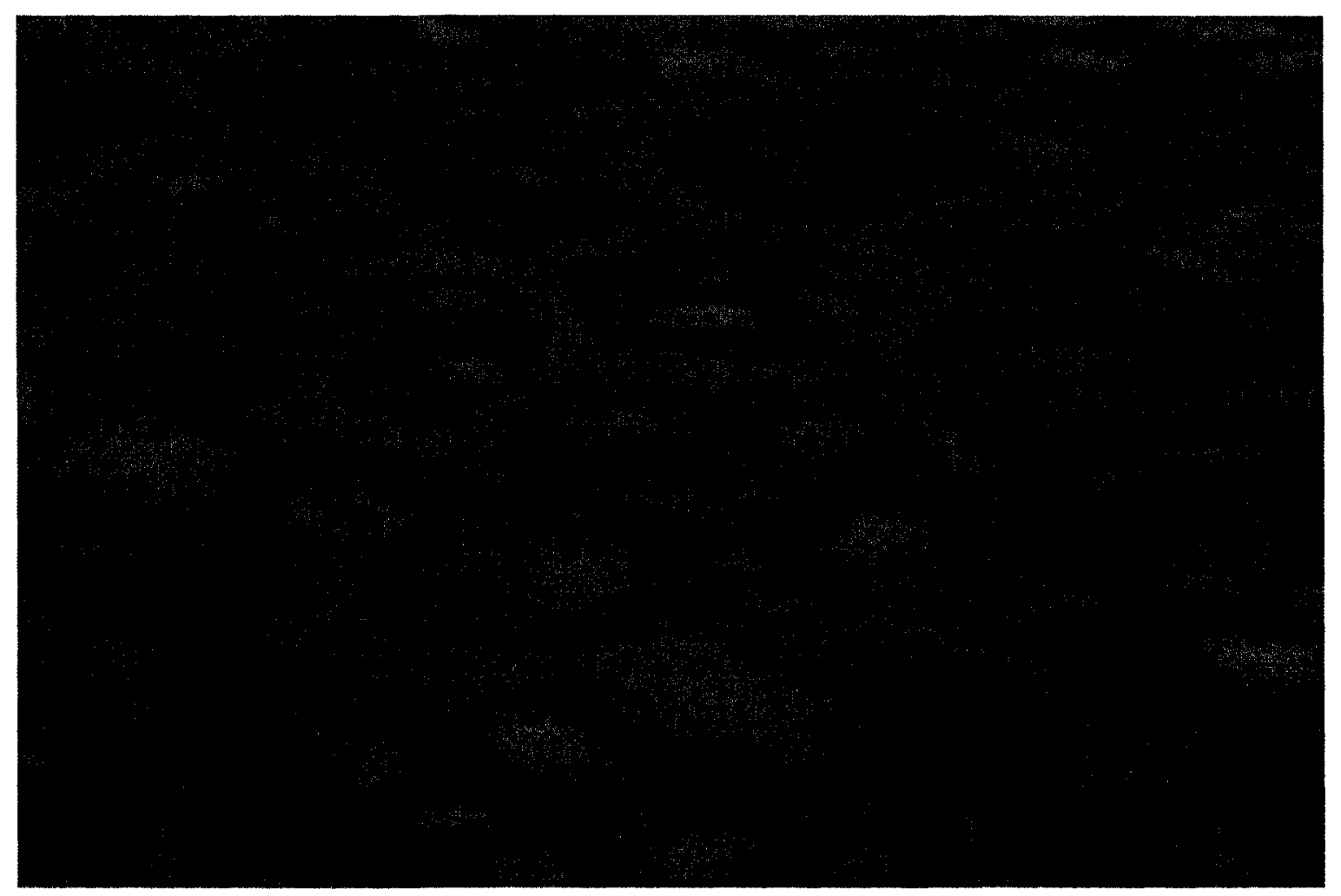

Figure 3.2. An example of wet-sedge LCP habitat on Fish Island in the outer Mackenzie Delta, Northwest Territories. The light polygon shaped features are raised polygon ridges. The darker areas represent standing water with emergent graminoids. The pale circular shapes are hummocks (one representative example.is marked) 


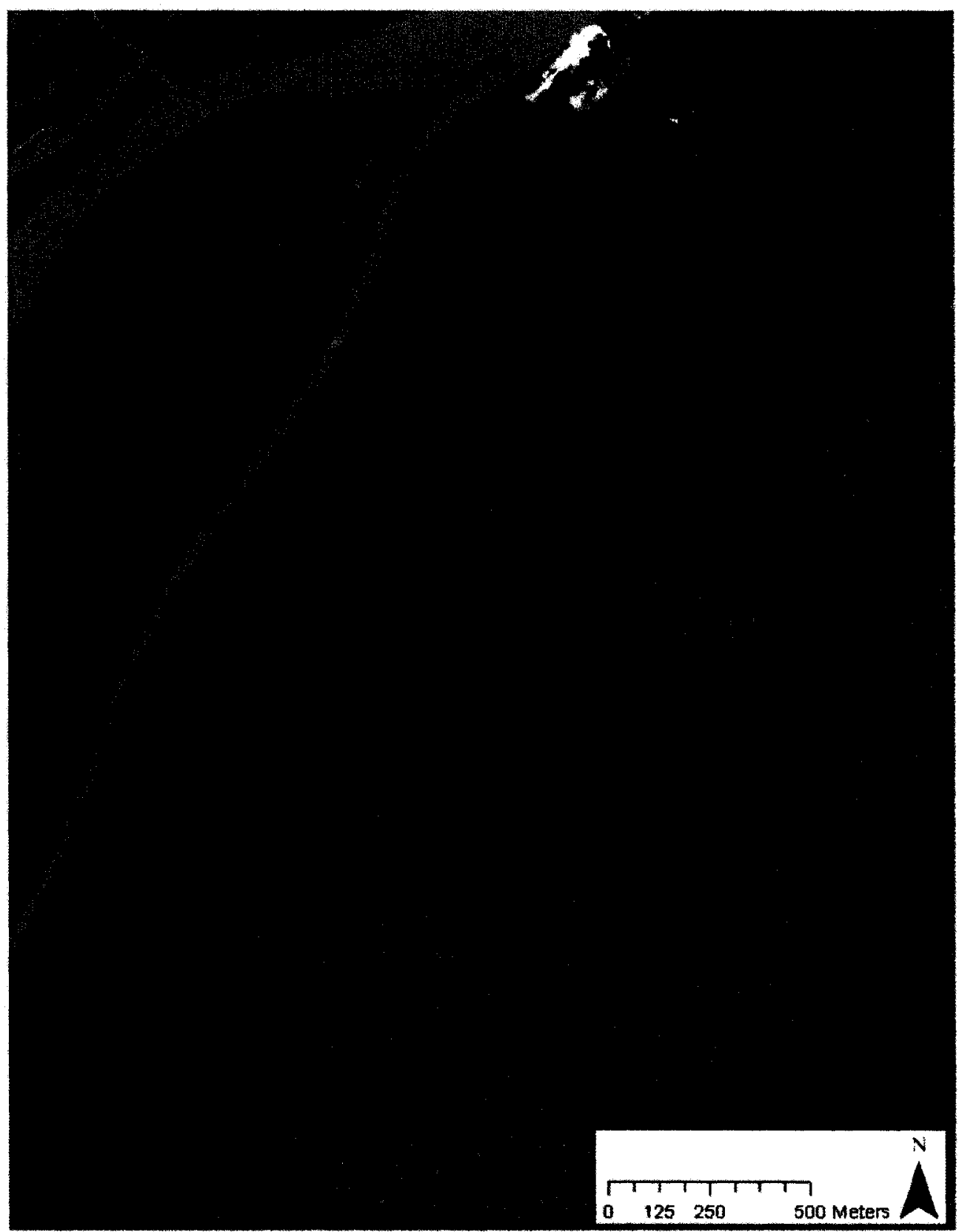

Figure 3.3. Location of radio-tracking points for adult Whimbrel breeding on Fish Island in the outer Mackenzie Delta, Northwest Territories. The * represents the nest and the + represents the points where tracked birds were observed. 


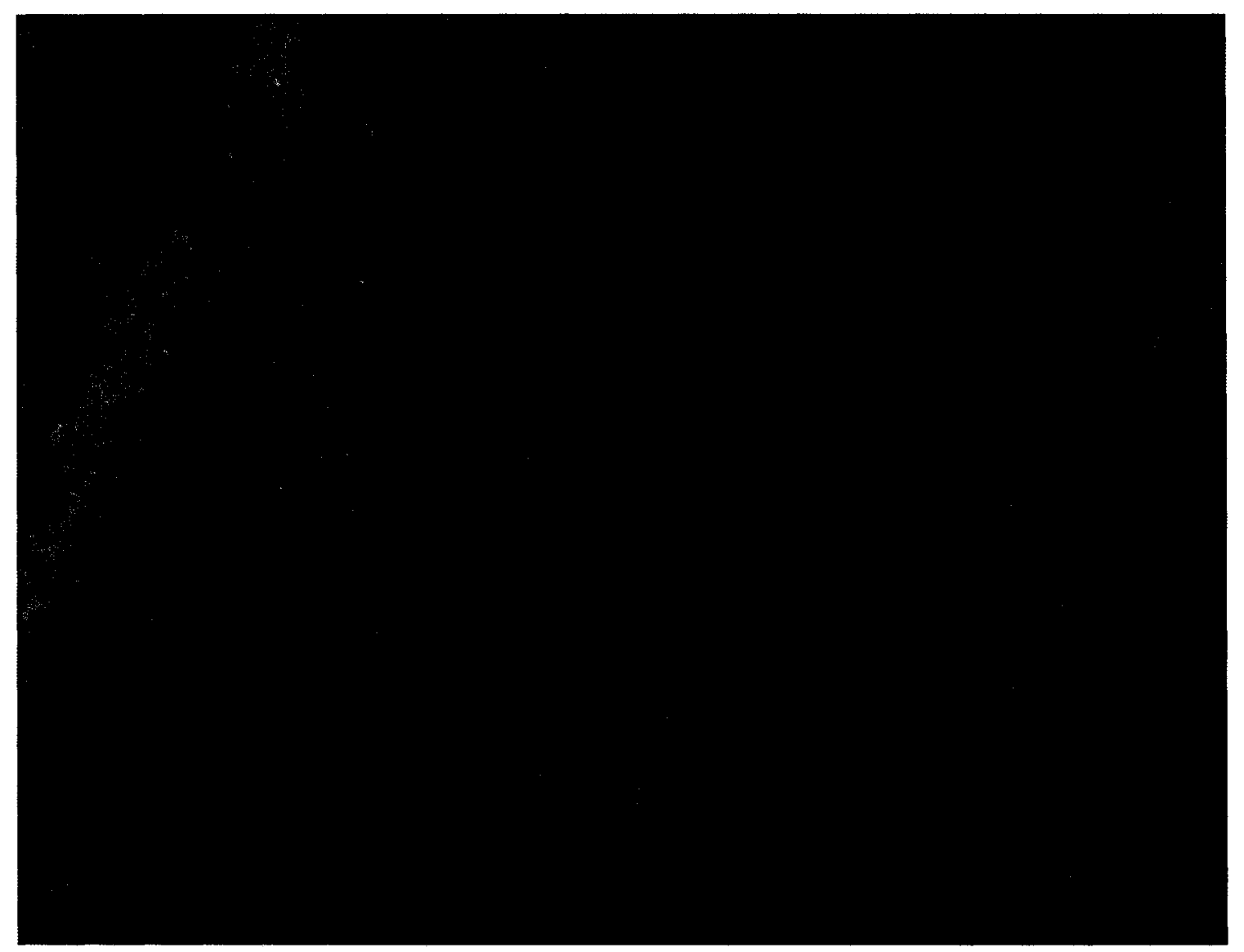

Figure 3.4. Example of three Whimbrel nests showing a $250 \mathrm{~m}$ radius around each to indicate the approximate size of their territories. These are not intended to show actual territory boundaries, but rather to provide a visual representation of the availability of hummocks and polygon ridges within a territory. In reality, nests are unlikely to be placed in the centre of a territory and territories are unlikely to be circular. Nests are identified by red crosses and the red circles indicate a $250 \mathrm{~m}$ radius around the nest. 
a.

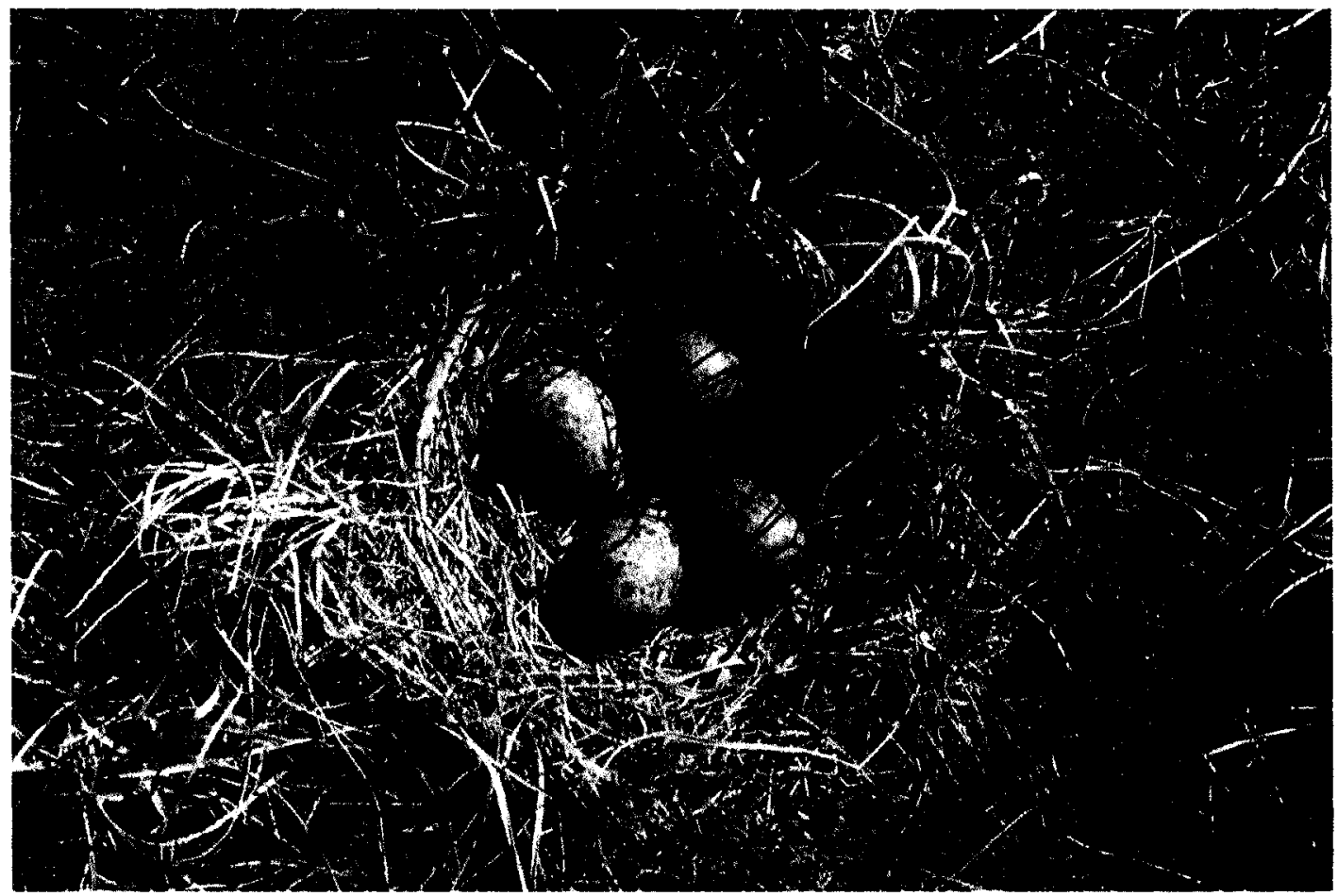

b.

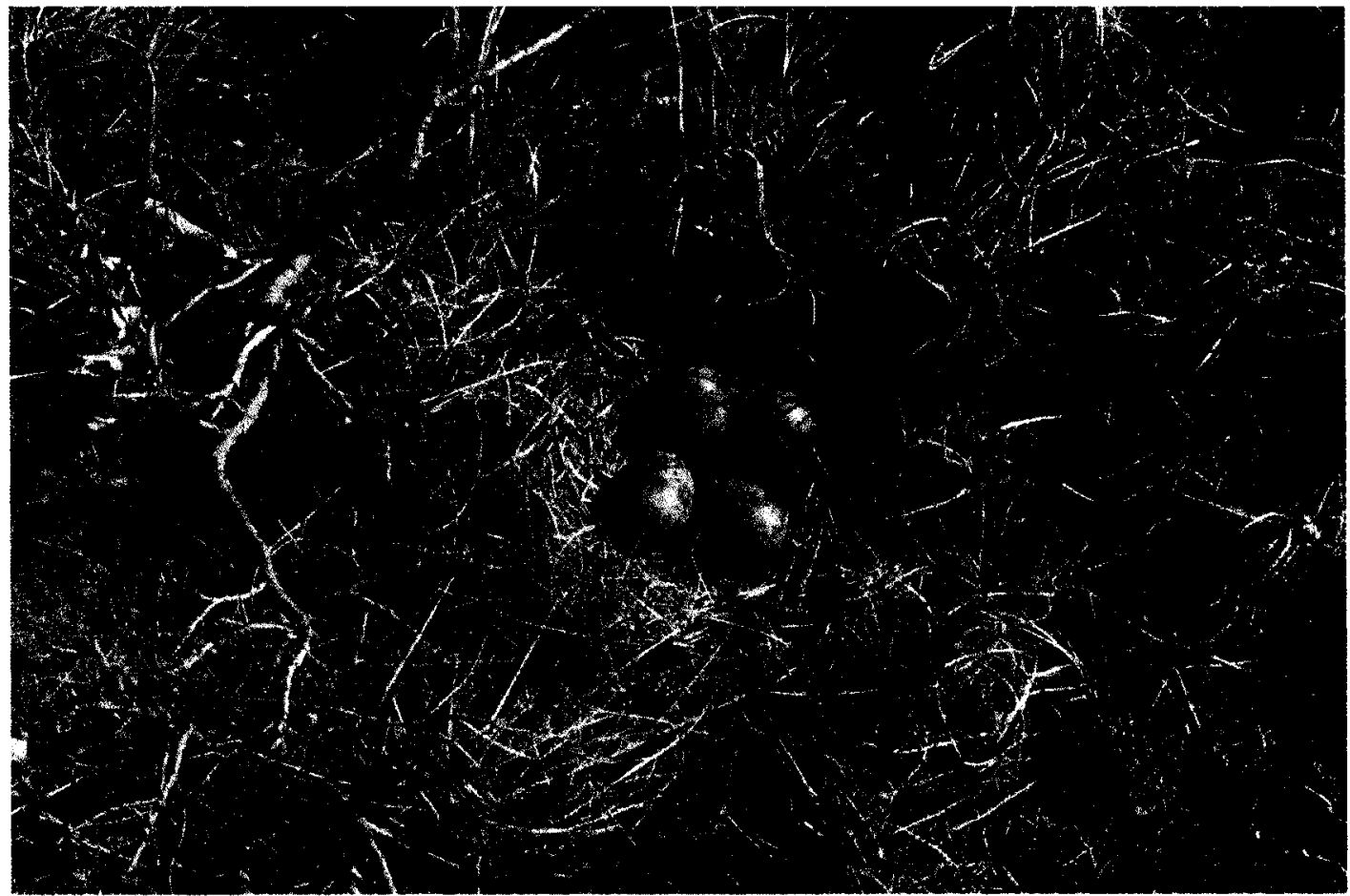

Figure 3.5. Example of a Whimbrel nest on a hummock (a) and on a ridge (b) in wet-sedge low-centred polygon habitat in the outer Mackenzie Delta, Northwest Territories. 
a.

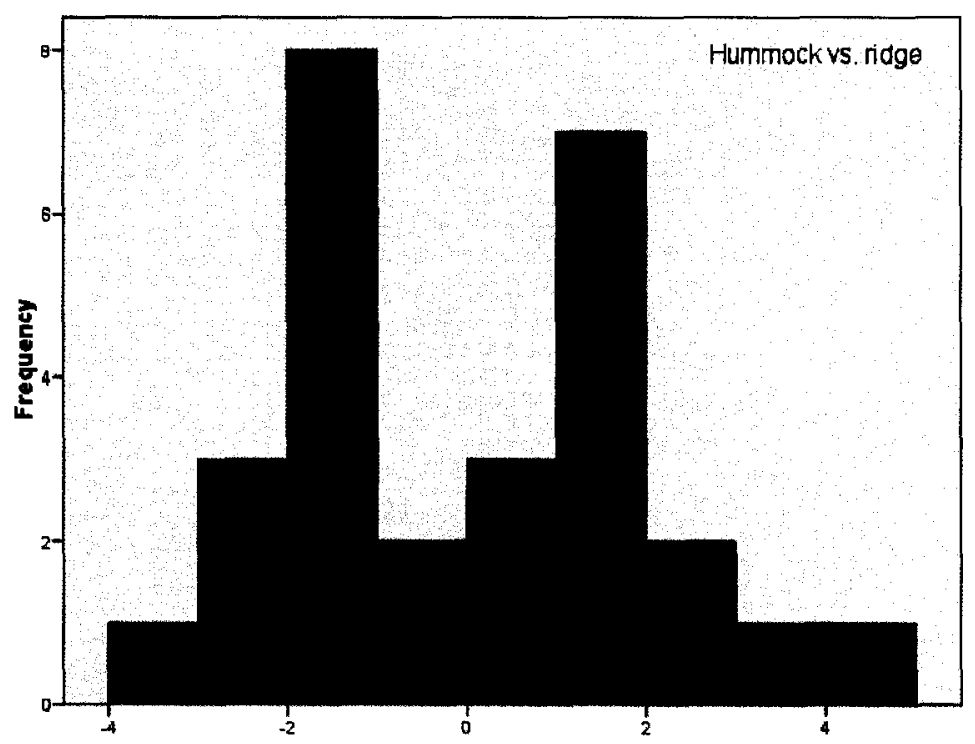

Less graminoids, more shrubs, less vegetation density at nest, closer to nearest shrub

b.

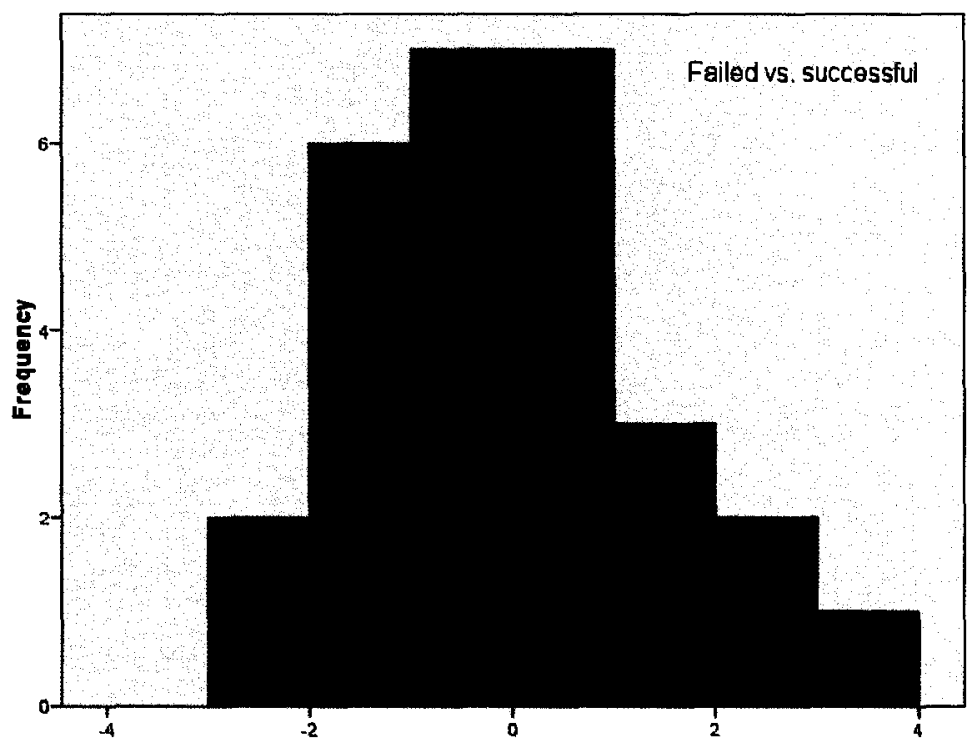

More graminoids, greater vegetation density at nest, Nearest shrub shorter and further away.

Figure 3.6. The distribution of discriminant function scores comparing failed and successful Whimbrel nests (above) and nests on hummocks and nests on ridges. 


\section{Chapter 4: General Discussion}

This study identified lowland wet-sedge low-centred polygon (LCP) habitat as important for Whimbrel foraging, nesting and chick-rearing. Dry upland tundra habitat was also used but to a much lesser extent in the study area. Further study is needed to determine the suitability of this habitat in the absence of suitable lowland habitats.

In chapter 2 I indentified the benefits and limitations of using IKONOS satellite imagery and supervised classification techniques to develop a habitat classification for the Kendall Island Bird Sanctuary (KIBS) and adjacent Fish Island. IKONOS imagery was able to identify areas of wet-sedge lowlands but spectral classifications could not differentiate between areas of patterned and unpatterned ground. Combinations of spectral analysis and visual identification of the LCP pattern type were necessary to produce a suitable habitat map for Whimbrel breeding in the outer Mackenzie Delta. Software that also extracts textural features could be valuable in situations such as this one, in which the spectral information alone insufficiently identifies spectrally heterogenous landscape structures (Ruiz et al., 2004).

Statistical methods based on the grey level cooccurrence matrices (GLCM), energy filters and edgeness factors, Gabor filters and more recently wavelet transform based methods can be used to extract textural information from high resolution satellite imagery (Ruiz et al., 2004). GCLM tabulates the 
frequency of occurrence of different combination of pixel brightness values within an image to identify textural features (Hall-Beyer, 2007). Energy filter and edgeness identify textures by calculating energy and the density of edges in the neighbourhood of a pixel (Ruiz et al., 2004). Gabor filters are composed of a set of Gaussian filters that analyse different radial frequencies and orientations (Ruiz et al., 2004). Wavelet transform based methods decompose the original images into a series of images with different trends and fluctuations (Junjie et al., 2004; Ruiz et al., 2004).

Alternatively, there is now a sophisticated software program that goes beyond spectral and spatial pattern recognition called eCognition. eCognition operates on the concept that image interpretation should be based on meaningful image objects and their mutual relationships rather than individual pixels. Using a segmentation algorithm, eCognition extracts homogenous image objects by integration of different object features such as spectral values, object shapes and contrast (Definiens Imaging, 2004). It would be worthwhile, in the future to test whether eCognition can recognize the LCP habitat.

In Chapter 3 I observed that lowland breeding Whimbrel nested in wetsedge LCP habitat and avoided habitats that had dense shrubs, low structural complexity or were too dry. Within these wet-sedge LCP habitats, nest success was correlated with better visibility of the surroundings. This may be related to the defensive behaviour of Whimbrel which respond to approaching predators with aggressive/mobbing distraction techniques (Skeel, 1983). Whimbrel may 
select nests that have a lower density of shrubs, are elevated higher above standing water and greater densities of herbaceous vegetation than that of nonnest sites to enhance visibility. However, these differences were confounded with differences between the microhabitat of hummocks and ridges. An alternative explanation is that ridges may have been more accessible to terrestrial predators such as Arctic Foxes which were observed in the area. Information was not available on which predators led to nest failure. Although nest success was higher on hummocks, limited availability of suitable hummocks may have forced many Whimbrel to nest on apparently less suitable ridge sites.

\section{Conservation}

The limited availability of suitable wet-sedge LCP habitat in the outer Mackenzie Delta suggests that conservation of this unique habitat is imperative for maintaining Whimbrel breeding populations there. This should be considered when conducting scenario analyses as described in chapter 2 . Scenario analyses are an important component to conducting a thorough environmental assessment of the impacts development might have on wildlife and wildlife habitat. My scenario analyses determined the amount of habitat that may be lost with the construction of a gas processing facility on Taglu Island and a pipeline that crosses Fish Island lowland habitat. Both of these structures will significantly reduce the availability of wet-sedge LCP habitat that is used by breeding Whimbrel. These scenarios and the new knowledge of Whimbrel breeding habitat preferences (chapter 3) and the availability of this habitat (chapter 2) 
should be used to develop plans to mitigate the effects of the proposed Mackenzie Gas Project (MGP) should it be approved.

\section{Future Studies}

Whimbrel selection of nests with a clear view of their surroundings could be further investigated by placing 'shrubs' at the nest and at varying distances from nests to compare nest success. Studies to determine the predator type in nest predation may lend further insight into the selection of nests on hummocks and ridges. Nests that are surrounded by water may be less accessible desirable or less visible to ground predators such as Arctic Foxes. Further studies on Whimbrel breeding habitat are necessary to understand the differences between upland nesting sites and the lowland nesting sites studied here. Lowland nesting Whimbrel are located in areas with high invertebrate productivities while upland habitats presumably have limited productivity of their preferred invertebrate food and may require Whimbrel to travel to nearby wetlands to forage during incubation and for chick rearing. Radio-tracking of an upland nesting adult Hudsonian Godwit Limosa haemastica indicated that Godwits will travel distances of $1 \mathrm{~km}$ or greater to forage during incubation and relocate their chicks to these wetland habitats after hatch (Pirie, Pers. Obs.). Upland breeding Whimbrel appear to nest in lower densities than those in lowland sites. This difference in densities could affect levels of predation. Whimbrel nesting in low densities do not benefit from the conspecific communication afforded by nesting in greater densities and may be more 
vulnerable to predators. A comparison of the predation levels as well as Whimbrel response to predators in both sites may offer some insight into the increased use of wet-sedge LCP habitats for breeding. 


\section{References}

Alexander, S. A., Ferguson, R. S., and McCormick, K. J. 1991. Key migratory bird terrestrial habitat sites in the Northwest Territories. Canadian Wildlife Service. Occasional Paper 71. Environment Canada, Yellowknife, Canada. $184 \mathrm{pp}$.

AMEC Americas Limited. 2005. Mackenzie Gas Project - Wildlife Habitat Suitability Modelling: Birds. Unpublished Report.

Ashenhurst, A. R. 2004. The effects of seismic lines and drill pads on breeding migratory birds in the Kendall Island Migratory Bird Sanctuary, NWT. Master's Thesis. University of Alberta, Edmonton, Alberta.

Barg, J. J., Aiama, D. M., Jones, J. and Robertson, R. J. 2006. Within-territory habitat use and microhabitat selection by male Cerulean Warblers (Dendroica cerulean). The Auk 123: 795-806.

Beveridge, B. 2007. Habitat associations and nest success of Red-necked Phalaropes (Phalaropus lobatus) in the Mackenzie Delta, Northwest Territories. Master's Thesis. Trent University, Peterborough, Ontario.

Beyer, H. 2008. Hawth's Analysis Tools for ArcGIS. http://www.spatialecology.com/htools/tooldesc.php

Brown, S., Hickey, C., Harrington, B., and Gill, R. 2001. United States Shorebird Conservation Plan, second edition. Manomet Center for Conservation Sciences.

Burger, J. 1985. Habitat selection in temperate marsh-nesting birds. In: Cody, M. L. (ed.) Habitat Selection in Birds. Academic Press, pp. 253-281. 
Burn, C. 2002. Mackenzie Delta. In: Natural History of the Western Arctic. Western Arctic Handbook Project. Pp. 24-29.

Canadian Endangered Species Conservation Council (CESCC). 2006. Wild Species 2005: The General Status of Species in Canada.

Canadian Wildlife Service. 1992. Management of migratory bird sanctuaries in the Inuvialuit settlement region. Yellowknife, Northwest Territories, Environment Canada: 91.

Canadian Wildlife Service. 2005. Kendall Island Migratory Bird Sanctuary, Northwest Territories. Pamphlet.

Clark, P. J., and Evans, F. C. 1954. Distance to nearest neighbour as a measure of spatial relationships in populations. Ecology 35: 445-453.

Cody, M. L. 1981. Habitat selection in birds: The roles of vegetation structure, competitors, and productivity. BioScience 31: 107-113.

Cody, M. L. 1985. An introduction to habitat selection in birds. In: Cody, M. L. (ed.) Habitat Selection in Birds. Academic Press, pp. 3-56.

Colwell, M. A., and Oring, L. W. 1990. Nest-site characteristics of prairie shorebirds. Canadian Journal of Zoology 68: 297-302.

Dickson, H. L., and Smith, A. R. 1991. Use of Landsat Thematic Mapper and multi-spectral scanning imagery to identify habitats and shorebird nesting areas on the outer Mackenzie River Delta, NWT. In: Marsh, P., and Ommanney, C.S.L., eds. Mackenzie Delta: Environmental interactions and implications of development. NHRI Symposium No. 4. Saskatoon, Saskatchewan: National Hydrology Research Institute, Environment Canada. 91-106. 
Dickson, H. L., Jaques, S., Barry, S., Telfer, E.S., and Smith, A. R. 1989. Identification of nesting and staging shorebird areas in the Mackenzie River delta and Richards Island area, Northwest Territories, using LANDSAT Thematic Mapper magery, 1985-1987, NOGAP Project C7.3. Edmonton: Canadian Wildlife Service. Unpubl. report. Available at the Departmental Library, Environment Canada, Place Vincent Massey, 351 St. Joseph Boulevard, Hull, Quebec K1A OH3, Canada.

Didiuk, A. B., and Ferguson, R. S. 2005. Land cover mapping of Queen Maud Gulf Migratory Bird Sanctuary, Nunavut. Canadian Wildlife Service Occassional Paper No. 111. Ottawa, Ontario: Canadian Wildlife Service, Environment Canada.

Donaldson, G., Hyslop, P., Morrison, G., Dickson, L., and Davidson, I. 2000. Canadian Shorebird Conservation Plan. Canadian Wildlife Service, Environment Canada.

Dyrcz, A., Witkowski, J., and Okulewicz, J. 1981. Nesting of "timid" waders in the vicinity of "bold" ones as an antipredator adaptation. Ibis 123: 542545.

Definiens Imaging. 2004. eCognition Elements. User Guide 4.

Emers, M., Jorgenson, J. C., and Raynolds, M. K. 1995. Response of arctic tundra plant communities to winter vehicle disturbance. Canadian Journal of Botany 73: 905-917. 
Environment Canada. 2006. Mackenzie Gas Project Environmental Assessment Review Written Submission. Joint Review Panel Topic Specific Hearing. Theme 3: Biological Environment - Fish and wildlife and their habitats. Topic 7: Wildlife and wildlife habitat, Migratory Birds including Kendall Island Bird Sanctuary. 15-16, November 2006.

Felix, N. A., and Raynolds, M. K. 1989. The effects of winter seismic trails on tundra vegetation in Northeastern Alaska, U. S. A. Arctic and Alpine Research 21: 188-202.

Ferguson, R. S. 1991. Detection and classification of muskox habitat on Banks Island, Northwest Territories, Canada, using Landsat Thematic Mapper data. Arctic 44(Supp. 1): 66-74.

Finch, D. M. 1989. Relationships of surrounding riparian habitat to nest-box use and reproductive outcome in house wrens. Condor 96: 761-768.

Fretwell, S. D., and Lucas Jr., H. L. 1970. On territorial behaviour and other Factors influencing habitat distributon of birds. I. Theoretical Development. Acta Biotheoretica 19: 16-36.

George, T. H., Stringer, W. J., Preston, J. E., Fibiel, W. R., and Scorup, P. C. 1977. Reindeer range inventory in western Alaska from computer-aided digital classification of Landsat data. In: Proceedings $28^{\text {th }}$ Alaska Science Conference, Anchorage, Alaska. 33-42.

Gochfeld, M. 1977. Colony and nest site selection by black skimmers. Proceedings of the Colonial Shorebird Group 1: 78-90. Godfrey, W. E. 1986. The Birds of Canada, revised edition. National Museum of Natural Sciences, Ottawa, Canada. 
Goetz, S. J., Wright, R. K., Smith, A. J., Zinecker, E., and Schaub, E. 2003. IKONOS imagery for resource management: Tree cover, impervious surfaces, and riparian buffer analyses in the mid-Atlantic region. Remote Sensing of Environment 88: 195-208.

Götmark, F., Blomqvist, D., Johansson, O. C., and Bergkvist, J. 1995. Journal of Avian Biology 26: 305-312.

Gratto-Trevor, C. L. 1994. Use of Landsat TM imagery in determining priority shorebird habitat in the outer Mackenzie Delta, N.W.T. (NOGAP subproject C.24). Unpubl. report. Available at Canadian Wildlife Service, Environment Canada, Prairie and Northern Wildlife Research Centre, 115 Perimeter Road, Saskatoon, Saskatchewan S7N 0X4, Canada. 217 pp. Gratto-Trevor, C. L. 1996. Use of Landsat TM imagery in determining important shorebird habitat in the outer Mackenzie Delta, Northwest Territories. Arctic 49: 11-22.

Hall-Beyer, M. 2007. The GLCM tutorial home page. University of Calgary. http://www.fp.ucalgary.ca/mhallbey/tutorial.htm. Updated: 21 February 2007.

Hines, J. E., and Sauer, J. R. 1989. Program CONTRAST - A General Program for the Analysis of Several Survival or Recovery Rate Estimates. US Fish \& Wildlife Service, Fish \& Wildlife Technical Report 24, Washington, DC. Hutto, R. L. 1985. Habitat selection by nonbreeding, migratory land birds. In: Cody, M. L. (ed.) Habitat Selection in Birds. Academic Press, pp. 455476. 
Imperial Oil Resources Ventures Limited. 2004. Environmental Impact Statement for the Mackenzie Gas Project. Submitted to the National Energy Board and Joint Review Panel, August 2004.

Jaques, D. 1987a. Landsat imagery for identification and mapping of shorebird Habitat in the Mackenzie Delta, Northwest Territories, Canada. Unpubl. Report prepared for the Canadian Wildlife Service, 4999-98 Avenue, Edmonton, Alberta T6B 2 X3 by Ecosat Geobotanical Surveys, Inc., North Vancouver.

Jaques, D. 1987b. Identification of potential shorebird nesting and staging Habitats using Landsat Thematic Mapper Imagery in the outer Mackenzie Delta, NWT, Canada. Unpubl. report prepared for the Canadian Wildlife Service, 4999 - 98 Avenue, Edmonton, Alberta T6B 2X3, by Ecosat Geobotanical Survyes, Inc., North Vancouver.

Jennings, M. D. 2000. Gap analysis: concepts, methods, and recent results. Landscape Ecology 15: 5-20.

Johnson, D. H. 1979. Estimating nest success: the Mayfield method and an alternative. The Auk 96: 651-661.

Johnson, D. H. 1980. The comparison of usage and availability measurements for evaluating resource preference. Ecology 61: 65-71. Johnston, V. H., Dockrill, C., and McKenzie, S. 2008. 2007 interim report Whimbrel surveys in the Mackenzie Delta and Storm Hills region, NWT. Canadian Wildlife Service, Unpublished Report, Yellowknife, NWT. Jones, J. 2001. Habitat selection studies in avian ecology: A critical review. The Auk 118: 557-562. 
Junjie, Z., Huadong, G., Xiangtao, F. and Yun, S. 2004. A wavelet transform method to detect boundaries between land and water in SAR image. Geoscience and Remote Sensing Symposium, 2004 6: 4262-4264.

Kemper, J. T. 2006. Vegetation changes on seismic lines from recent (20002001) and historic (1970-1986) seismic programs in the Mackenzie Delta area. Environmental Studies Research Funds Report No. 159, Calgary. $29 \mathrm{pp}$.

Kerr, J. T., Southwood, T. R. E., and Cihlar, J. 2001. Remotely sensed habitat Diversity predicts butterfly species richness and community similarity in Canada. Proceedings of the National Academy of Sciences 98: 1136511370.

Kerr, J. T. and M. Ostrovsky. 2003. From space to species: ecological applications for remote sensing. Trends in Ecology and Evolution 18: 299305.

Krebs, C. J. 1989. Ecological Methodology. Harper Collins, New York.

Kristan III, W. B. 2003. The role of habitat selection behaviour in population dynamics: source-sink systems and ecological traps. Oikos 103: 457-468.

Larsen, T. and Grundetjern, S. 1997. Optimal choice of neighbour: predator protection among tundra birds. Journal of Avian Biology 28: 303-308.

Larsen, T. and Moldsvor, J. 1992. Antipredator behaviour breeding associations of Bar-tailed Godwits and Whimbrels. The Auk 109: 601-608.

Lawson, D. E. 1986. Response of permafrost terrain to disturbance: A synthesis of observations from northern Alaska. Arctic and Alpine Research 18: 117. 
Lavers, C. P., Haines-Young, R. H., and Avery, M. I. 1996. The habitat associations of Dunlin (Calidris alpine) in the Flow Country of Northern Scotland and an improved model for predicting habitat quality. The Journal of Applied Ecology 33: 279-290.

Lillesand, T. M., Kiefer, R. W. and Chipman, J. W. 2004. Remote Sensing and Image Interpretation, Fifth Edition. New York: John Wiley and Sons. 763 pp.

Markon, C. J. And Derksen, F.V. 1994. Identification of tundra land cover near Teshekpuk Lake, Alaska using SPOT satellite data. Arctic 47: 222-231.

Martin, T. E. 1987. Food as a limit on breeding shorebirds: a life-history Perspective. Annual Review of Ecology and Systematics 18: 453-487. Martin, T. E. 1988. Processes organizing open nesting bird assemblages: Competition or nest predation? Evolutionary Ecology 2: 37-50.

Martin, T. E. 1995. Avian life history evolution in relation to nest sites, nest predation, and food. Ecological Monographs 65: 101-127.

Martin, T. E. 2001. Abiotic vs. biotic influences on habitat selection of coexisting species: climate change impacts? Ecology 82: 175-188

Matthews, S. B. 1991. An assessment of bison habitat in the Mills/Mink Lakes Area, Northwest Territories, using Landsat Thematic Mapper data. Arctic 44(Supp. 1): 75-80.

Mayfield, H. 1961. Nesting success calculated from exposure. The Wilson Bulletin 73: 255-261.

Mohren, G. M. J. 2003. Large-scale scenario analysis in forest ecology and forest management. Forest Policy and Economics 5: 103-110. 
Morrison, R. I. G. 1997. The use of remote sensing to evaluate shorebird habitats and population on Prince Charles Island, Foxe Basin, Canada. Arctic 50: 55-75.

Morrison, R. I. G. 2001. Shorebird population trends and issues in Canada - an overview. Bird Trends 8: 1-4.

Morrison, R. I. G. 2001. Estimates of shorebird populations in North America. Bird Trends 8: 5-9.

Morrison, R. I. G., McCaffery, B. J., Gill, R. E., Skagen, S. K., Jones, S. L., Page, G. W., Gratto-Trevor, C. L., and Andres B. A. 2006. Population estimates of North American shorebirds, 2006. Wader Study Group Bulletin 111: $67-$ 85.

Mumby, P. J. and Edwards, A. J. 2002. Mapping marine environments with IKONOS imagery: enhanced spatial resolution can deliver greater thematic accuracy. Remote Sensing of Environment 82: 248-257.

Nature Canada. 1996. Birds, bird habitat and the Mackenzie Gas Project: Important bird areas and migratory birds as valued components. Nature Canada Intervener Report.

Partridge, L. 1978. Habitat selection. In: Krebs, J. R. And Davies, N. B., eds. Behavioral Ecology an Evolutionary Approach.. Sinauer Associates. pp.351-376.

Pasqualini, V., Pergent-Martini, C., Pergent, G., Agreil, M., Skoufas, G., Sourbes, L., and Tsirika, A. 2005. Use of SPOT 5 for mapping seagrasses: An Application to Posidonia oceanica. Remote Sensing of Environment 94: $39-45$. 
Pearce, C. M. 1991. Mapping muskox habitat in the Canadian High Arctic with SPOT satellite data. Arctic 44(Supp. 1): 49-57.

Pirie, L. D. 2007. Personal Observation.

Pulliam, H. R. 1988. Sources, sinks and population regulation. The American Naturalist 132: 652-661.

Ramsey, S. M., Otter, K., and Ratcliffe, L. M. 1999. Nest-site selection by female Black-capped Chickadees: Settlement based on conspecific attraction? The Auk 116: 604-617.

Rees, W. G. 1990. Physical principles of remote sensing. Cambridge: Cambridge University Press.

Reid, J. M., Cresswell, W., Holt, S., Mellanby, R. J., Whitfield, D. P. and Ruxton, G. D. 2002. Nest scrape design and clutch heat loss in Pectoral Sandpipers. Functional Ecology 16: 305-312.

Ritchie, J. C. 1984. Past and present vegetation of the far Northwest of Canada. Toronto: University of Toronto Press. $251 \mathrm{pp}$.

Rodrigues, R. 1994. Microhabitat variables influencing nest-site selection by tundra birds. Ecological Applications 4: 110-116.

Rosenzweig, M. L. 1985. Some theoretical aspects of habitat selection In: Cody, M. L. (ed.) Habitat Selection in Birds. Academic Press, pp. 517541.

Ruiz, L. A., Fdez-Sarría, A., and Recio, J. A. 2004. Texture feature extraction for classification of remote sensing data using wavelet decomposition: a comparative study. Proceedings: XXth ISPRS Congress "Geo-Imagery Bridging Continents," 12 - 23 July, 2004, Istanbul, Turkey. 
Skeel, M. A. 1976. Nesting strategies and other aspects of the breeding biology of the Whimbrel (Numenius phaeopus) at Churchill, Manitoba. Master's Thesis. University of Toronto, Ontario.

Skeel, M. A. 1983. Nesting success, density, philopatry, and nest-site selection of the Whimbrel (Numenius phaeopus) in different habitats. Canadian Journal of Zoology 61: 218-225.

Skeel, M. A. and Mallory E. P. 1996. Whimbrel (Numenius phaeopus). In: Poole, A. and Gill, F. (eds.), The Birds of North America, No. 219. The Birds of North America.

Smith, P. A., Gilchrist, H. G., and Smith, J. N. M. 2007. Effects of nest habitat, food, and parental behaviour on shorebird nest success. The Condor 109: $15-31$.

Soper, J.D. 1952. Proposed bird sanctuary in the vicinity of Kendall Island Mackenzie Bay, NWT. Canadian Wildlife Service, Edmonton, Alberta.

Storaas, T., and Wegge, P. 1987. Nesting habitats and nest predation in sympatric populations of Capercaillie and Black Grouse. Journal of Wildlife Management 51: 167-172.

Taft, O. W., and Haig, S. M. 2004. Use of radar remote sensing (RADARSAT) to map winter wetland habitat for shorebirds in an agricultural landscape. Environmental Management 33: 750-763.

Tarves, T. L. 1987. Shorebirds of the outer Mackenzie Delta, N.W.T./Fish Island area habitat and nest data of the Whimbrel and the Semipalmated Plover. BSc. Northern Alberta Institute of Technology. 
Tinbergen, N., Impekoven, M., and Franck, D. 1967. An experiment on spacingout as a defence against predators. Behaviour. 28: 307-321.

Titus, K., Mosher, J. A., and Williams, B. K. 1984. Chance-corrected classification for use in discriminant analysis: Ecological Applications. American Midland Naturalist 111: 1-7.

Truett, J. C., Senner, R. G. B., Kertrell, K., Rodrigues, R., and Pollard, R. H. 1994. Wildlife responses to small-scale disturbances in Arctic tundra. Wildlife Society Bulletin 22: 317-324.

U.S. Shorebird Conservation Plan. 2004. High Priority Shorebirds - 2004. Unpubl. report, U.S. Fish and Wildlife Service, 4401 N. Fairfax Dr., MBXP 4107, Arlingon, VA, 22203 U.S.A. 5 pp.

Wickware, G. M., Sims, R. A., Ross, R. K., and Cowell, D. W. 1980. The Application of remote sensing techniques for an ecological land survey of The snow goose colony at Cape Henrietta Maria, Hudson Bay. Proceedings, Sixth Canadian Symposium on Remote Sensing, Halifax, N. S. $387-395$. 


\section{Appendix}

Table A-1: 2006 and 2007 Whimbrel nest UTM co-ordinates (NAD 83) in the outer Mackenzie Delta, Northwest Territories.

\begin{tabular}{lllll}
\hline Nest ID & Year & Easting & Northing & Site \\
\hline W1 & & & \\
W2 & 2006 & 501205 & 7695986 & Taglu Island \\
W3 & 2006 & 501189 & 7696370 & Taglu Island \\
W4 & 2006 & 501516 & 7695865 & Taglu Island \\
W5 & 2006 & 500943 & 7695621 & Taglu Island \\
W6 & 503260 & 7693352 & Fish Island \\
W7 & 2006 & 503137 & 7693058 & Fish Island \\
W8 & 2006 & 504456 & 7695056 & Fish Island \\
W9 & 2006 & 503593 & 7693482 & Fish Island \\
W10 & 2006 & 503301 & 7693699 & Fish Island \\
W11 & 503344 & 7692643 & Fish Island \\
W12 & 2006 & 503958 & 7694899 & Fish Island \\
W13 & 2006 & 503015 & 7692520 & Fish Island \\
W14 & 2006 & 502961 & 7692684 & Fish Island \\
W15 & 2006 & 504310 & 7694893 & Fish Island \\
W16 & 2006 & 503474 & 7693896 & Fish Island \\
W17 & 2006 & 503115 & 7693614 & Fish Island \\
W18 & 2007 & 501192 & 7696102 & Taglu Island \\
W19 & 2007 & 503284 & 7693226 & Fish Island \\
W20 & 2007 & 503333 & 7693862 & Fish Island \\
W21 & 2007 & 504276 & 7694986 & Fish Island \\
W22 & 2007 & 504111 & 7694672 & Fish Island \\
W23 & 2007 & 501565 & 7698692 & Taglu Island \\
W24 & 2007 & 498823 & 7687572 & Upland \\
W25 & 2007 & 503832 & 7694816 & Fish Island \\
W26 & 503373 & 7693619 & Fish Island \\
W27 & 504941 & 7695642 & Fish Island \\
W28 & 503286 & 7693729 & Fish Island \\
W29 & 503167 & 7693472 & Fish Island \\
\hline & 2007 & 503373 & 7693839 & Fish Island \\
\hline & 2007 & & &
\end{tabular}




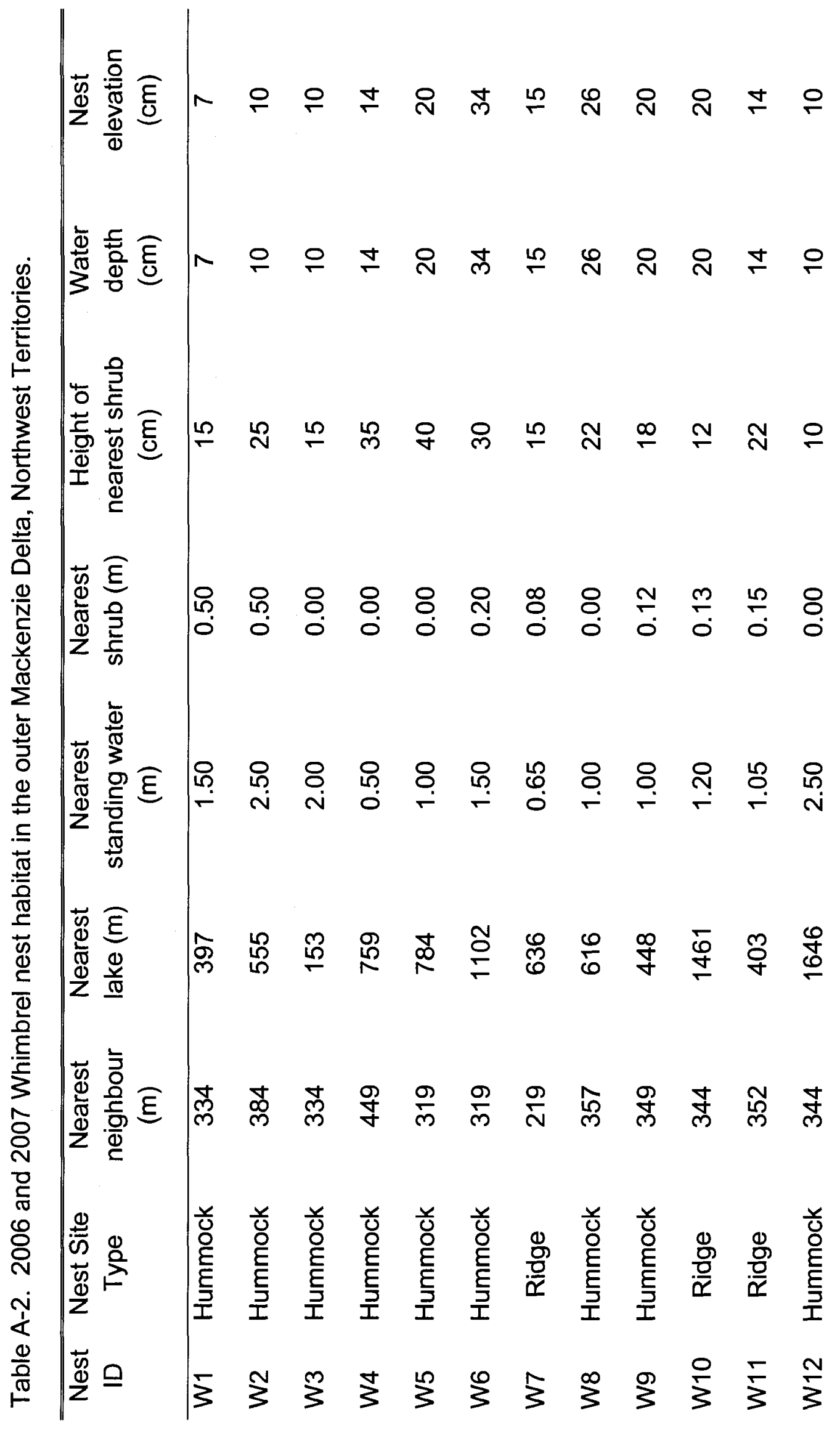




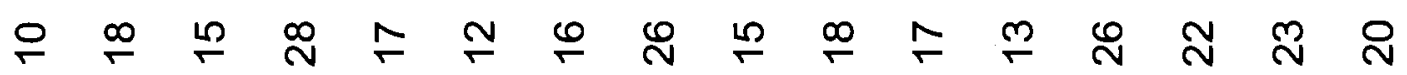

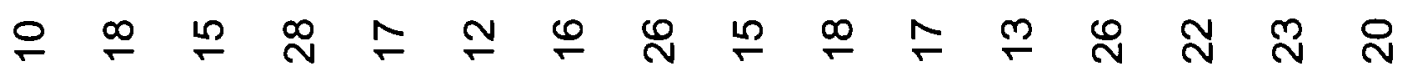

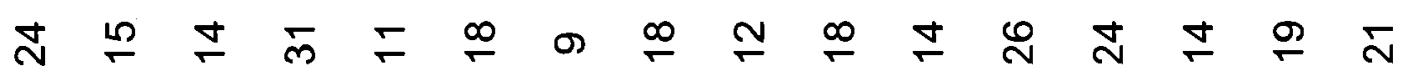

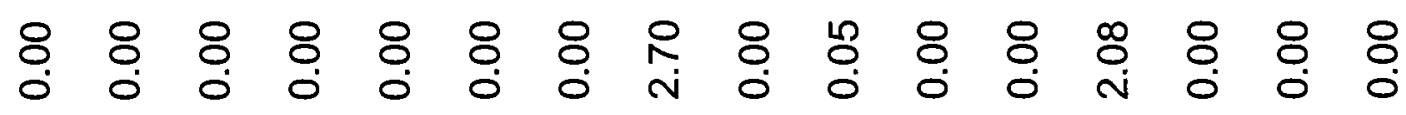

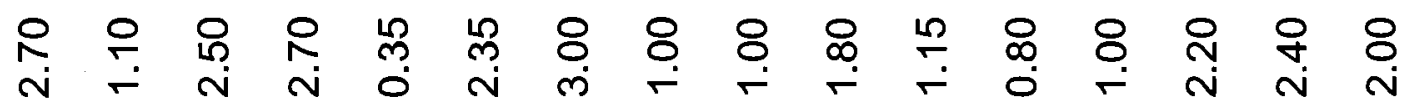

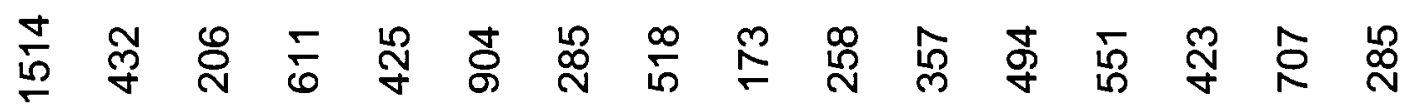

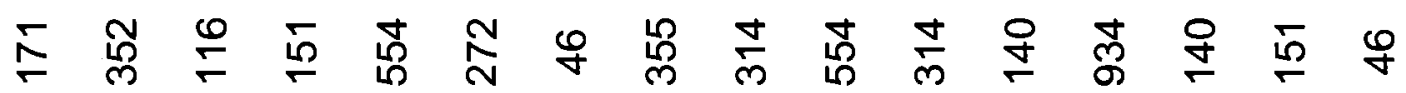

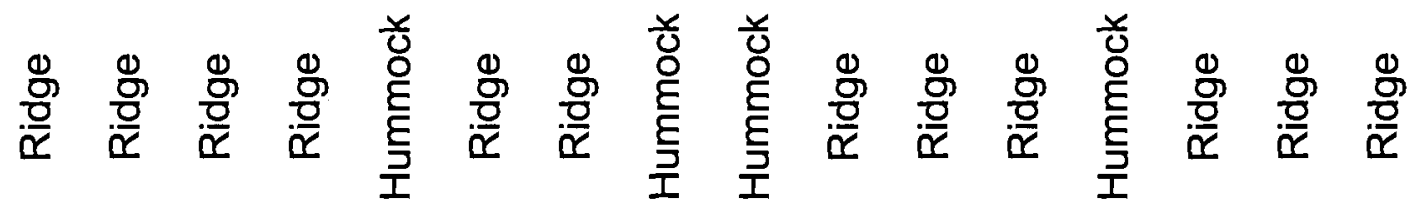

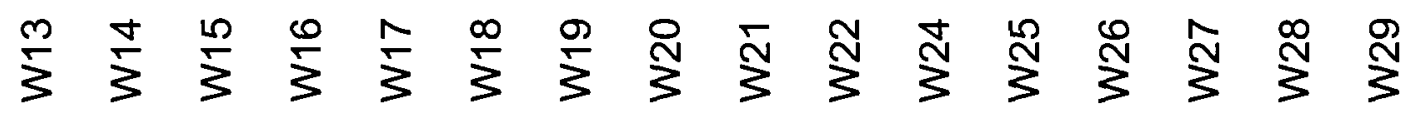




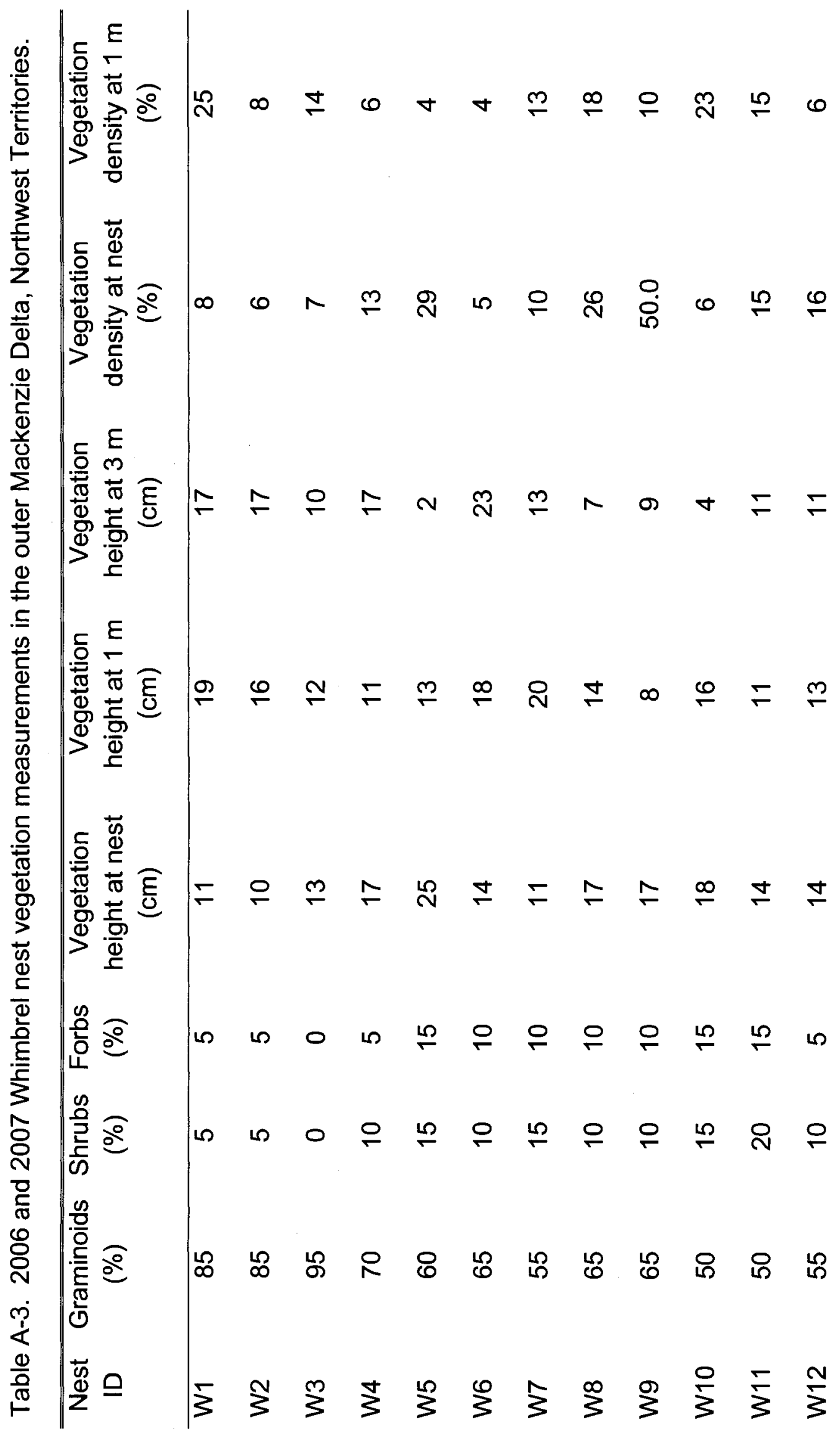




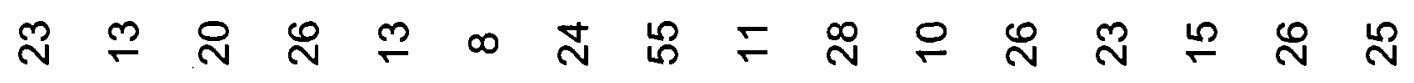

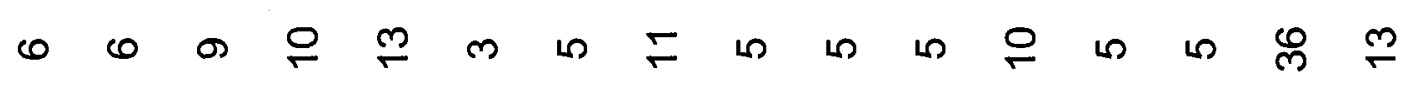

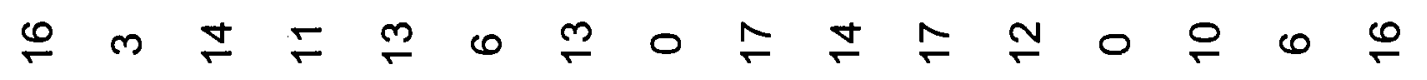

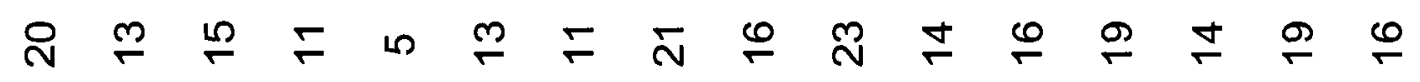

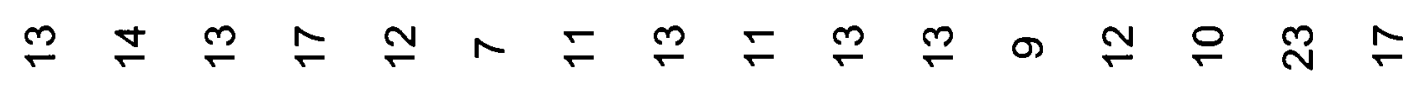

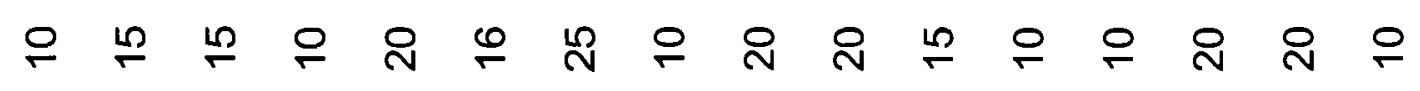

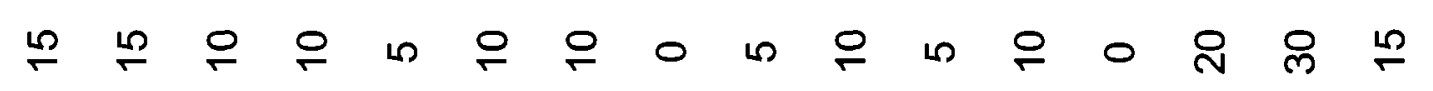

แ

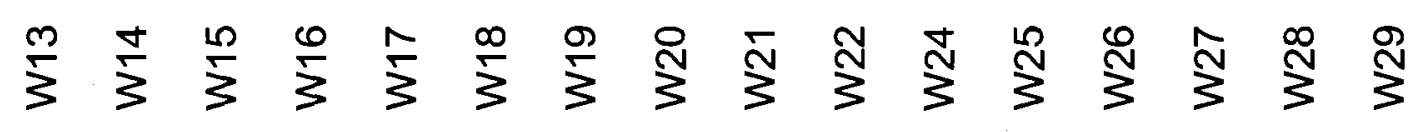


Table A-4. 2006 and 2007 Whimbrel nest fate, including date nest was found and the last visit.

\begin{tabular}{|c|c|c|c|c|}
\hline Nest ID & First Visit & Last Visit & No. of Eggs & Nest Fate \\
\hline W1 & 11 Jun-06 & $8 \mathrm{Jul}-06$ & 4 & Successful \\
\hline W2 & 11 Jun-06 & $8 \mathrm{Jul}-06$ & 4 & Successful \\
\hline W3 & 13 Jun-06 & 8 Jul-06 & 4 & Successful \\
\hline W4 & 11 Jun-06 & 4 Jul-06 & 4 & Depredated \\
\hline W5 & 15 Jun-06 & 3 Jul-06 & 4 & Depredated \\
\hline W6 & 16 Jun-06 & 29 Jun-06 & 4 & Depredated \\
\hline W7 & 17 Jun-06 & 4 Jul-06 & 5 & Depredated \\
\hline W8 & 19 Jun-06 & 24 Jun-06 & 4 & Depredated \\
\hline W9 & 21 Jun-06 & 5 Jul-06 & 4 & Successful \\
\hline W10 & 24 Jun-06 & $7 \mathrm{Jul}-06$ & 4 & Successful $\left.\right|^{* *}$ \\
\hline W11 & $1 \mathrm{Jul}-06$ & 6 Jul-06 & 4 & Successful \\
\hline W12 & 3 Jul-06 & $10 \mathrm{Jul}-06$ & 4 & Successful \\
\hline W13 & 3 Jul-06 & 7 Jul-06 & 4 & Depredated \\
\hline W14 & 4 Jul-06 & 10 Jul-06 & 4 & Depredated \\
\hline W15 & 9 Jun-07 & 20 Jun-07 & 4 & Depredated \\
\hline W16 & 9 Jun-07 & 12 Jun-07 & 3 & Depredated \\
\hline W17 & 10 Jun- 07 & 13 Jun-07 & 3 & Depredated \\
\hline W18 & 11 Jun-07 & 17 Jun-07 & 3 & Depredated \\
\hline W19 & 11 Jun-07 & 20 Jun-07 & 1 & Depredated \\
\hline W20 & 12 Jun-07 & 4 Jul-07 & $4^{\star}$ & Successful \\
\hline W21 & 12 Jun-07 & 3 Jul-07 & $4^{*}$ & Successful \\
\hline
\end{tabular}




$\begin{array}{lcccc}\text { W22 } & \text { 13 Jun-07 } & \text { 19 Jun-07 } & 4^{*} & \text { Depredated } \\ \text { W23 } & \text { 14 Jun-07 } & 2 \text { Jul-07 } & 4^{*} & \text { Successful } \\ \text { W24 } & \text { 14 Jun-07 } & 2 \text { Jul-07 } & 4^{*} & \text { Abandoned } \\ \text { W25 } & 14 \text { Jun-07 } & 11 \text { Jul-07 } & 4^{*} & \text { Depredated } \\ \text { W26 } & 17 \text { Jun-07 } & 8 \text { Jul-07 } & 4^{*} & \text { Successful } \\ \text { W27 } & 23 \text { Jun-07 } & 8 \text { Jul-07 } & 2 & \text { Depredated } \\ \text { W28 } & 26 \text { Jun-07 } & 14 \text { Jul-07 } & 4^{*} & \text { Successful } \\ \text { W29 } & 8 \text { Jul-07 } & \text { NA } & \text { Unknown } & \text { Depredated }\end{array}$

*Number of eggs represents the number of eggs prior to the removal of one egg from each nest in 2007 for genetic studies with the US Fish and Wildlife Service, Anchorage, Alaska.

${ }^{\star \star}$ One egg did not hatch. 